\title{
Transactive Systems Simulation and Valuation Platform Trial Analysis
}

\section{April 2017}

SE Widergren

DJ Hammerstrom

TE McDermott

Q Huang

D Sivaraman

K Kalsi

Y Tang

J Lian

A Veeramany

A Makhmalbaf

JT Woodward 


\title{
DISCLAIMER
}

This report was prepared as an account of work sponsored by an agency of the United States Government. Neither the United States Government nor any agency thereof, nor Battelle Memorial Institute, nor any of their employees, makes any warranty, express or implied, or assumes any legal liability or responsibility for the accuracy, completeness, or usefulness of any information, apparatus, product, or process disclosed, or represents that its use would not infringe privately owned rights. Reference herein to any specific commercial product, process, or service by trade name, trademark, manufacturer, or otherwise does not necessarily constitute or imply its endorsement, recommendation, or favoring by the United States Government or any agency thereof, or Battelle Memorial Institute. The views and opinions of authors expressed herein do not necessarily state or reflect those of the United States Government or any agency thereof

\author{
PACIFIC NORTHWEST NATIONAL LABORATORY \\ operated by \\ BATTELLE \\ for the \\ UNITED STATES DEPARTMENT OF ENERGY \\ under Contract DE-AC05-76RL01830
}

Printed in the United States of America

Available to DOE and DOE contractors from the

Office of Scientific and Technical Information,

P.O. Box 62, Oak Ridge, TN 37831-0062;

ph: (865) 576-8401

fax: $(865) 576-5728$

email: reports@adonis.osti.gov

Available to the public from the National Technical Information Service

5301 Shawnee Rd., Alexandria, VA 22312

ph: (800) 553-NTIS (6847)

email: orders/antis.gov <http://www.ntis.gov/about/form.aspx>

Online ordering: http://www.ntis.gov

This document was printed on recycled paper. 


\section{Transactive Systems Simulation and Valuation Platform Trial Analysis}

April 2017

$\begin{array}{ll}\text { SE Widergren } & \\ \text { DJ Hammerstrom } & \text { T McDermott } \\ \text { Q Huang } & \text { D Sivaraman } \\ \text { K Kalsi } & \text { Y Tang } \\ \text { J Lian } & \text { A Veeramany } \\ \text { A Makhmalbaf } & \text { JT Woodward }\end{array}$

Prepared for

the U.S. Department of Energy

under Contract DE-AC05-76RL01830

Pacific Northwest National Laboratory

Richland, Washington 99352 



\begin{abstract}
Transactive energy systems use principles of value to coordinate responsive supply and demand in energy systems. Work continues within the Transactive Systems Program, which is funded by the U.S. Department of Energy at Pacific Northwest National Laboratory, to understand the value of, understand the theory behind, and simulate the behaviors of transactive energy systems. This report summarizes recent advances made by this program. The main capability advances include a more comprehensive valuation model, including recommended documentation that should make valuation studies of all sorts more transparent, definition of economic metrics with which transactive mechanisms can be evaluated, and multiple improvements to the time-simulation environment that is being used to evaluate transactive scenarios.
\end{abstract}





\section{Summary}

Transactive system designs are intended to drive electric system operations toward an optimal balance of supply and demand at all levels of the grid. To accomplish this, they actively seek the engagement of all potentially responsive electrical assets, including customer-owned and third-party assets, through transparent, competitive means. This provides the flexibility required by tomorrow's power grid, whether generation shifts from centralized to more distributed resources or from dispatchable generation plants to intermittent renewables. Operating such a grid, capable of powering our society by providing the reliability and affordable electricity rates it demands, necessitates new operational flexibility from resources on a large scale. In order to do this at reasonable cost, much of this flexibility is expected to be derived from distributed assets such as continually responsive loads, distributed electrical and thermal storage, smart inverters for solar photovoltaic systems, electric vehicles, etc.

The U.S. Department of Energy's (DOE’s) Transactive Systems Program (TSP) encourages the development of transactive designs that offer systematic, scalable, and equitable approaches for managing energy system operations. Because several designs have already been proposed, some have also been and demonstrated in the field, and more are sure to follow, the program works to inform decision makers on alternative transactive designs and their characteristics. It does this by developing a simulation environment capable of testing a variety of transactive system designs. This includes establishing a set of test scenarios with realistic models and data sets for testing such alternative transactive system designs. In addition, criteria and a disciplined process for evaluation are proposed as part of the TSP's valuation methodology element. The valuation criteria are supplemented with systemic criteria for measuring proper behavior of the transactive system being studied on topics such as scalability, optimality, and convergence. These are derived from TSP elements that contribute to a theoretical framework for transactive systems.

This document reports on an early trial of the first year's progress developing an analysis platform for evaluating transactive designs. The trial was created to show how various parts of the TSP (valuation, simulation, and theory) are designed to work together to support such an analysis platform. The trial analysis also serves to make sure that the contributing parts are consistent in their ability to deliver platform integrity in support of the program's mission.

The report emphasizes the establishment of initial capabilities that the analysis platform provides. The strategy is to stretch the extent of these capabilities in several directions to demonstrate a structure that integrates a breadth of functionality needed to reasonably evaluate different transactive designs. In this regard, it is incomplete, with rough edges and gaps; however, the resulting set of capabilities is more analogous to the composition of a round of Swiss cheese than disjointed pieces. That is, the contributing areas are not only working toward a unified platform, the connected parts of that platform can be demonstrated through a trial analysis, even though the program still has many gaps to fill.

In the valuation area, the analysis platform applied the valuation methodology developed in the previous year to diagram $e^{3}$-value ${ }^{\mathrm{TM}}$ principles (Hammerstrom 2016a) in grid services and building services scenarios. These defined a set of metrics that may need to be measured in a transactive systems analysis depending upon its scope. The diagrams are also important for defining the flow of values and where they accrue. This is needed to perform the calculations of the results of the analysis. In the case of the trial analyses, the team looked at two use cases (both situations that stimulate the electric system away from normal operating conditions). The $e^{3}$-value diagrams were produced to cover these use cases, and the resulting value metrics informed the design of the simulation environment, known as the Transactive Energy Simulation Platform (TESP), so that it was configured to capture the simulated measurements that support the calculation of the metrics. 
The definitions of the use cases were coordinated between the valuation and simulation efforts to support the trial analyses. Existing capabilities in GridLAB-D ${ }^{\mathrm{TM}}$ (a distribution-level analysis tool that supports analysis of transactive systems) and the Framework for Network Co-Simulation (a co-simulation environment) were modified to support the objectives of the simulation effort. The major additional capabilities are

- integration of separate transactive energy agents (TEAgents) that encapsulate behaviors of market mechanisms and participants,

- separation of the valuation function from simulation that supports capturing results for more efficient post-processing,

- implementation of an efficient and completely open-source platform for Windows, Mac OS X, and Linux (available on GitHub), and

- definition of a growth model for multi-year TE simulations.

All of these accomplishments are demonstrated in the trial analyses. Lastly, the TSP's theory element contributed to the definition of metrics associated with an evaluation of economic performance in the trial analyses.

These accomplishments culminate in the summary of results from the trial analyses. The importance of these results lies not with the final numbers or ratings, but with the methods and tools that were deployed to calculate them. To develop these results, many assumptions were applied to simplified models of a bulk power system with a prototypical feeder that had many homes and one complex building (an elementary school) modeled. One transactive design (a double-auction market) was applied to the distribution feeder as a test scenario to compare with the baseline scenario system. The number of responsive devices was limited to the number currently supported by the TESP, and aspects of the use cases were scaled back to exercise the TESP capabilities presently in place while avoiding functionality that is planned for future versions. Nevertheless, the trial is able to show a) how a distribution-level transactive market can be simulated to work with a wholesale market, b) how responsive equipment in homes and a commercial-scale building can interact in this market with arguably realistic quasiequilibrium dynamics, and c) how the results of this simulation can feed valuation calculations. These calculations are based on a rigorous approach to modeling the flow of effects on system operation caused by the use cases.

Throughout the course of the program's development, collaboration with other researchers has been important. Direct program involvement from Ohio State University on the theory framework and from Iowa State University on wholesale-retail market integration have contributed to the theory development and will influence simulation and valuation elements going forward. The program is also collaborating closely with the National Institute of Standards and Technology and their TE Challenge community ${ }^{1}$ to help set a constructive direction for research on transactive systems with a foundation in co-simulation approaches, power and buildings systems models, a conceptual model for describing transactive system designs, and use cases for testing simulators offered by TE Challenge participants. Lastly, the program is also collaborating with TNO (a national research organization in the Netherlands) on TE simulations and advancing TE approaches toward commercial deployment. Expanding these collaborations and outreach to the TE community in general will continue to be important.

\footnotetext{
${ }^{1}$ NIST Transactive Energy Modeling and Simulation Challenge for the Smart Grid. https://www.nist.gov/engineering-laboratory/smart-grid/hot-topics/transactive-energy-modeling-and-simulationchallenge
} 
The initial capabilities developed for analyzing transactive systems in the valuation, simulation (TESP), and theory areas means that there are a number of opportunities to fill gaps in the future. Future work should extend the simulation and modeling capabilities to include more responsive devices, accommodate different transactive designs, and integrate other simulation tools, such as more sophisticated wholesale market modeling, communications systems modeling, and human behavior modeling. More work is needed to enhance the growth model and add agent learning behavior, as well as enhance the use of stochastic models to more realistically model equipment behavior and the human decision-making processes in operation and growth scenarios. Improvements in the TESP should also continue to offer functionality in ways that support open or affordable software development environments that allow a large community of users to access, apply, and extend these tools for their own and the community's benefit. In addition, the valuation methodology should consider developing a body of use cases and associated $e^{3}$-value diagrams to support testing different transactive designs in various regional electric power and buildings systems configurations. And, new research on the theory of transactive systems should offer quantifiable metrics to the analysis process.

From a larger perspective, the TSP proposes to move the TESP forward using configuration-management to support public release of the software tools with new features, error corrections, and a compatible valuation methodology. This will be particularly important as the program moves to support the design of transactive mechanisms that may be proposed for simulation comparisons, and ultimately, field

demonstrations. The better the methods and tools the transactive energy community has at its disposal, the demonstrations and progress toward commercial deployments will be faster and more successful. 



\section{Acronyms and Abbreviations}

\begin{tabular}{|c|c|}
\hline ANSI & American National Standards Institute \\
\hline API & application program interface \\
\hline ARPA-E & Advanced Research Projects Agency - Energy \\
\hline ASHRAE & American Society of Heating, Refrigerating and Air-Conditioning Engineers \\
\hline ASW & adjusted social welfare \\
\hline BCVTB & Building Control Virtual Test Bed \\
\hline CSV & comma-separated value \\
\hline DER & distributed energy resources \\
\hline DOE & U.S. Department of Energy \\
\hline EIOC & Electricity Infrastructure Operations Center \\
\hline EMS & energy management system \\
\hline FNCS & Framework for Network Co-Simulation \\
\hline GB & gigabyte ( 1 billion bytes of storage) \\
\hline GENSETS & Generators for Small Electrical and Thermal Systems \\
\hline GMLC & Grid Modernization Lab Consortium \\
\hline GUI & graphical user interface \\
\hline HVAC & heating, ventilating, and air conditioning \\
\hline IEEE & Institute of Electrical and Electronics Engineers \\
\hline JSON & JavaScript Object Notation \\
\hline LMP & locational marginal price \\
\hline LOESS & locally weighted smoothing \\
\hline MAIFI & Momentary Average Interruption Frequency Index \\
\hline NASA & National Aeronautics and Space Administration \\
\hline NIST & National Institute of Science and Technology \\
\hline PNNL & Pacific Northwest National Laboratory \\
\hline PV & photovoltaic \\
\hline RTP & real-time pricing \\
\hline SAIDI & System Average Interruption Duration Index \\
\hline SAIFI & System Average Interruption Frequency Index \\
\hline SGIP & Smart Grid Interoperability Panel \\
\hline SW & social welfare \\
\hline TDC & transmission, distribution, and communications \\
\hline $\mathrm{TE}$ & transactive energy \\
\hline TEAgent & transactive energy agent \\
\hline TESP & transactive energy simulation platform \\
\hline TNO & Netherlands Organisation for Applied Scientific Research \\
\hline
\end{tabular}


TSP Transactive Systems Program

UML Unified Modeling Language

VL violation level 


\section{Contents}

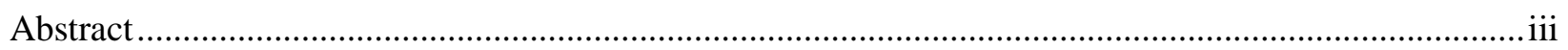

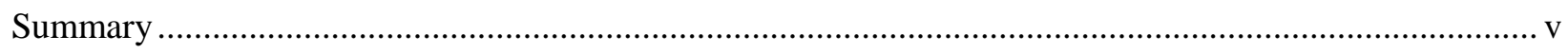

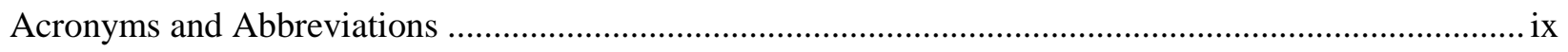

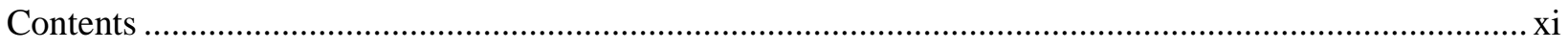

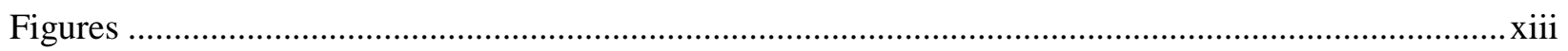

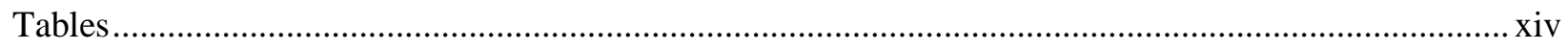

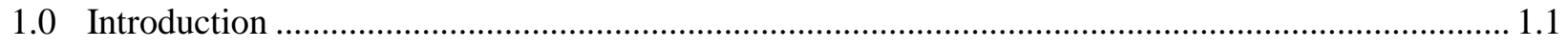

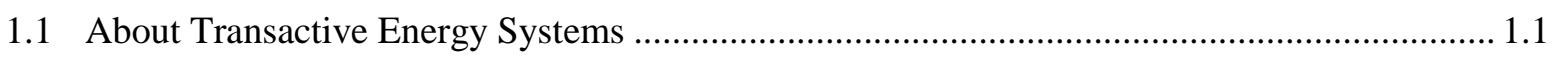

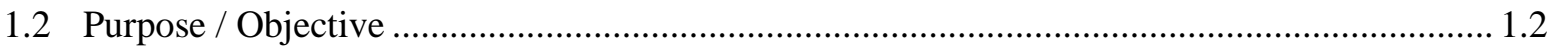

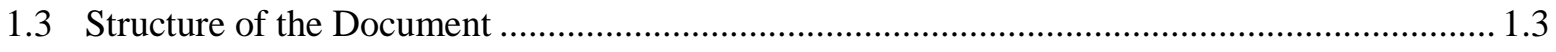

2.0 Valuation Methodology for Transactive Systems .................................................................... 2.1

2.1 Dissecting the Structure of Valuation Studies....................................................................... 2.1

2.2 Recommended Documentation for Transparent Valuation Studies ......................................... 2.3

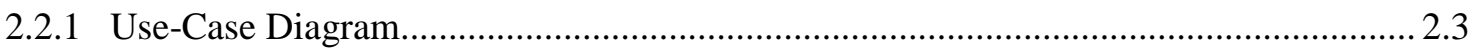

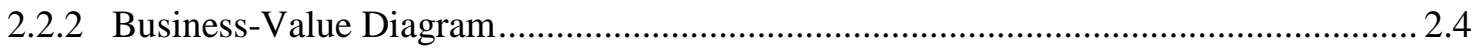

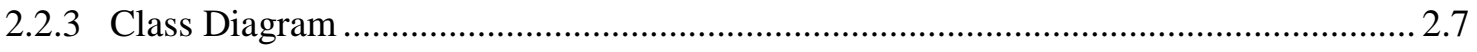

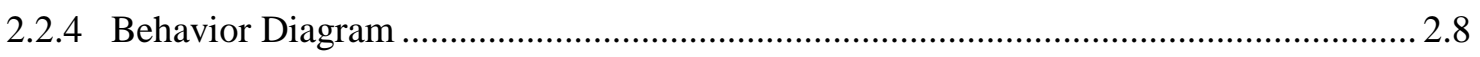

2.2.5 Metric and Valuation Model Definitions .............................................................. 2.10

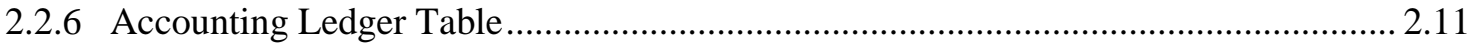

2.3 Addressing Risk in Valuation Studies........................................................................... 2.12

2.4 A Useful Categorization of Transactive Mechanisms ........................................................... 2.13

3.0 Transactive System Performance Metrics ................................................................................... 3.1

3.1 Transactive System Metrics used in the Trial Analysis ......................................................... 3.1

4.0 Advancing Simulation Capabilities ............................................................................................... 4.1

4.1 Goals of the Transactive Energy Simulation Platform............................................................ 4.1

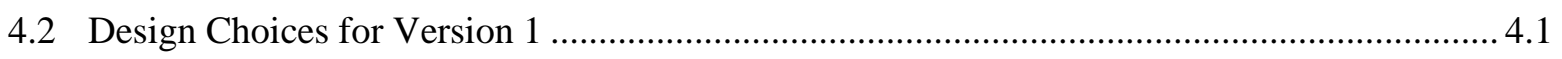

4.3 Operational and Growth Models ....................................................................................... 4.2

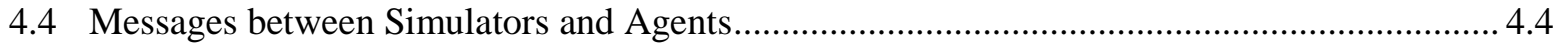

4.5 Output Metrics to Support Evaluation............................................................................... 4.6

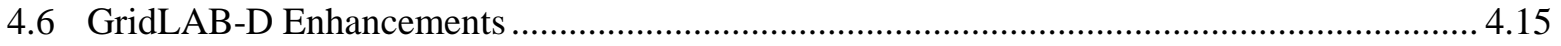

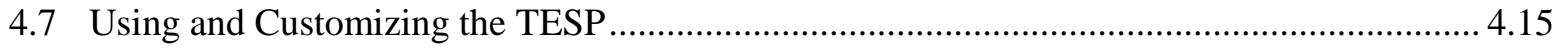

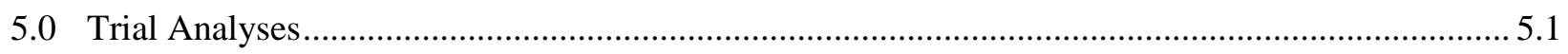

5.1 Trials Inspired by TE Use Cases and Growth Model........................................................... 5.1

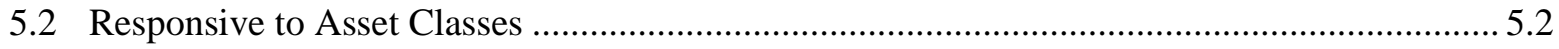

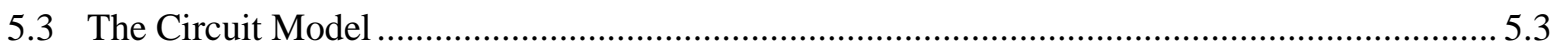

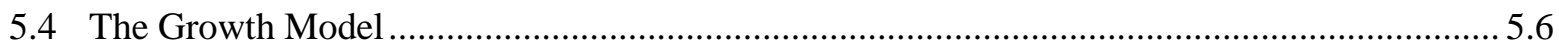




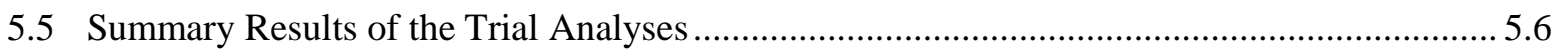

5.5.1 Trial Analysis \#1-Inadequate Generation Supply................................................... 5.7

5.5.2 Trial Analysis \#2-Modeling Growth of Solar PV Generation .................................... 5.7

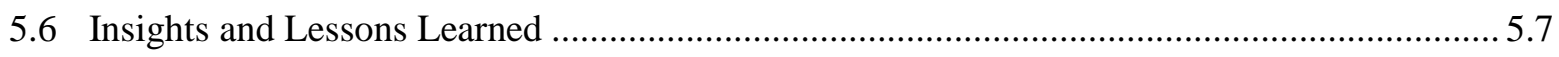

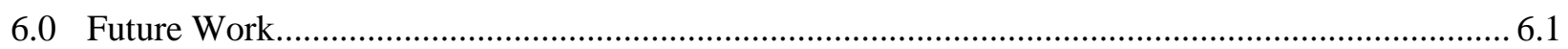

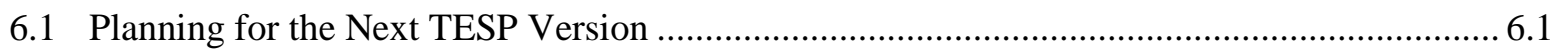

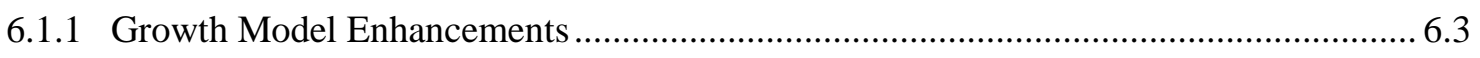

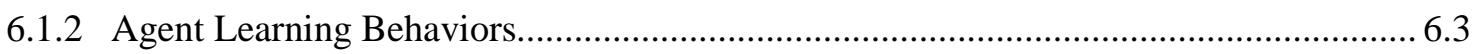

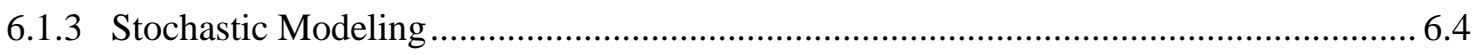

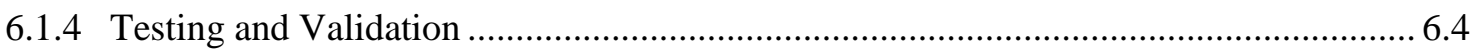

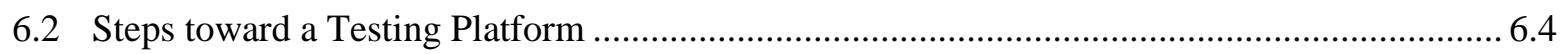

6.3 Transactive System Metrics to be Developed .......................................................................... 6.4

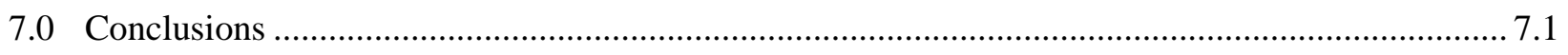

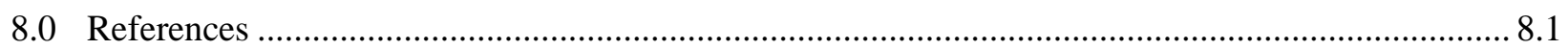

Appendix A - Source of Uncertainty in Valuations .............................................................................. A.1

Appendix B - Valuation Metric Model Definition Template......................................................................1

Appendix C - Valuation Results from the Trial Analyses ..................................................................1

Appendix D - Valuation Results from Trial Analysis 2 (Growth Model)........................................... D.1 


\section{Figures}

Figure 1.1. Transactive System Mechanisms and Categories............................................................... 1.1

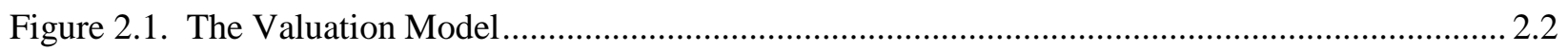

Figure 2.2. SGIP-1 Use-Case Diagram Applied to a Trial Analysis ..................................................... 2.4

Figure 2.3. Business-Value Diagram concerning Retail Electricity Distribution ................................... 2.5

Figure 2.4. Business-Value Diagram concerning Wholesale Electricity .............................................. 2.6

Figure 2.5. Business-Value Diagram concerning Emergency Load Curtailment ................................... 2.7

Figure 2.6. Example Class Diagram. Modeled attributes of the classes are listed below the titles.......... 2.8

Figure 2.7. UML Activity Diagram concerning the Behavior of a Transactive Double-Auction

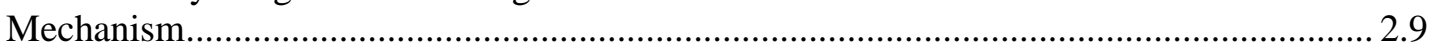

Figure 4.1. TESP Version 1 Components Federated through FNCS .................................................... 4.2

Figure 4.2. Interaction of Growth Model with Operational Model........................................................ 4.3

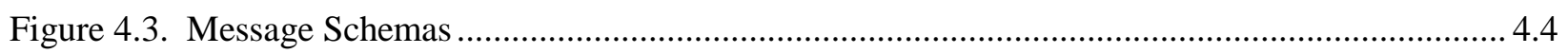

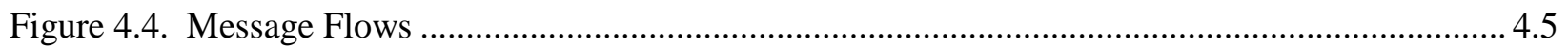

Figure 4.5. Partitioning the Valuation Metrics between Simulation and Post-Processing........................ 4.6

Figure 4.6. New Metrics Collection Classes for GridLAB-D......................................................... 4.7

Figure 4.7. MATPOWER Dictionary with Generator and FNCS Bus Metrics ...................................... 4.8

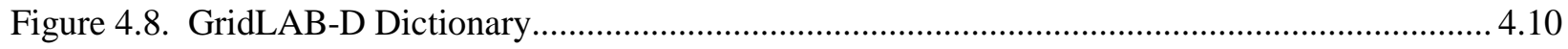

Figure 4.9. GridLAB-D Substation Metrics.................................................................................. 4.11

Figure 4.10. GridLAB-D Billing Meter Metrics ........................................................................... 4.11

Figure 4.11. GridLAB-D House Metrics ........................................................................................... 4.12

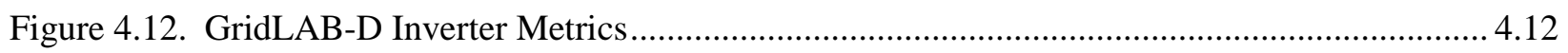

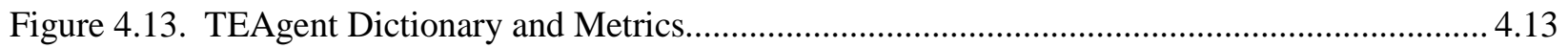

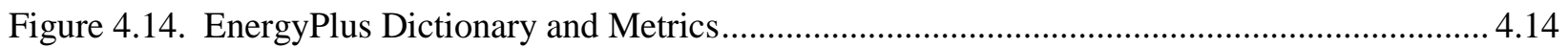

Figure 5.1. SGIP-1 System Configuration with Partial PV and Storage Adoption ................................ 5.3

Figure 5.2. 9-Bus Bulk System Model with Maximum Generator Real Power Output Capacities .......... 5.4

Figure 5.3. R1-1 Distribution Feeder Model........................................................................................ 5.5

Figure 5.4. Primary School Model (DOE Commercial Reference Building) ........................................ 5.6

Figure D.1. The Total Load at Bus 7 and the LMP..................................................................... D.2

Figure D.2. The Total Load at Bus 7 and the LMP....................................................................... D.3

Figure D.3. Total Feeder Load by Case ......................................................................................... D.4

Figure D.4. The Total Operation Costs, Revenues, and Profits of the Bulk Generators by Case ID....... D.6

Figure D.5. The Total Operation Costs, Revenues, and Profits of the Bulk Generators by Case ID....... D.7 


\section{Tables}

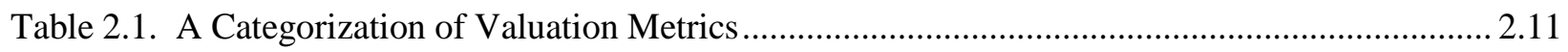

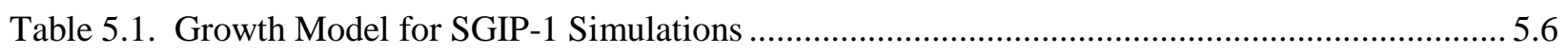

Table A.1. Sources of Uncertainty and their Effects on Valuation..................................................... A.1

Table C.1. Example Valuation Ledger from the Trial Analysis \#1 (Inadequate Generation Supply) ......C.1

Table D.1. Summary of Study Cases .............................................................................................. D.1

Table D.2. Statistics of the LMP at Bus 7 .................................................................................. D.2

Table D.3. Total Electricity Consumption by Case ID ................................................................. D.4

Table D.4. Electricity Bills of Customers on One Feeder Served by Bus 7 by Case ID ....................... D.5

Table D.5. PV Outputs and Revenue by Case ................................................................................. D. D.

Table D.6. Battery Outputs and Revenue by Case ID................................................................... D.6

Table D.7. The Total Operation Costs, Revenues, and Profits of the Bulk Generators by Case ID ........ D.6

Table D.8. Total House HVAC Energy Consumption.................................................................... D.7

Table D.9. Total Greenhouse Gas Emissions from the Generation Sector .......................................... D.8

Table D.10. Example Valuation Ledger from the Trial Analysis that Tested the TESP

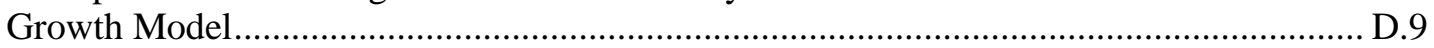




\subsection{Introduction}

The U.S. Department of Energy began funding the Transactive Systems Program (TSP) research at PNNL beginning in 2015. The program is currently organized as a suite of elements concerning (1) economic control theory that underlies transactive energy systems, (2) valuation methodology that is needed for evaluating energy systems that are coordinated by transactive energy systems, (3) time-series simulation of transactive energy systems, and (4) outreach and collaboration.

\subsection{About Transactive Energy Systems}

Figure 1.1 presents a taxonomy of energy management approaches in distribution systems: direct load control, centralized optimization, price-reactive systems, and transactive control and coordination. As shown in Figure 1.1, these approaches reside in quadrants of a two-axis graph, in which the axes are decision making (whether decisions are made locally, or at a more centralized location), and flow of communication (whether communication is unidirectional or bidirectional).

First, top-down switching is the simplest form of conventional demand response. Signals sent through local utilities turn off devices at homes, typically during times of peak demand. This approach does not consider the device state, and probably does not take advantage of the potential of devices to continuously respond. This approach does not take user preferences into account, and interferes with the autonomy of end-use customers. Decisions on local issues are made centrally under this approach, and the communication only needs to be unidirectional, from utility to consumers. Second, in centralized optimization, a centralized optimization engine consolidates flexible supply and demand data and computes an optimal solution for the entire system. With local data serving as inputs, this mechanism differs from direct demand response by accounting for customer preferences and taking advantage of the complete response potential of devices. While the communication is bidirectional, privacy concerns arise regarding data sharing from end-use customers. With increasing flexible supply and demand sources, computation time for optimal solutions grows nonlinearly.

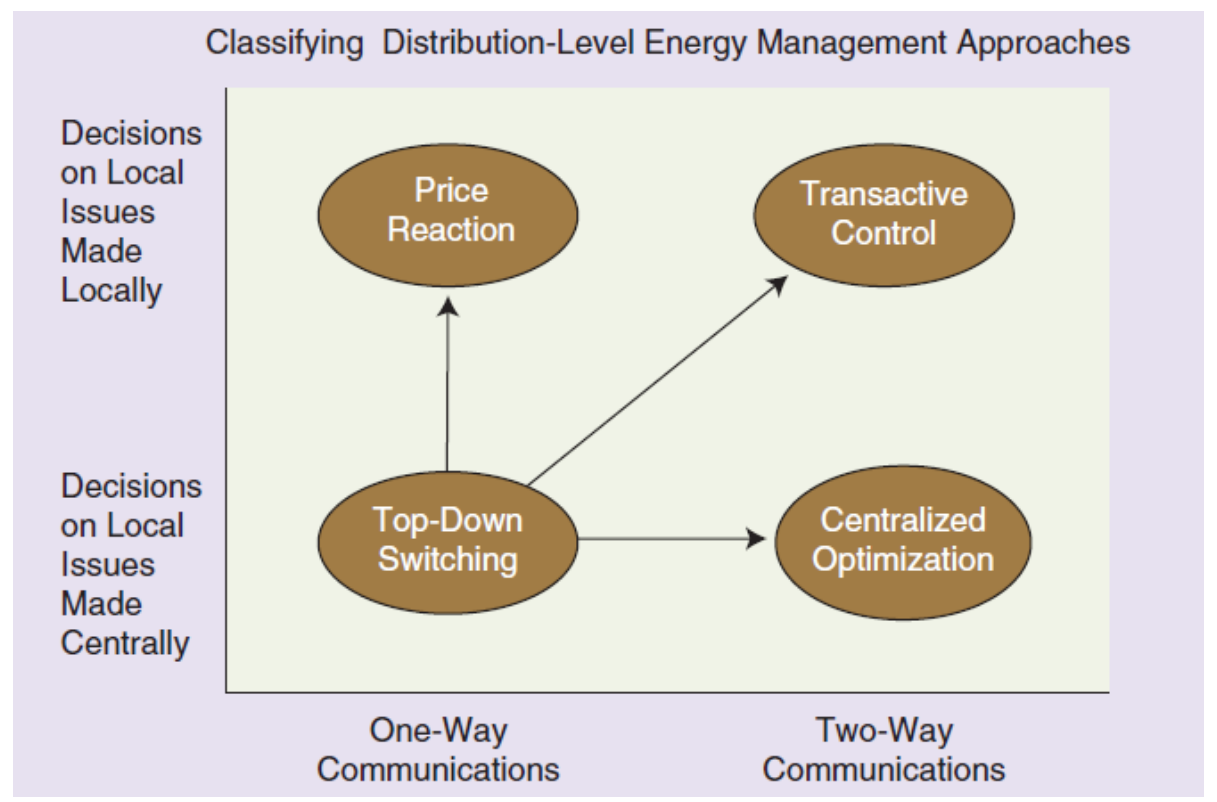

Figure 1.1. Transactive System Mechanisms and Categories (IKok, K. and Widergren 2016) 
Third, for price-reactive systems, dynamic price or incentive signals are sent to end-use customers. Upon receiving the signal, a local intelligent controller economically optimizes the operation of intelligent devices, taking into account both user preferences and device states. This mechanism is predicated on unidirectional communication, and decisions on local issues are made locally. Given a diverse set of enduser preferences, the fundamental limitation with this approach originates from not being confident regarding the availability of cumulative flexible demand assets in any given period of time.

Fourth and finally, a transactive control and coordination approach expands significantly on the pricereactive systems approach. Under this framework, operational flexibility of local equipment is coordinated by a market-based mechanism that coordinates the use of electricity through financial tradeoffs of bids and offers. An important aspect of this type of coordination is the use of automation and software agents that are able to negotiate on behalf of the equipment's or facility's end users based on preferences set up by the end users. With information available on willingness to pay (for consuming devices) and willingness to sell (for producing devices), this distributed decision-making mechanism resolves the operational state of all devices in the system as a community. While the price-reactive approach must guess at the response of equipment to a price signal, this approach discovers the optimal system operation of all participating devices based on their direct participation in price/quantity tradeoffs. Given the aggregated nature of bids under this framework, end-user privacy may also be effectively preserved. In addition, the complete response potential of devices can be harnessed, and eventually an efficient market can be constructed under this framework.

\subsection{Purpose / Objective}

This report documents progress of the elements that contribute to transactive systems analysis (valuation, simulation (the TESP) and theory) by using a trial analysis to demonstrate the supportive aspects of these elements. Prior to this report, the progress in these areas was reported independently.

The program puts forward valuation as a process for informing potential decision makers about merits and weaknesses of transactive systems. Strong methodology is necessary. The valuation discipline of this work advocates that studies should be accompanied by specific types of diagrams and tables. While previous reports about the valuation element describe intriguing insights and recommendations, this document presents a more cohesive, connected view of a valuation methodology and its products. Such clarity will be important as a community of practitioners develops. The community will be stronger and more effective if it can converge on a common understanding of the valuation process and its products.

By exploring the theoretical underpinnings of transactive energy systems, the control-theory element has begun to identify useful system metrics. The theory aspects address basic stability, for example, and economic measures like the attainment of social good. Control theory aims to eventually improve the designs of transactive energy systems. The lessons learned from developing a valuation methodology invites a more introspective approach from theoreticians to consider the qualities of transactive energy systems that might make one transactive energy system preferable to another.

Many valuation metrics must be predicted through time-series simulation. Because transactive energy systems meld physical systems with economic value, time-series simulations must also meld the physics of power flow and devices with market-like behaviors of various transactive system mechanisms. Basic transactive double-auction mechanisms have been co-simulated with distribution systems in prior years. This year, a simulation environment (the transactive energy simulation platform - TESP) has been developed with improvements to simulate alternative transactive energy mechanisms, to co-simulate effects across distribution and transmission, and to allow interplay between existing wholesale market mechanisms and new transactive distribution systems. One of the biggest steps taken this year is the 
definition of a metric schema within the simulation environment that stores the most basic metrics and makes them available in post-processing by the valuation process. This directly supports the integration of the elements to accomplishment transactive systems analyses.

This document is intended to report the progress toward providing a valuation methodology, a theoretical framework, and a simulation platform that form an integrated set of tools for analyzing proposed transactive energy mechanisms. The report is for persons interested in transactive energy systems research, and for persons who are interested in time simulation.

\subsection{Structure of the Document}

Chapter 2.0 reviews valuation methodology to evaluate and compare alternative transactive energy mechanisms. Chapter 3.0 introduces some new valuation metrics needed to state performance of transactive energy systems in light of economic principles or control-system principles.

Time simulations are one tool for exercising valuation models and quantifying valuation metrics. Chapter 4.0 lists recent advancements made toward time simulation of transactive energy systems. Chapter 5.0 addresses trial analyses, which demonstrate the integration of simulation and market theory with the valuation process. Finally, Chapters 6.0 and 7.0, respectively, list future work for consideration in TSP plans and summarize the conclusions made in this report. 



\subsection{Valuation Methodology for Transactive Systems}

Improvements have been made to a valuation methodology for comparing the performance of alternative transactive energy mechanisms.

\subsection{Dissecting the Structure of Valuation Studies}

The following discussion is supported by Figure 2.1 and a prior report (Hammerstrom et al. 2016b). While this description of the valuation model was developed specifically for the valuation of transactive energy systems, the figure and the discussion are equally applicable to and advisable for other valuations in other domains.

The TSP valuation methodology is, at its heart, the scientific method. It sets up an experiment to contrast alternative scenarios concerning their abilities to achieve an objective.

Figure 2.1 includes boundaries of two scenarios. The boundary of the baseline scenario (dashed blue) overlaps the boundary of an alternative test scenario (solid red). In the TSP, the test scenario uses a transactive energy system and might be contrasted with a conventional energy system baseline scenario that uses no transactive system. The multiple boxes on the left-hand side are class elements of the valuation model. The ones toward the top are more closely associated with the physical system; those toward the bottom are more closely associated with the more abstract valuation process. The solid arrows are annotated associations between the class elements. The green boxes toward the right are documentation artifacts that the TSP project advises using to capture assumptions of the valuation and to enhance the transparency of the valuation. An annotated dependency arrow points from each documentation artifact to the class element or elements that it documents.

Consider the bottommost class element. Valuation studies inform decisions. They help decision makers select from among various alternative technologies, strategies, and plans. A decision is supported and defensible if the decision is derived from impacts—the measured differences between alternative scenarios. If a comparison is to be fair, the alternative scenarios must be measured by a common set of shared metrics.

A valuation model is the analyst's tool for quantifying a metric. It is a model in that it necessarily includes a representation of an activity of the physical system. The model may be embodied in time-series simulation, but time-series simulation is not the only way to model a system. There are potentially multiple alternative valuation models for a given metric.

Systems necessarily undertake different courses of action (i.e., activities) to achieve a business or operational objective under the alternative scenarios. For example, an activity under the test scenario might entirely displace another in the baseline scenario (e.g., perhaps looking at a smart charging electric vehicle future versus a "dumb" charging one). Often, however, an activity implemented identically under both scenarios will be found to perform differently because of its interactions with other subsystems.

A shared operational or business objective is critical to a valuation. The comparison of alternative scenarios will not be meaningful if the scenarios possess differing objectives.

A valuation study is often initiated by a use case. In its informal usage, a use case is often a practical statement of an experience or event that a system might encounter. In PNNL's experience, expert insight is then needed to infer the alternative scenarios, activities, and even objectives from the provided use case. Use cases are often too broadly stated, including not one, but multiple use cases and objectives. A 
layman might state a use case in respect to the unique scenarios he understands. That is, the challenge may be stated in terms of business as usual, or alternatively in terms of a novel asset or system feature that is being proposed. In these instances, expert insight must be used to list the implied scenarios and objectives and to re-pose the valuation study properly as a comparison.

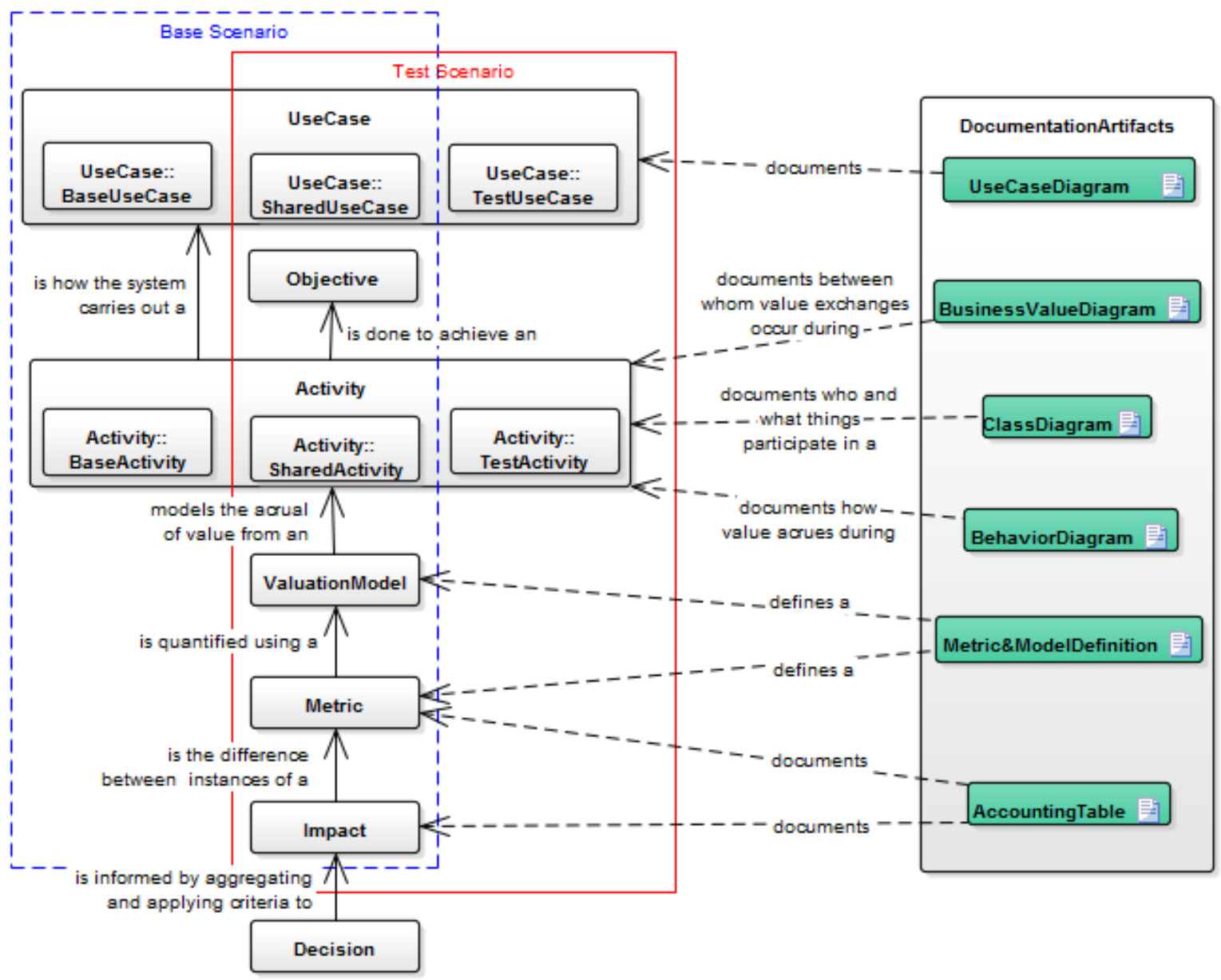

Figure 2.1. The Valuation Model

An informally stated Smart Grid Interoperability Panel (SGIP) use case is adopted as the challenge for the first trial analysis (Chapter 5.0), in which the grid is severely strained in capacity. There are three important shared sub use cases: total system generation resources become inadequate, distribution utilities employ conventional demand response, and distribution utilities employ emergency load curtailment. Because electricity outages and transactive systems potentially affect customer electricity costs and utility revenue, another shared use case is posed to capture these secondary effects on the electricity retail revenue stream. The test scenario employs one additional important use case: modify demand using a transactive system. The overriding objective is to mitigate the effects of encountering inadequate supply resources. Toward this end, the system performs its activities, the process behind the sub use cases for the respective scenarios. That is, the processes of demand response, emergency curtailment, and the transactive system must be defined well enough to unambiguously state how and how much the alternative scenarios differ. Because many process details are unavailable, analysts necessarily make many assumptions. There are many degrees of freedom, for example, in how the transactive system might be defined and implemented. The assumptions heavily affect the way the time-series simulation is configured and run. The time-series simulation, in this case, embodies most of the valuation models. That 
is, it hosts the functions that convert a model of system activities into quantifiable metrics. There could be a multitude of metrics, but because the reliable supply of electricity is being threatened, the most important metrics are those that quantify how many customers incur electricity outages and for how long. The impacts are simply the differences between these metrics.

The next section will address the documentation artifacts shown in Figure 2.1.

\subsection{Recommended Documentation for Transparent Valuation Studies}

The valuation model certainly seems simple, but modeling assumptions, complexities of systems, and the complex interactions between system components can make valuations seem obscure. This lack of clarity and transparency, while unintended, may lead those reading the valuation study to question or fully discard the results. Clarity and transparency can be improved by several helpful diagrams. Just as the precision of musical notation helps others - at least those who also know how to read musical notationunambiguously understand, or even reproduce, music, standard diagramming languages can help us precisely document and communicate details about systems and valuation studies. The Unified Modeling Language $^{\mathrm{TM}}$ (UML), is useful in this respect (OMG 2017). Three of the recommended diagrams come directly from the UML. In this section, we will provide examples of the documentation artifacts that were introduced in Figure 2.1 to more transparently document valuation studies.

\subsubsection{Use-Case Diagram}

The first recommended artifact document is the use-case diagram, which, of course, documents a use case. A use-case diagram is a standard type of UML structural diagram. It organizes the stimuli that are being posed to a system and can also specify the actors who initiate or are affected by the stimuli. This report will not repeat the rich information available from the UML concerning how to construct use-case diagrams.

An example use-case diagram is shown as Figure 2.2. Each blue oval identifies one of the five sub use cases that are part of the first trial analysis. The boundaries of two systems-the conventional system baseline and the transactive test system—are cleverly nested to indicate that four of the use cases are shared, and one is unique to the transactive test system and its scenario. Several actors are introduced for either instigating or being acted on by the use cases.

These actors were not necessarily specified in SGIP-1. An analyst specified these needed actors based on his understanding of SGIP-1. The diagram conveys the analyst's understanding of the systems and the stimuli of SGIP-1. The analyst's assumptions affect the outcome of the valuation study, but the assumptions can be revealed by this artifact.

In addition, the trial analysis did not develop a valuation model to represent a demand-response process and quantify metrics uniquely for this sub use case aspect of SGIP-1 including the actors that are associated with it. Instead, emergency load shedding was modeled, albeit using a very simplified model. 


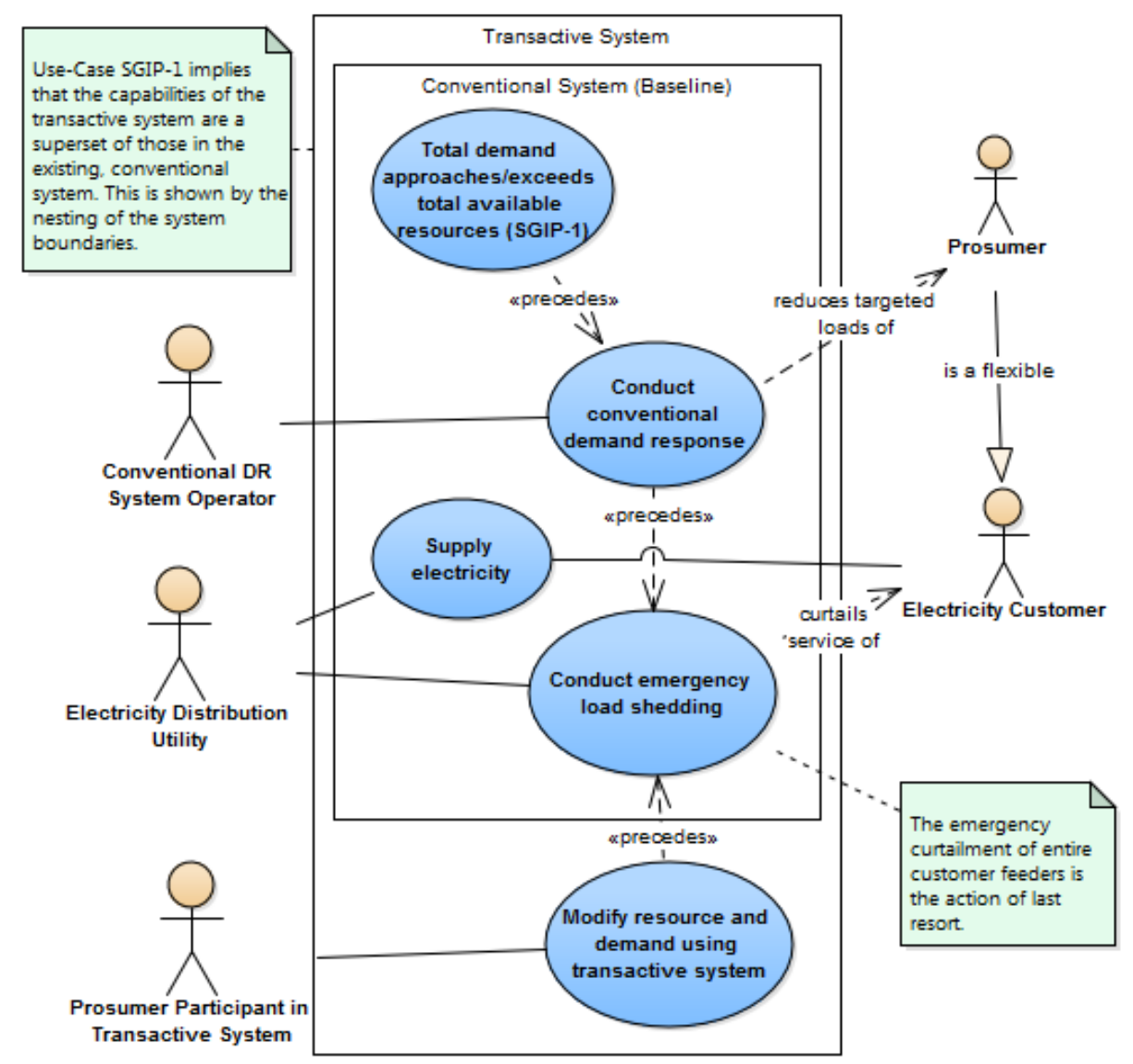

Figure 2.2. SGIP-1 Use-Case Diagram Applied to a Trial Analysis

\subsubsection{Business-Value Diagram}

Business-value diagrams document a system's activities. Like the class diagram to be described in Section 2.2.3, the business-value diagram addresses what and perhaps where the activities take place. Specifically, the business-value diagram should focus on transactions, including to whom and from whom value flows during a system activity. This knowledge is especially important in transactive systems, which are all about the exchange of value.

Business-value diagrams show many similarities with $e^{3}$ value ( $\mathrm{e}^{3}$ value 2017), the starting point from which the TSP project started its exploration, which has been discussed in Hammerstrom et al. (2016a, b). Starting from principles developed in $e^{3}$ value, the project has learned how to draw these diagrams-again consistent with the UML-in a way that pinpoints the transactions $\left(e^{3}\right.$ value refers to value objects being exchanged) in a system.

Business-value diagrams have a clear and important role in valuations: The net business case for any represented actor class may be calculated by summing the values entering and leaving the actor class in a set of business-value diagrams.

Figure 2.3 is a relatively simple example that happens to correspond to the distribution retail side of the "supply electricity" use case. Two actors participate-the electricity distribution utility and electricity customer. The rectangular actor element is chosen because it is similar to the $e^{3}$-value representations that are being emulated. One might interpret this diagram as follows: An electric distribution utility distributes 
electricity to an electricity customer, who pays the electric distribution utility for the amount of electricity used. Electricity and electricity fee are closely coupled, meaning that if one of these items becomes transferred, the other must be transferred also.

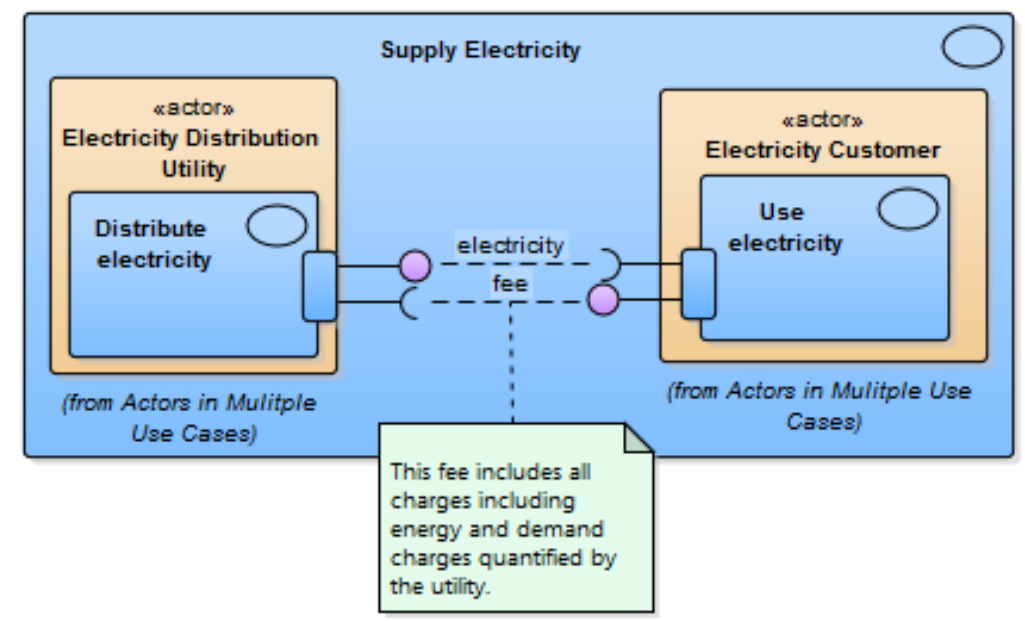

Figure 2.3. Business-Value Diagram concerning Retail Electricity Distribution

Incidentally, the transactive system business-value diagram would be like, or identical to, Figure 2.3, especially if the electric distribution utility also serves as the distribution system operator. While there are indeed many differences between system processes with and without a transactive system, the basic transaction being modeled (at least according to the interpretation the TSP project has adopted for the trial analysis) still concerns the exchange of electricity for a fee between an electricity customer and the electricity supplier.

The business-value diagram for the wholesale side of "supply electricity,” Figure 2.4, is a little more involved. The system operator plays a central role in this diagram as it manages electricity purchases from generation owners to a distribution utility. For the purposes of trial analysis, this includes the generation dispatch model and locational marginal pricing. Losses are represented by an incomplete transaction, a new technique in this report. The complexity of this diagram should match the modeling that can actually be achieved during the trial analysis. It is important to understand that the electricity distribution utility in Figure 2.3 is the same as that in Figure 2.4. 


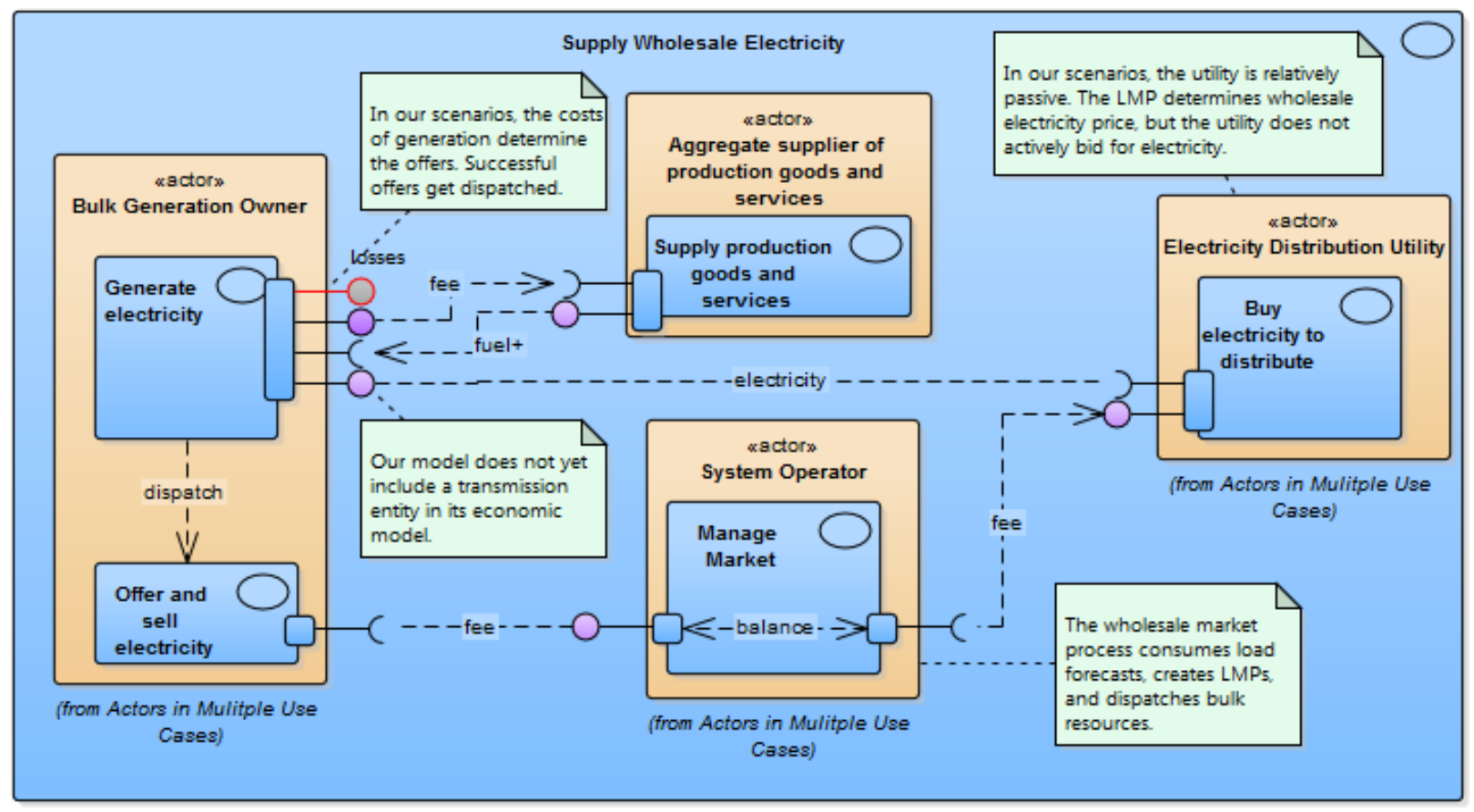

Figure 2.4. Business-Value Diagram concerning Wholesale Electricity

Figure 2.5 shows still one more example concerning the shared sub use case "conduct emergency load shedding." The transaction seems a little one-sided between the customer and distribution utility, which today possesses few options when supply becomes limited. There is not much give and take there. An aggregate actor has been introduced to represent all the entities with whom the electricity customer might interact concerning detrimental effects of the ensuing electricity outage. These could entail, for example, damages to owned equipment that must be repaired or replaced, payments for repair labor, and labor that becomes idled by the power outage. 


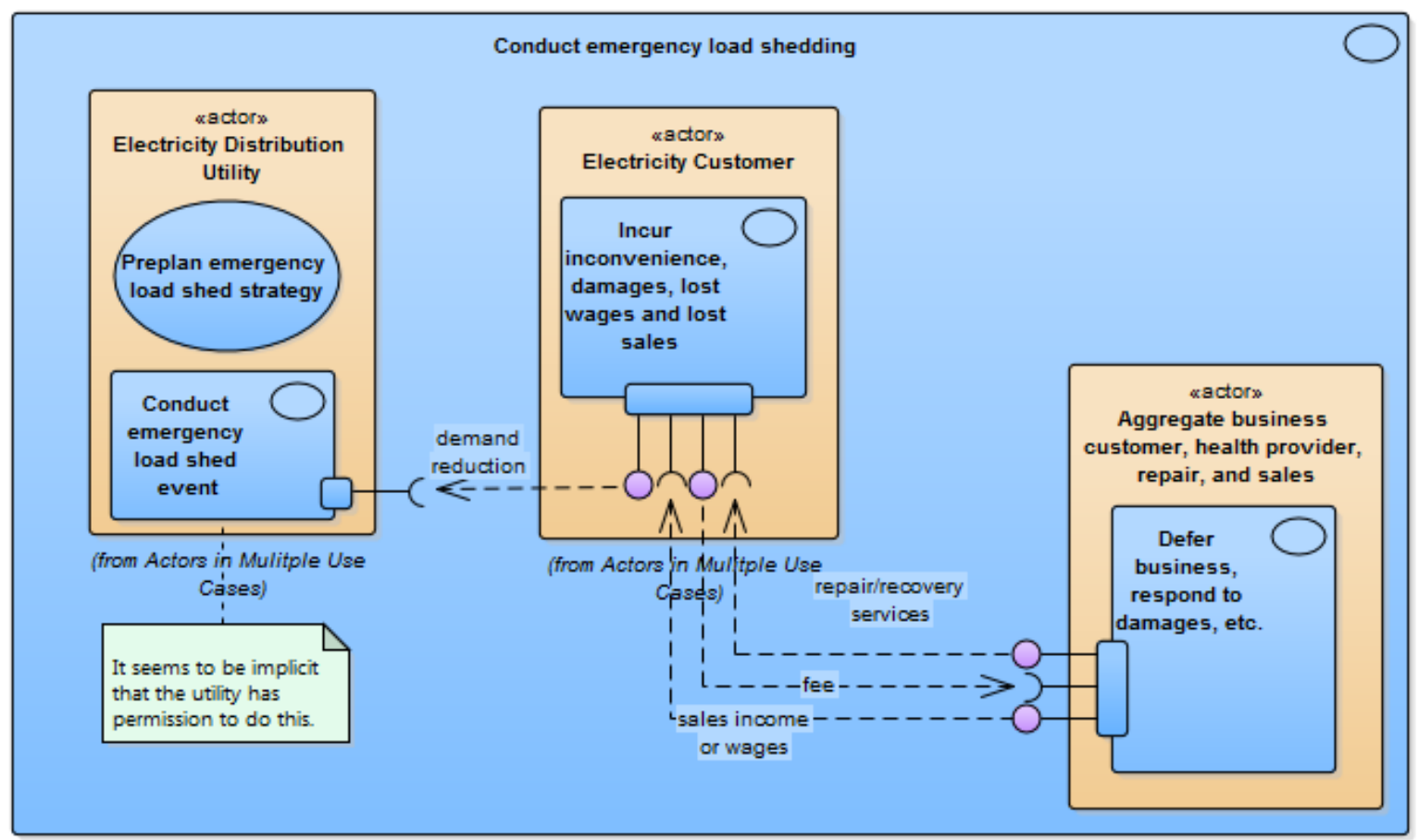

Figure 2.5. Business-Value Diagram concerning Emergency Load Curtailment

\subsubsection{Class Diagram}

Another useful and important UML diagram is the class diagram. A class diagram is another standard type of UML structure diagram. This diagrammatically lists the things, or objects, that play a role in a scenario and tells us how the things are interrelated. An example class diagram is shown in Figure 2.6. These diagrams have proven useful for simplifying the challenging associations between the elements of an electric power system, including its actors. 


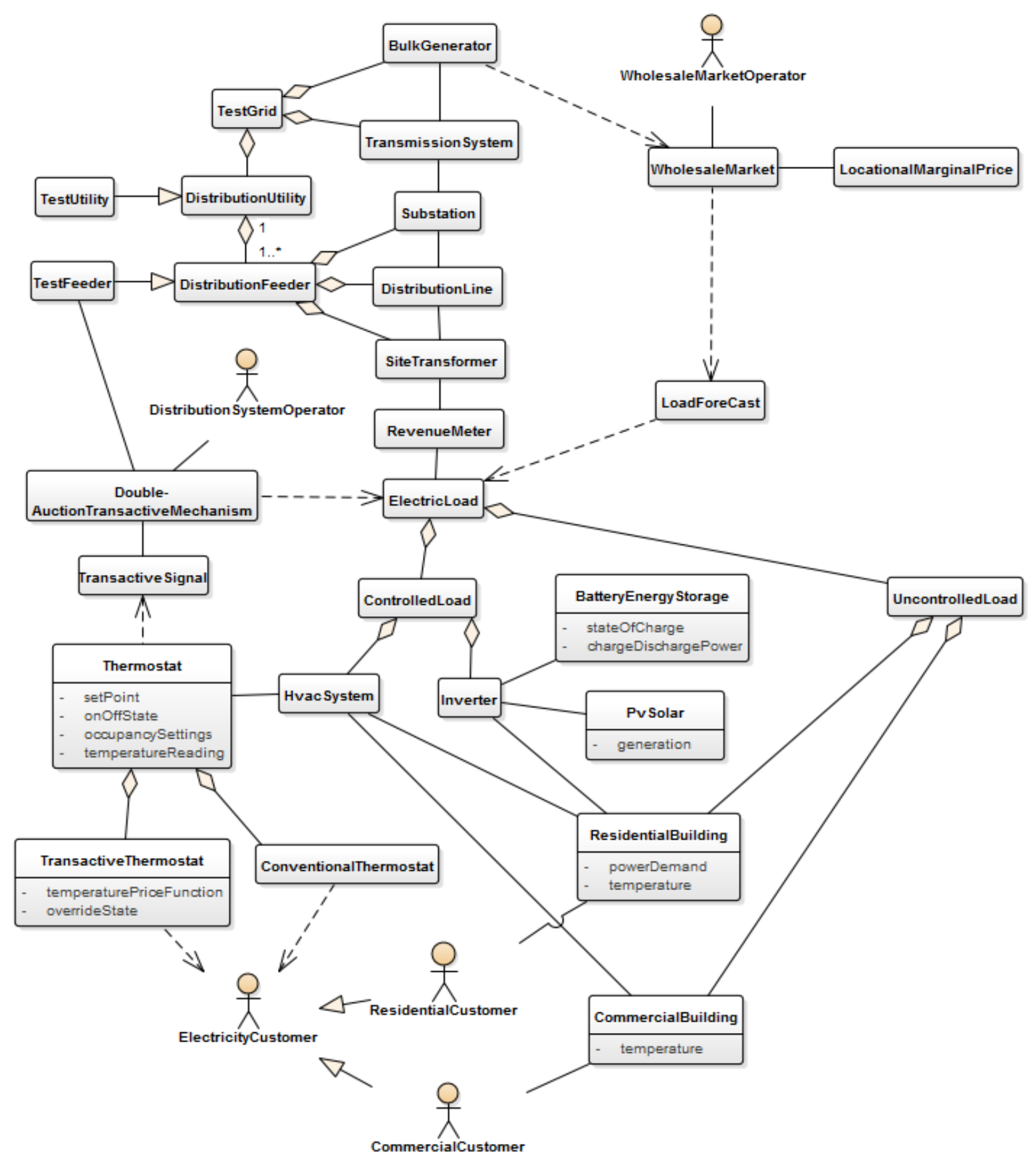

Figure 2.6. Example Class Diagram. Modeled attributes of the classes are listed below the titles.

\subsubsection{Behavior Diagram}

Behavior diagrams represent processes and might therefore make transparent precisely how value accrues in a scenario. Most importantly, the diagrams for the baseline and test scenarios should accentuate how the two scenarios' approaches differ. We foresee an eventual push to also include a UML behavioral diagram to further document how the things interact, which ultimately lets us contrast—and quantifyaspects of the alternative scenarios. Figure 2.7 is an example behavior diagram, in this case a UML activity diagram, that describes the working of a transactive double-auction mechanism. 


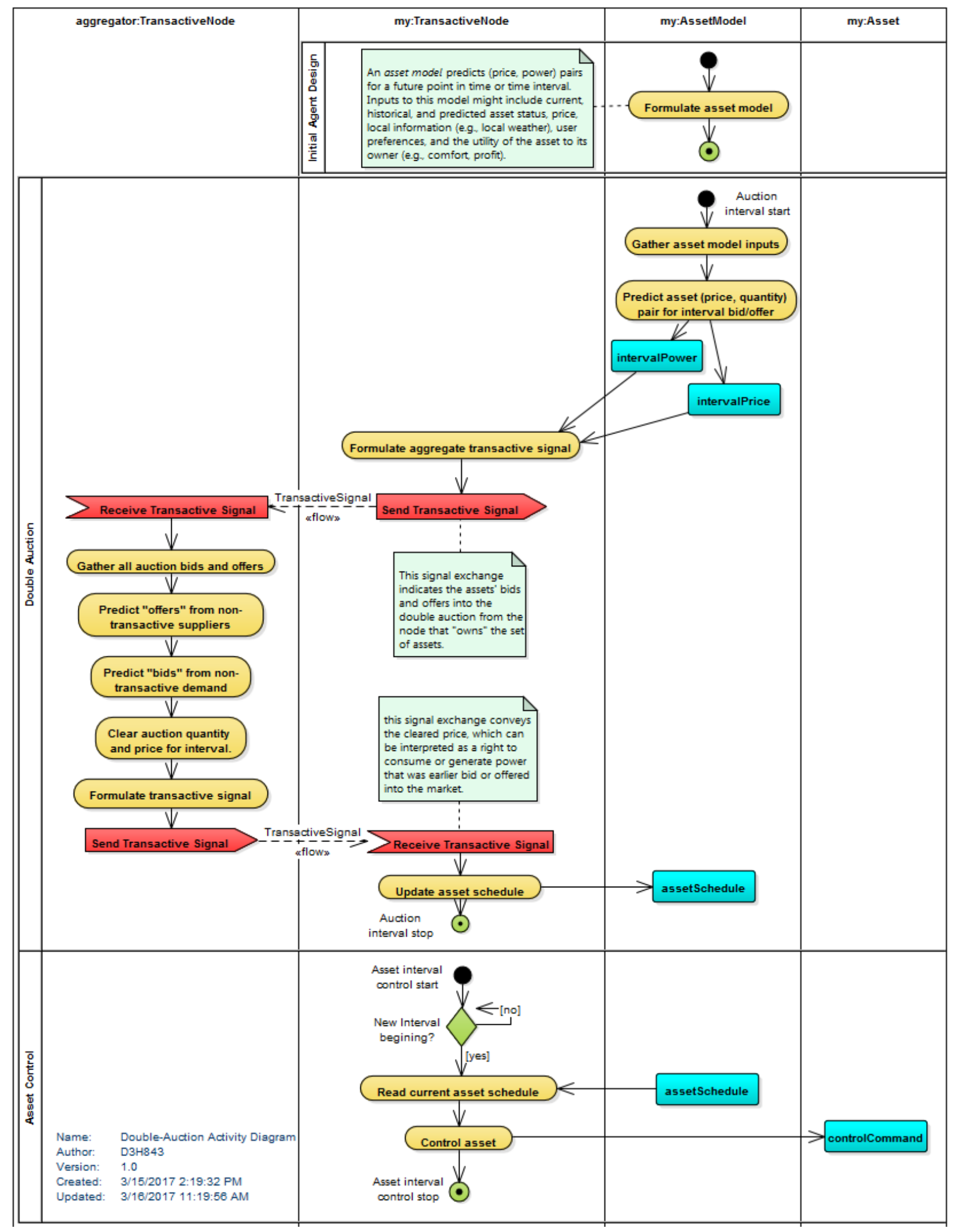

Figure 2.7. UML Activity Diagram concerning the Behavior of a Transactive Double-Auction Mechanism 


\subsubsection{Metric and Valuation Model Definitions}

The TSP developed valuation model documents for over 70 valuation metrics, which the team decided were key to evaluating a wide array of features in a transactive system. For each valuation metric, the metric and valuation model documents outline-preferably using one page or less—the metric's definition, the relevance of the metric to valuation, necessary inputs for computing the metric, one calculation method, and available tools (e.g., software) for computing the metric. The valuation documents are homogeneous, in that they consistently adhere to the structure discussed immediately above. A template for valuation model documents and a filled-in example are provided in Appendix B.

A library of collected metric and valuation metric documents is dynamic. It should grow as new metrics are defined and needed. Alternative methods may be found or invented for quantifying existing metrics, in which case the library of metric and valuation model documents should grow to include such alternative methods. We believe the metric and valuation model documents and the corresponding concept for a library of such documents may be a key to collaboration among a community of analysts. The documentation of valuation methods may further support eventual automation of valuations, which is exceedingly challenging today.

The TSP organizes the documents under five overarching topics: engineering, system, financial, economic, and renewable. Table 2.1 presents a list of metric and valuation metric documents indexed under the five categories. 
Table 2.1. A Categorization of Valuation Metrics

\begin{tabular}{|c|c|c|c|c|}
\hline Engineering & System & Financial & Economic & Renewable \\
\hline $\begin{array}{l}\text { Convergence rate } \\
\text { Count of under- } \\
\text { voltage violations } \\
\text { Deviation from } \\
\text { temperature set } \\
\text { point } \\
\text { Expected load loss } \\
\text { Frequency of } \\
\text { imbalance events } \\
\text { Load forecast } \\
\text { accuracy } \\
\text { Load forecast error } \\
\text { Loss of load } \\
\text { expectation } \\
\text { (LOLE) } \\
\text { Number of iterations } \\
\text { Phase imbalance } \\
\text { Price convergence } \\
\text { time } \\
\text { SAIDI } \\
\text { SAIFI } \\
\text { Severity of } \\
\text { imbalance event } \\
\text { Severity of voltage } \\
\text { violation } \\
\text { Shutdown count } \\
\text { Unserved electric } \\
\text { load } \\
\text { Violation level }\end{array}$ & $\begin{array}{l}\text { Communication } \\
\text { intensity } \\
\text { Energy losses } \\
\text { Reactive power } \\
\text { Real power* } \\
\text { Resource margin } \\
\text { Predicted mean } \\
\text { vote } \\
\text { Voltage* }\end{array}$ & $\begin{array}{l}\text { Cost of energy } \\
\text { resources } \\
\text { Cost of frequency } \\
\text { regulation } \\
\text { Cost of imbalance } \\
\text { resources } \\
\text { Cost of primary } \\
\text { regulation } \\
\text { Cost of resources } \\
\text { during an imbalance } \\
\text { event } \\
\text { Cost of spinning } \\
\text { reserves } \\
\text { Demand-response } \\
\text { incentive } \\
\text { DER installation cost } \\
\text { DER production cost } \\
\text { Monetary value of } \\
\text { energy loss } \\
\text { Payments for PV } \\
\text { generation } \\
\text { Peak marginal } \\
\text { resource unit cost } \\
\text { PV incentives paid }\end{array}$ & $\begin{array}{l}\text { Adjusted social } \\
\text { welfare } \\
\text { Consumer surplus* } \\
\text { Cost* }^{*} \\
\text { Elasticity } \\
\text { Flexibility } \\
\text { Market activity } \\
\text { Market efficiency } \\
\text { Market fairness } \\
\text { Market purity } \\
\text { Market stability } \\
\text { Market volatility } \\
\text { Market vulnerability } \\
\text { to being gamed } \\
\text { Price distribution } \\
\text { Robustness } \\
\text { Scalability } \\
\text { Social welfare } \\
\text { Supplier surplus } \\
\text { Unit price* }\end{array}$ & $\begin{array}{l}\text { Availability of PV } \\
\text { reactive power } \\
\text { Availability of PV } \\
\text { real power } \\
\text { Availability of wind } \\
\text { reactive power } \\
\text { Availability of wind } \\
\text { real power } \\
\text { PV energy } \\
\text { production } \\
\text { PV forecast } \\
\text { accuracy } \\
\text { PV hosting capacity } \\
\text { PV reactive power* } \\
\text { PV real power* } \\
\text { Wind energy } \\
\text { production } \\
\text { Wind forecast } \\
\text { accuracy } \\
\text { Wind hosting } \\
\text { capacity } \\
\text { Wind reactive } \\
\text { power* } \\
\text { Wind real power }\end{array}$ \\
\hline $\begin{array}{l}\text { customer classes, } \\
{ }^{*} \text { These each represe } \\
\text { are applied to sets }\end{array}$ & $\begin{array}{l}\text { nerous metrics } \\
\text { dividual sample }\end{array}$ & when minimization & imization, and va & $\begin{array}{l}\text { ity to subsystems, } \\
\text { averaging functions }\end{array}$ \\
\hline
\end{tabular}

\subsubsection{Accounting Ledger Table}

Behavior diagrams represent process, and might therefore make transparent precisely how value accrues in a scenario. Most importantly, the diagrams for the baseline and test scenarios should accentuate how the two scenarios' approaches differ. The authors foresee an eventual push to also include a UML behavioral diagram to further document how the things interact, which ultimately lets analysts contrastand quantify_aspects of the alternative scenarios.

The exchanges in a business-value diagram are then the basis for a ledger accounting of all the measures and differences. At this point, the various characteristics of alternative approaches can be analyzed from the different stakeholder perspectives, leading to informed and defensible decision making. An accounting table is recommended to account for the aggregated transactions. The authors recommend a double-entry approach that makes sure value is neither lost nor inexplicably gained during transactions. 
An important guiding principle is that the summation of value flowing into and away from an actor class amounts to the net business case for that entity.

The reader is invited to preview the example accounting ledger tables in Appendixes C and D.

\subsection{Addressing Risk in Valuation Studies}

Valuation metrics are modeled, meaning they can be derived from a set of defined inputs. Uncertainty can arise while exercising a valuation, in the form of natural system variability, lack of knowledge, and random events. In the context of the valuation model, risk is the combination of these sources of uncertainty and their consequences. Uncertainty propagates in a valuation study from its inputs to its valuation metric outputs. When two models from different sources or vendors are identical in all respects, but differ in the valuation outcome, assumptions will form an important basis for distinguishing them. In the context of energy systems and a valuation model, uncertainties are of two types: probabilistic (aleatory) variability, and true unknowns and inaccurate assumptions of the given system (epistemic uncertainty). Specific uncertainties of interest falling in either category include inherently uncertain events and those in the time dimension. This discussion is anticipated to help analysts more consistently incorporate the effects of uncertainty and risk into valuation studies so that the resulting valuation metrics better support decision makers.

Probabilistic variability, also called randomness, is intrinsic, embedded in the very nature of the physical problem. It can be characterized but not reduced. A common example is the randomness within consumer electricity consumption. A consumer's electricity consumption may be characterized by its average and typical diurnal pattern, but the consumer's precise usage of electricity in time is determined by the appliances, building occupancy, weather conditions, and many other factors. Decision makers need a complete picture of the embedded variabilities in the outcome appropriated from all sources. First and foremost, the valuation analysis should retain and represent variabilities and characterize them as uncertainty distributions. Ignoring these variabilities challenges the ability to compare future alternative scenarios.

Epistemic uncertainty derives from incomplete, erroneous, or missing knowledge. Epistemic uncertainty can be reduced through education by eliciting expert opinion, collecting data, or borrowing experience from other domains. For example, an analyst may lack an adequate history of real-world events from which a meaningful "typical” average value can be derived. The inaccurate value introduces bias in the outcome of a valuation study because the actual input value differs from the assumed one. Sensitivity analysis supports risk characterization in the presence of epistemic uncertainty through "what-if" assessments of key inputs to observe the effect on the outcomes of valuation.

There are sets of inherently uncertain events that, while generally infrequent, may have very costly or damaging consequences. These events are initiated by equipment failures, extreme weather, and accidental or intentional intervention. The direct consequences are measured in the cost of electrical equipment and lost energy sales, but secondary consequences may extend further to discomfort, lost productivity, or loss of life. A model of equipment failures might include inputs for ambient temperatures, electrical loading, age of the device, and maintenance history, as well as statistical parameters possessing probabilistic variability. Epistemic uncertainty similarly affects the statistical representations of these events: the presumed frequency of the events and the distributions of their occurrences may be inaccurate.

Uncertainty in the time dimension is important because many valuations (integrated resource portfolio studies, for example) address long time periods and necessarily consider growth and evolution of the system. The associated parameters are complex, and their uncertainty probably originates from the overly 
simplistic or flawed models currently available for their prediction-a type of epistemic uncertainty. The number of uncertain events in a year discussed above is an example of variability over time. Weather affects variability in time. It changes energy consumption, and it can delay or accelerate construction of new assets. The analyst should check the valuation to make sure that interim decisions within the timeframe of the valuation are not overly optimistic and do not unrealistically presume perfect foresight. Refer to the table in Appendix A that lists the sources, implications, and treatment of these uncertainties.

A valuation is asserted to be separate from the decision-making process. Otherwise, the decision-making criteria would necessarily be hard-coded and immutable. If the valuation propagates probabilistic variability, then many of its valuation metrics will exhibit statistical distributions. These uncertainty distributions facilitate inquiries about not only the typical outcome, but also the range of expected outcomes. Decision making in the presence of epistemic uncertainty is more challenging. If an input to a calculation is uncertain but can be bounded with some level of confidence, then the input bounds might be used to similarly narrow the output metric range through sensitivity analysis. Where a valuation exercise is intended for long-term planning, it is advised to adopt a multistage decision-making model (Ho et al. 2015) with a "wait-and-see” approach regarding long-term needs.

\subsection{A Useful Categorization of Transactive Mechanisms}

A long-term goal of the Transactive Systems Program is to compare alternative transactive mechanisms. This means that (1) valuation methodology must be strong enough to differentiate the outcomes of scenarios operating under the alternative transactive mechanisms, (2) modeling, including time-series simulation, must differentiate operations under the alternative mechanisms, and (3) the theory of the mechanisms must be understood well enough to compare the relative stabilities and market performances of the alternative mechanisms.

The authors propose that there are three fundamental transactive mechanisms:

- Bilateral trades_-any willing buyer and seller are welcome to bid and sell blocks of energy ${ }^{1}$ to one another. A parallel mechanism ensures access to transport rights for the conveyance of energy that has been traded.

- Double auctions - an entity assumes an aggregator function to clear a region's energy offers and bids. The cleared price is conveyed back to offerors and bidders to affect the amount of power that they generate or consume during an interval.

- Consensus negotiations-nodes iteratively negotiate price/quantity pairs for the power that is to flow between them during a time interval. Each node's criterion for convergence is based on the consistency and optimality of constrained power flow that it calculates based on its locally available information and observations.

While new fundamental mechanisms might emerge, most transactive systems may be found to build upon or combine these three. Still others may be found to be distributed control systems without necessarily being transactive ones. Each of these three fundamental mechanisms describes a type of value-based negotiation that is multi-scaled — one that can be similarly described at multiple levels or layers in the energy system. Interfaces will be needed at the intersections between these fundamental mechanisms and at the interfaces between any one of them and non-transactive parts of energy systems.

\footnotetext{
${ }^{1}$ While these mechanisms have been stated in respect to transactive energy, the mechanisms might be applied to commodities other than energy.
} 



\subsection{Transactive System Performance Metrics}

In this section, define a set of metrics is defined for the performance analysis of various transactive systems. These metrics can be used to provide insights about the effectiveness of the transactive system designs. They can also provide guidance to improve the design of future transactive energy systems.

The following five metrics are introduced in this chapter and will be quantified among the Chapter 5 trial analyses results:

- social welfare

- (constraint) violation level

- adjusted social welfare

- market efficiency

- market volatility

\subsection{Transactive System Metrics used in the Trial Analysis}

A control objective of transactive energy systems can often be formulated as the maximization of the system's social welfare each market period. Hence, the first metric is social welfare (SW, \$). For transactive approaches that solve the coordination problem among generators and load entities, social welfare is defined as the difference between the total utility of energy consumption and the total cost of energy production during the interval. That is,

$$
S W=\sum_{i=1}^{N_{L}} U_{i}\left(p_{i}^{L}\right)-\sum_{j=1}^{N_{G}} C_{j}\left(p_{j}^{G}\right),
$$

where $U_{i}(\cdot)$ are the utility functions of individual load entities, $C_{j}(\cdot)$ are the cost functions of individual generators, $p_{i}^{L}$ and $p_{j}^{G}$ are the average power consumption and generator production, and $N_{L}$ and $N_{G}$ are the total numbers of loads and generators, respectively. It is usually expected that a better transactive design will have a higher social welfare during any single time interval. For transactive approaches that solve the coordination problem among only loads, social welfare is defined as

$$
S W=\sum_{i=1}^{N} U_{i}\left(p_{i}\right)-C\left(\sum_{i=1}^{N} p_{i}\right)
$$

where $C(\cdot)$ is the cost function of total load consumption, $p_{i}$ is the average power consumption of individual loads for the market period, and $N$ is the total number of loads.

The next metric, violation level $(V L, \mathrm{~kW})$, measures the severity of violating power flow constraints. For transactive mechanisms that are proposed to manage feeder congestion, for example, violation level can be defined as the power that exceeds the feeder capacity limit $D$. That is, 


$$
V L=\max \left\{0, \sum_{i=1}^{N} p_{i}-D\right\}
$$

where $p_{\mathrm{i}}$ represents the average power of loads on the same feeder. Violation level can also be expressed as a percentage of the feeder capacity limit. That is,

$$
V L \%=\frac{\max \left\{0, \sum_{i=1}^{N} p_{i}-D\right\}}{D} \times 100 \%,
$$

which is sometimes more convenient and informative.

There is a trade-off between metrics $S W$ and $V L$. It is possible to end up with higher $S W$ if power flow constraint violations are allowed. Increased energy consumption may result in higher system-wide utility. Thus, both $S W$ and $V L$ should be considered in a valuation study. One simple but effective way of reflecting the trade-off is to penalize $S W$ by $V L$, which leads to the metric adjusted social welfare (ASW, \$), defined as

$$
A S W=S W-\omega \cdot V L
$$

where $\omega(\$ / \mathrm{kW})$ is the weighting factor for penalizing system violations. A large weighting factor lowers the tolerance for system violations. Let $A S W_{\max }$ denote the maximum value of $A S W$. Then the metric market efficiency ( $\eta$, \%) can be defined as the ratio between $A S W$ and $A S W_{\text {max }}$. That is,

$$
\eta=\frac{A S W}{A S W_{\max }}
$$

which measures the market efficiency of the transactive system.

The metric market volatility ( $R S S, \$ / k W h$ ) measures the degree of fluctuation in market clearing prices. It is defined as a root mean squared error between market clearing prices over an extended period of time. That is,

$$
R S S=\sqrt{\frac{\sum_{k=1}^{T}\left(\lambda_{\text {clear }}(k)-\bar{\lambda}_{\text {clear }}(k)\right)^{2}}{T}},
$$

where $\lambda_{\text {clear }}$ and $\bar{\lambda}_{\text {clear }}$ are the original and averaged market clearing prices for individual periods, and $k$ is a count of market clearing periods up to $T$ such periods. The averaged signals may be represented by locally weighted smoothing (LOESS). 


\subsection{Advancing Simulation Capabilities}

Building on GridLAB-D and other software modules, a Transactive Energy Simulation Platform (TESP) has been developed that addresses a wide variety of the use cases and drivers that were described earlier. Equally important, the TESP has been designed for easier customization and use by other researchers, so it can support a greater variety of design, test, and experimentation work in transactive systems.

The source code, design documents, and examples for the TESP are available on a public site at https://github.com/pnnl/tesp/, with minimally restrictive open-source license terms. The main goal of this section is to summarize and explain the design choices in the TESP, in particular the message schemas and metrics, so that other researchers may evaluate the costs and benefits of using the TESP. The public repository will have more detailed and up-to-date information.

\subsection{Goals of the Transactive Energy Simulation Platform}

Preliminary functional requirements were based on the valuation approach developed last year (Hammerstrom et al. 2016a), supplemented by additional study of use cases and drivers to be published in a companion report. The possibility of new transactive pilot projects was also considered, as suggested by NIST's TE Challenge (NIST 2017). This led to adoption of the following objectives:

1. integration of separate transactive energy agents (TEAgents) that encapsulate behaviors of market mechanisms and participants

2. separation of the valuation function from simulation

3. implementation of an efficient and completely open-source platform for Windows, Mac OS X and Linux.

4. definition of a growth model for multi-year TE simulations.

Objectives 1-3 specifically support use by others, while objective 4 ultimately extends the simulation time horizon up to 20 years.

\subsection{Design Choices for Version 1}

Figure 4.1 shows the simulation modules federated in Version 1 of the TESP. GridLAB-D covers the electric power distribution system (Chassin et al. 2014), MATPOWER covers the bulk electric power system (Zimmerman et al. 2011), and EnergyPlus covers large commercial buildings (Hao et al. 2016). These three simulators have been previously federated at PNNL, but only pairwise (i.e., GridLAB-D with MATPOWER, and GridLAB-D with EnergyPlus). The use of all three together in a transactive simulation is new this year. The integrating Framework for Network Co-Simulation (FNCS) manages the time step synchronization and message exchange among all of the federated simulation modules (Ciraci et al. 2014). In this way, the TESP builds mostly on proven components, which helps mitigate risk in software development. Some of these components may be upgraded or replaced in future versions, as is described later. However, the overall platform design in Figure 4.1 still applies. 


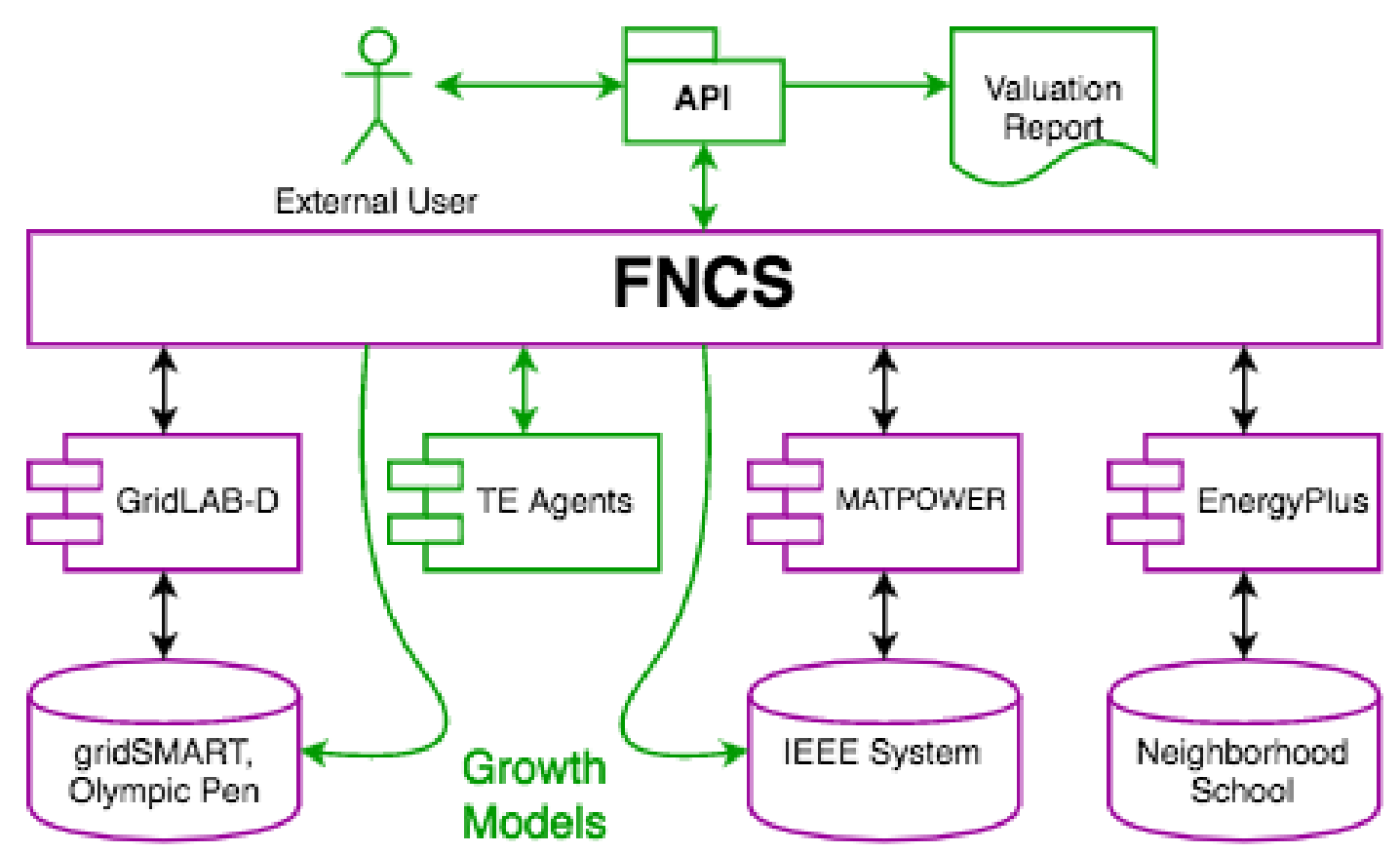

Figure 4.1. TESP Version 1 Components Federated through FNCS.|New work is shown in green.

New work in Figure 4.1 has been highlighted in green. This primarily represents custom code implemented in the Python programming language, which was chosen for the following reasons:

1. Python is now commonly used in colleges to teach new programmers.

2. Python has many available add-on packages for numerics, graphics, and data handling.

3. Python bindings to FNCS already existed.

Custom code for the TESP can also be implemented in other languages like $\mathrm{C}++$ and Java, and in fact, the "wrappers" or "agents" for MATPOWER and EnergyPlus have been implemented as separate C++ programs. PNNL's experience has been that developers with experience in C++ or Java can easily work in Python, while the converse is not always true. These factors led to the choice of Python as a default language for customizing the TESP.

Initially, the TEAgents include a double-auction market mechanism, one per substation, and a dual-ramp thermostat controller, one per house (Fuller et al. 2011). These were previously hard-coded in GridLAB-D, and those implementations remain in GridLAB-D, but the separate Python versions allow others to study and modify just the transactive code without having to rebuild all of GridLAB-D. Much of the future work envisioned for the TESP would focus on significantly expanding the numbers and capabilities of TEAgents. Regarding the other new work highlighted in Figure 4.1, Section 4.3 (next) describes the growth model and Section 4.5 describes the valuation scripts.

\subsection{Operational and Growth Models}

The TESP adopts a time-stepping simulation that separates the operational model—of a system with fixed infrastructure running for hours or days - from the growth model—of a system with infrastructure that evolves over months or years. Figure 4.2 shows these two models in a UML activity diagram (Arlow and Neustadt 2005). After configuration, the simulation begins with a system in the initial year-zero state, i.e., with no growth included. The operational model then begins to run with federated co-simulators in the 
form of GridLAB-D, TEAgents, MATPOWER, and EnergyPlus. The operational model has two different time steps, which may vary with time and between simulators under supervision by FNCS. These are

1. the operational time step for power system load and resource variations, weather variations, and power system control actions, e.g., 1 to 60 seconds

2. the market-clearing time step for transactive systems, e.g., 5, 15, or 60 minutes.

Events like peak load days, power system faults, transmission line outages, and bulk generator outages would occur within the operational model. These involve no permanent changes to the system infrastructure, and the power system is expected to respond autonomously to such events. Events like new loads, new distributed energy resources (DER), and capital investments would occur within the growth model because they represent permanent changes to system infrastructure. Most of the time, this will require stopping and restarting the operational model and its federated simulators. Future TESP versions will make these transitions more efficiently. Growth model time steps would usually be monthly, quarterly, or yearly, but could also be as short as weekly. After the last growth time step, the simulation ends for valuation by post-processing.

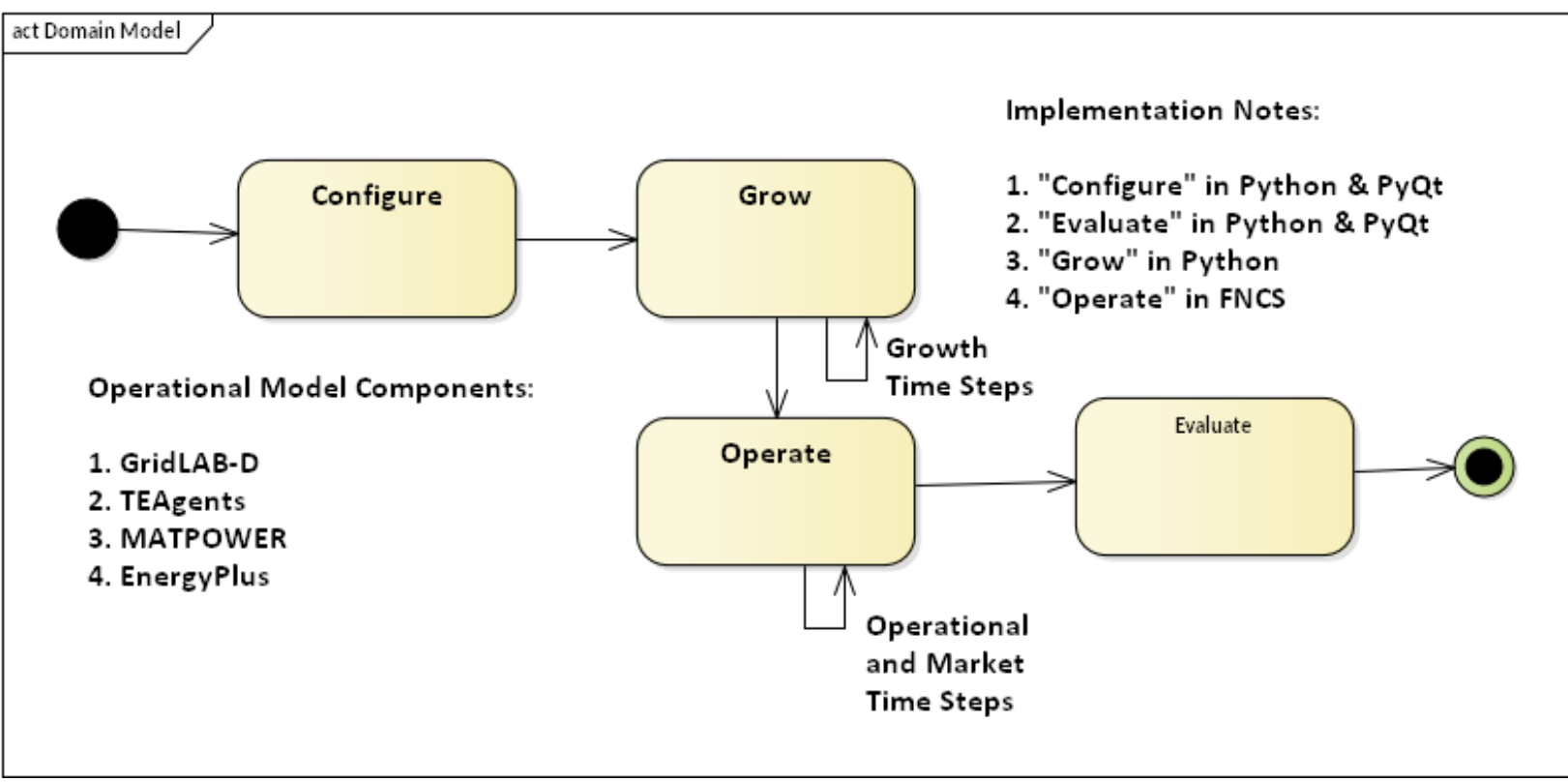

Figure 4.2. Interaction of Growth Model with Operational Model

Early versions of the growth model will only include the following:

1. fixed growth factors for existing solar, storage, and controllable (or uncontrollable) loads; input as a schedule of \%/year vs. time

2. pre-identified feasible sites for new capacitor banks, chosen from a list of fixed sizes

3. residential rooftop solar adoption models for existing houses (Zhang et al. 2015; Sultan et al. 2016), or a simpler one based on total energy use and floor area of the house

4. changing size of an existing substation or service transformer.

Later versions are planned to have heuristics that utility system planners and other agents would use in making investment decisions. These heuristics will execute between growth model time steps, using only information available at that point in the simulation. 


\subsection{Messages between Simulators and Agents}

In Version 1, TESP simulators exchange a minimal set of messages shown in Figure 4.3 and Figure 4.4.

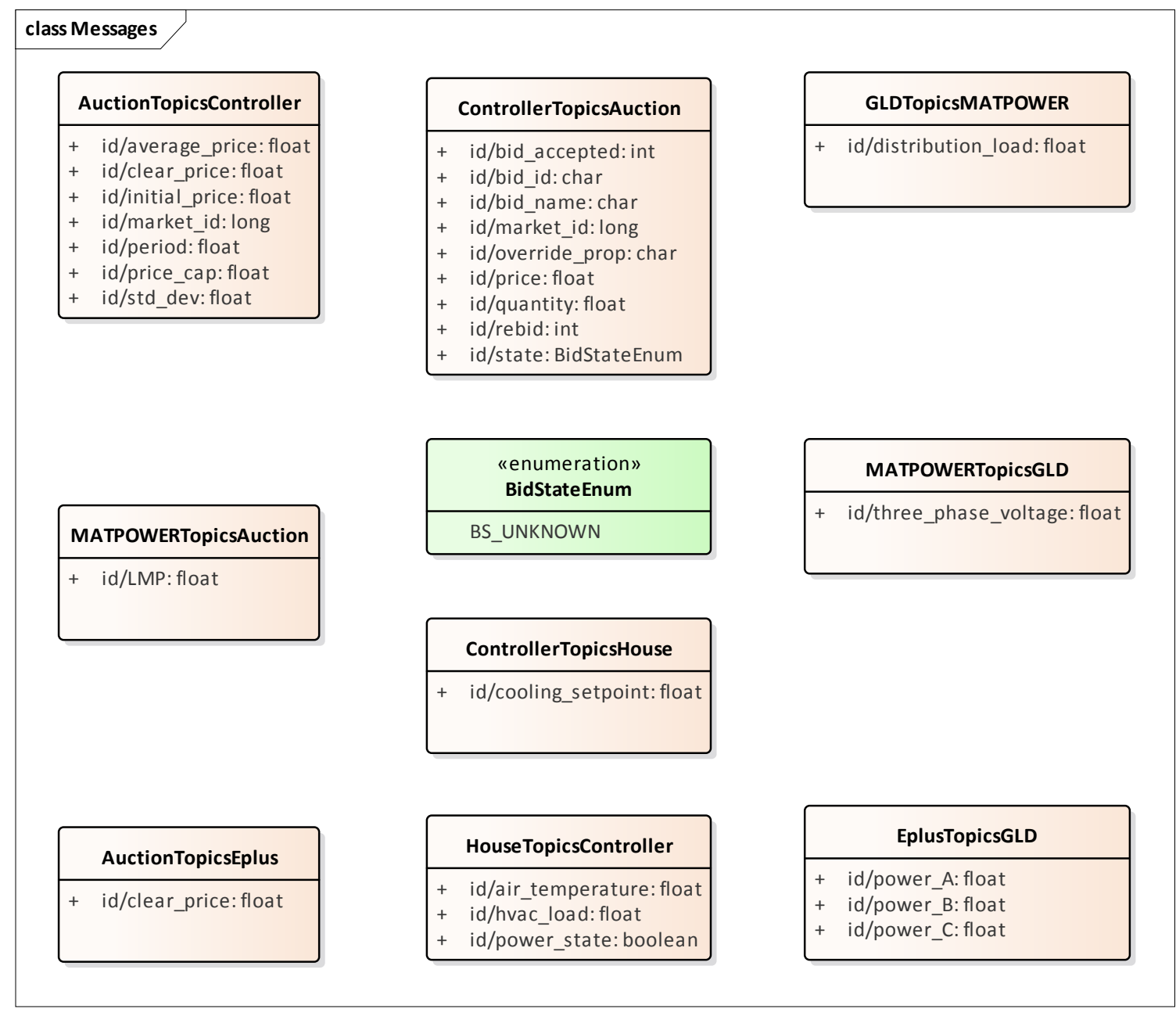

Figure 4.3. Message Schemas

These messages route through FNCS in a format like "topic/keyword=value". In Figure 4.3, the "id" would refer to a specific feeder, house, market, or building, and it would be the message topic. Once published via FNCS, any other FNCS simulator can access the value by subscription. For example, MATPOWER publishes two values, the locational marginal price (LMP) at a substation bus and the positive sequence three-phase voltage at the bus. GridLAB-D subscribes to the voltage, using it to update the power flow solution. The double-auction for that substation subscribes to the LMP, using it to represent a seller in the next market clearing interval. In turn, GridLAB-D publishes a distribution load value at the substation following each significantly different power flow solution; MATPOWER subscribes to that value for its next optimal power flow solution. 


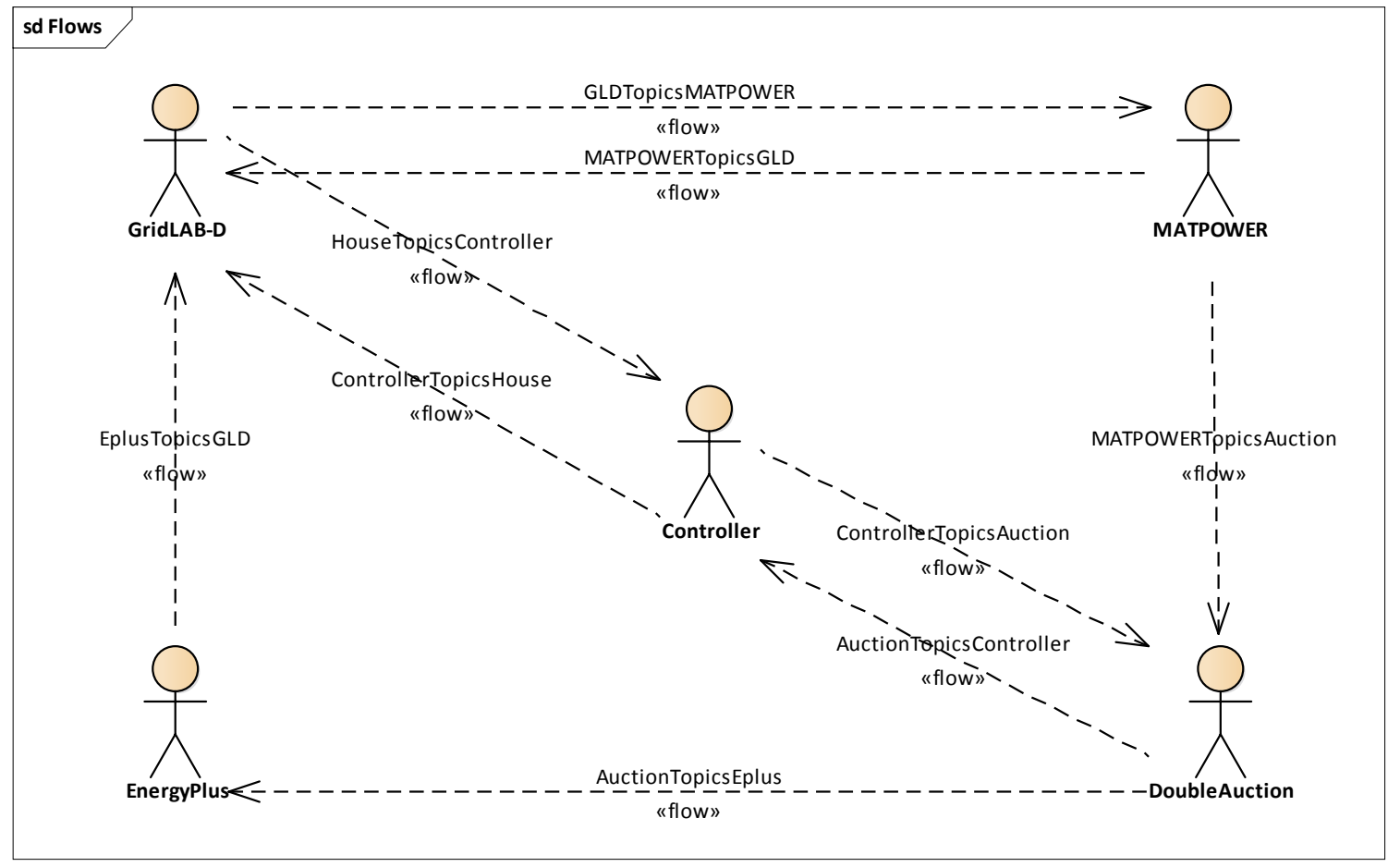

Figure 4.4. Message Flows

EnergyPlus publishes three-phase power values after each of its solutions (currently on five-minute intervals). These are all numerically equal, at one third of the total building power that includes lights, office equipment, refrigeration, and HVAC loads. GridLAB-D subscribes in order to update its power flow model at the point of interconnection for the building, which is typically at a $480-\mathrm{V}$ or $208-\mathrm{V}$ threephase transformer. EnergyPlus also subscribes to the double-auction market's published clearing price, using that value for a real-time price (RTP) response of its HVAC load.

Message flows involving the thermostat controller, at the center of Figure 4.4, are a little more involved. From the associated house within GridLAB-D, it subscribes to the air temperature, HVAC power state, and the HVAC power if turned on. The controller uses this information to help formulate a bid for electric power at the next market clearing, primarily the price and quantity. Note that each market clearing interval will have its own market id, and that rebidding may be allowed until that particular market id closes. When bidding closes for a market interval, the double-auction market will settle all bids and publish several values, primarily the clearing price. The house thermostat controllers use that clearing price subscription, compared to their bid price, to adjust the HVAC thermostat set point. As noted above, the EnergyPlus building model also uses the clearing price to determine how much to adjust its thermostat setting. Figure 4.3 shows several other keyword values published by the double-auction market and thermostat controllers; these are mainly used to define "ramps" for the controller bidding strategies. See the GridLAB-D documentation at http://gridlab-d.sourceforge.net/wiki, or TESP design documentation at https://github.com/pnnl/tesp, for more details.

These message schemas are limited to the minimum necessary to operate Version 1 , and it is expected that the schema will expand as new TEAgents are added. Beyond that, note that any of the simulators may subscribe to any values that it "knows about," i.e., there are no security and access control emulations. This may be a layer outside the scope of the TESP. However, there is also no provision for enforcement of bid compliance, i.e., perfect compliance is built into the code. That is clearly not a realistic assumption, and is within the scope for future versions as described in Chapter 6.0. 


\subsection{Output Metrics to Support Evaluation}

The TESP will produce various outputs that support comparative evaluation of different scenarios. Many of these outputs are nonmonetary, so a user will have to apply different weighting and aggregation methods to complete the evaluations. This is done in the Evaluation Script, which is written in Python. These TESP outputs all come from the operational model, or from the growth model applied to the operational model. For efficiency, each simulator writes intermediate base metrics to JavaScript Object Notation (JSON) files during the simulation, as shown in Figure 4.5. For example, if GridLAB-D simulates a three-phase commercial load at 10 -second time steps, the voltage metrics output would only include the minimum, maximum, mean, and median voltage over all three phases, and over a metrics aggregation interval of 5 to 60 minutes. This saves considerable disk space and processing time versus the handling of multiple CSV files. Python and other languages have library functions optimized to quickly load JSON files.

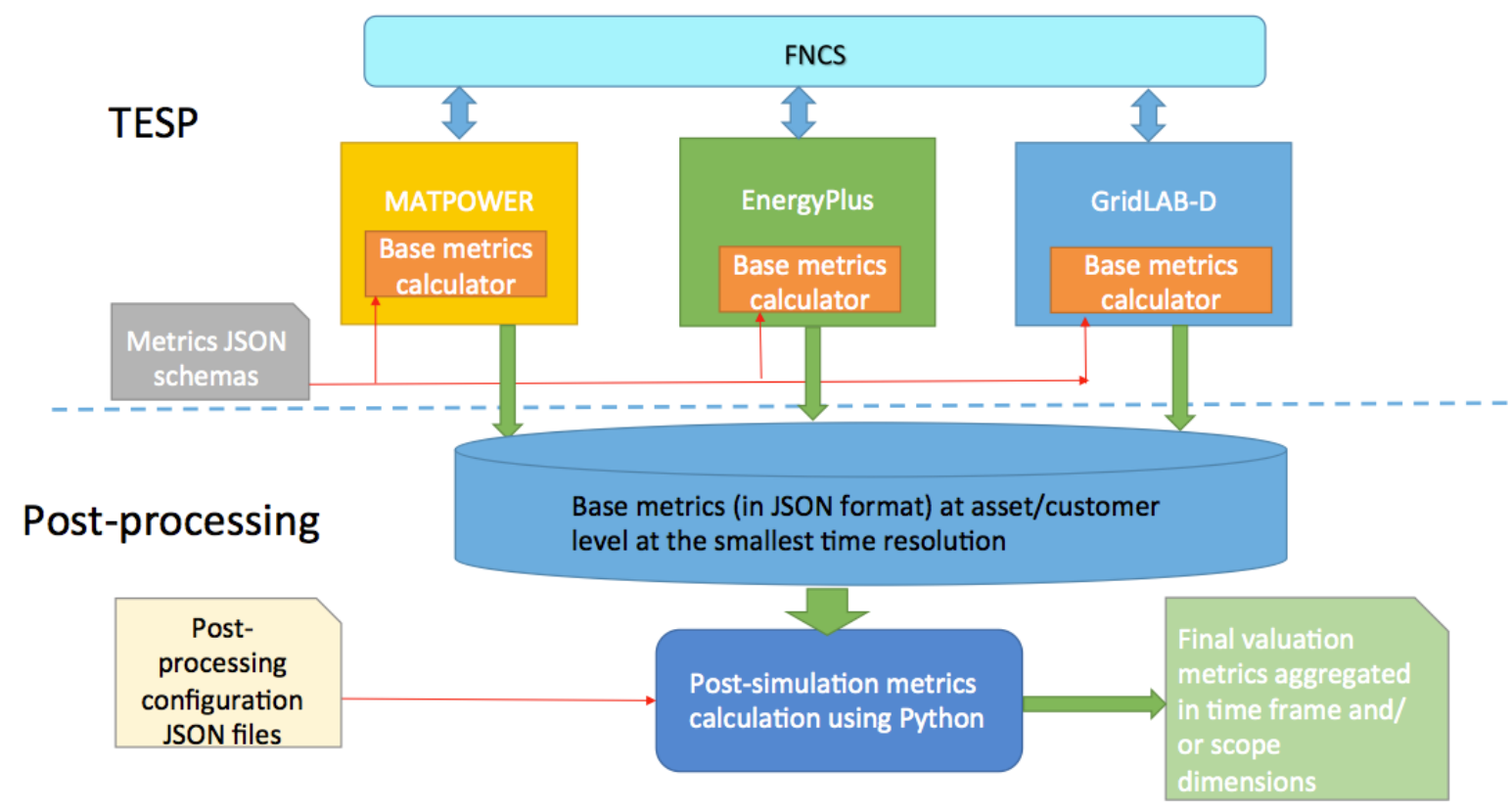

Figure 4.5. Partitioning the Valuation Metrics between Simulation and Post-Processing

To support these intermediate metrics, two new classes were added to the "tape" module of GridLAB-D, as shown in Figure 4.6. The volume and variety of metrics generated from GridLAB-D are currently the highest among simulators within the TESP, so it was especially important here to provide outputs that take less time and space than CSV files. Most of the outputs come from billing meters, either single-phase triplex meters that serve houses, or three-phase meters that serve commercial loads. The power, voltage, and billing revenue outputs are linked to these meters, of which there may be several thousand on a feeder. Houses, which always connect to triplex meters, provide the air temperature and set point deviation outputs for evaluating occupant comfort. Inverters, which always connect to meters, provide real and reactive power flow outputs for connected solar panels, battery storage, and future DER such as vehicle chargers. Note that inverters may be separately metered from a house or commercial building, or combined on the same meter as in net metering. Feeder-level metrics, primarily the real and reactive losses, are also collected by a fourth class that iterates over all transformers and lines in the model; this substation-level class has just one instance, and is not shown in Figure 4.6. An hourly metrics output interval is shown, but this is adjustable. 


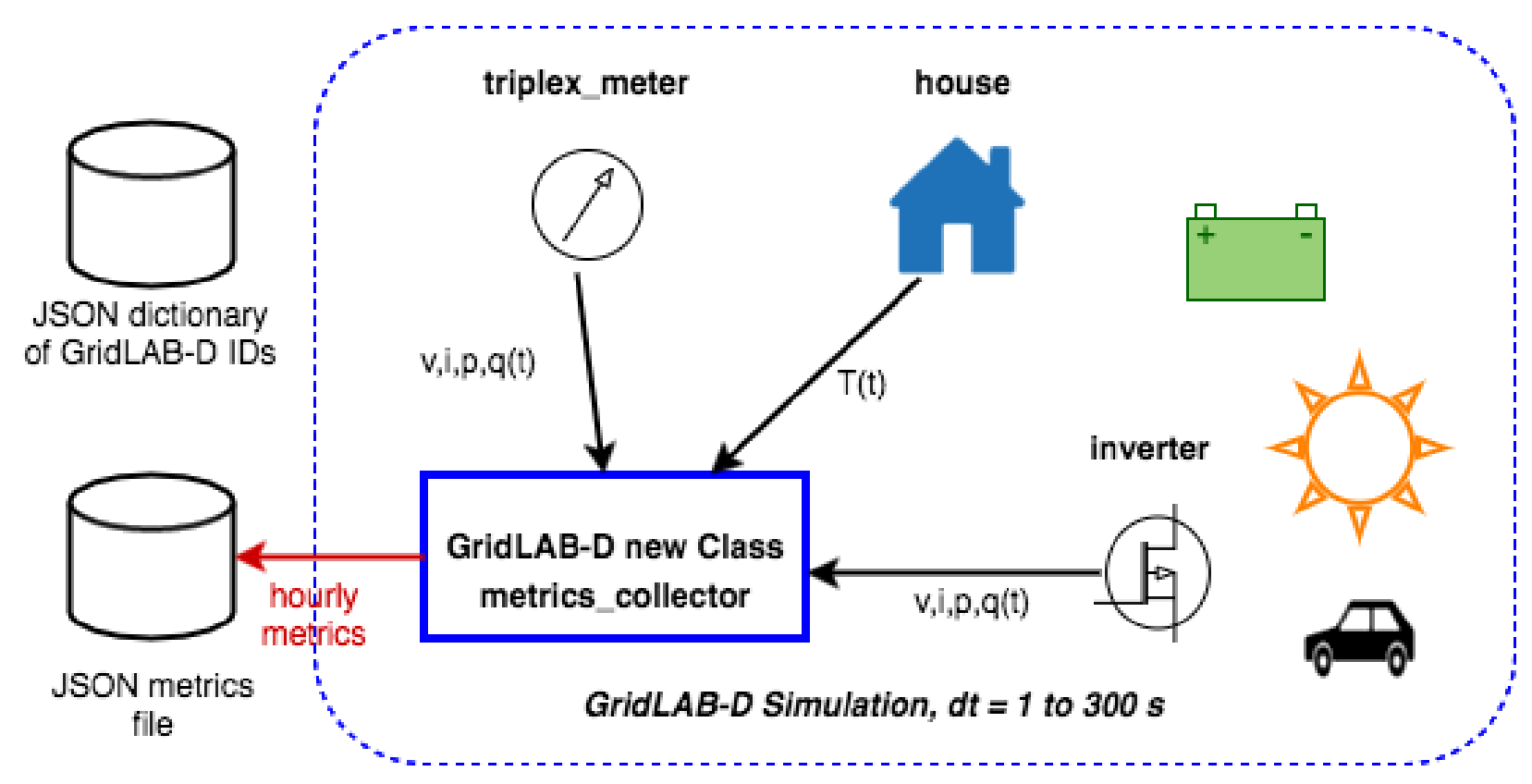

Figure 4.6. New Metrics Collection Classes for GridLAB-D

The initial GridLAB-D metrics are detailed in five UML diagrams. The UML metric descriptions begin with MATPOWER, which is much simpler. During each simulation, MATPOWER will produce two JSON files, one for all of the generators and another for all of the FNCS interface buses to GridLAB-D. A third JSON file, called the dictionary, is produced before the simulation starts from the MATPOWER case input file. The dictionary serves as an aid to post-processing. Figure 4.7 shows the schemas for all three MATPOWER metrics files.

The MATPOWER dictionary (top of Figure 4.7) includes the system MVA base (typically 100) and the GridLAB-D feeder amplification factor. The amplification factor is used to scale up the load from one simulated GridLAB-D feeder to represent many similar feeders connected to the same MATPOWER bus. Each generator has a bus number (more than one generator can be at a bus), power rating, cost function $\left(f(P)=c_{0}+c_{1} P+c_{2} P^{2}\right)$, startup cost, shutdown cost, and other descriptive information. Each FNCSBus has nominal real power, $\mathrm{P}$, and reactive power, $\mathrm{Q}$, that MATPOWER can vary outside of GridLAB-D, plus the name of a GridLAB-D substation that provides additional load at the bus. All GridLAB-D loads are currently scaled by the same user-defined ampFactor, but the next version of TESP will have a separate ampFactor for each FNCSBus. In total, the MATPOWER dictionary contains four JSON objects: the ampFactor, the baseMVA, a dictionary (map) of generators keyed on the generator id, and a dictionary (map) of FNCSBuses keyed on the bus id. In MATPOWER, all id values are integers, but the other simulators use string ids. 


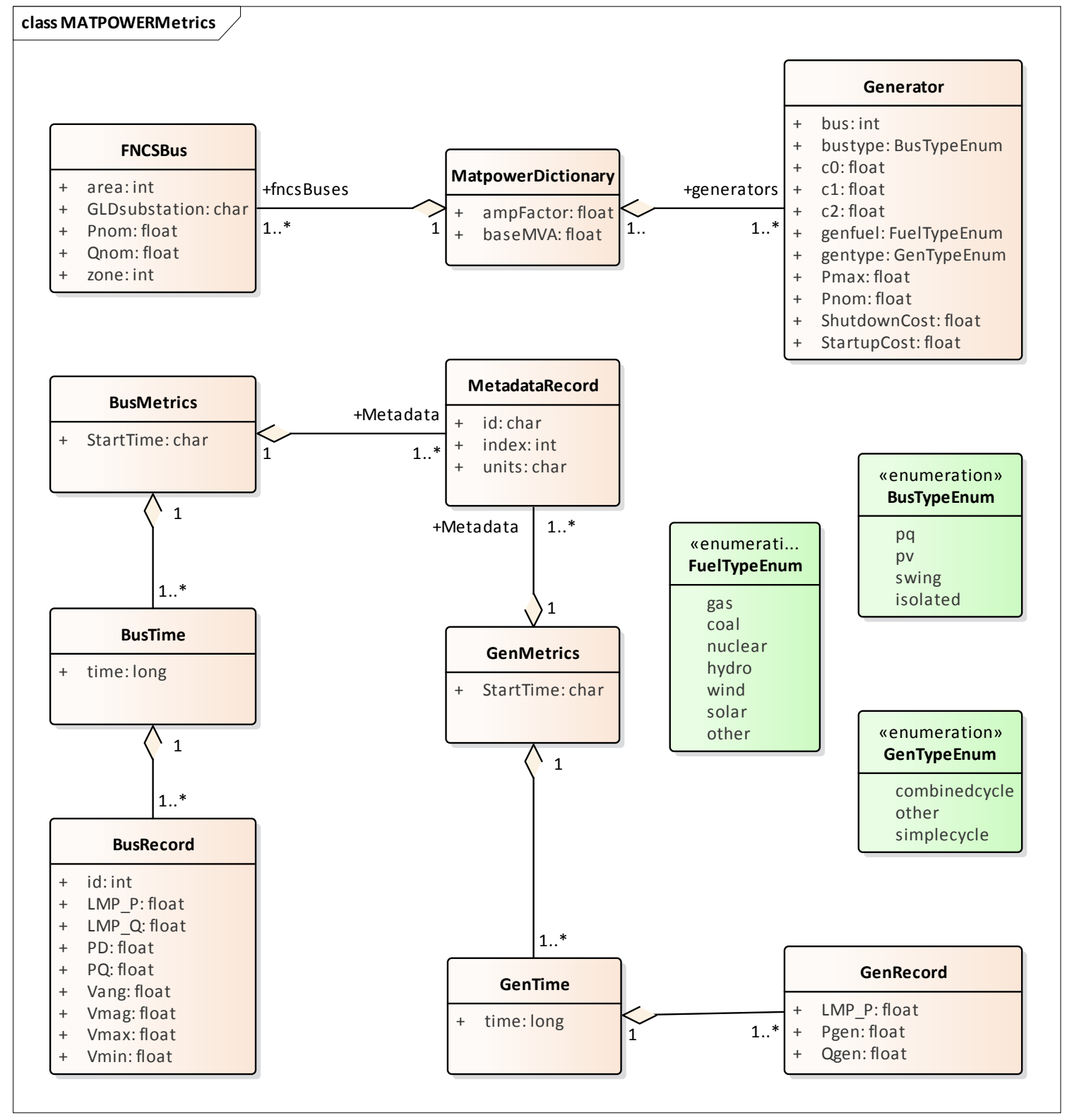

Figure 4.7. MATPOWER Dictionary with Generator and FNCS Bus Metrics

The GenMetrics file (center of Figure 4.7) includes the simulation starting date, time, and time zone as StartTime, which should be the same in all metrics output files from that simulation. It also contains a dictionary (map) of three MetadataRecords, which define the array index and units for each of the three generator metric output values. These are the real power LMP, along with the actual real and reactive power outputs, Pgen and Qgen. At each time of metrics output, a GenTime dictionary (map) object will be written with a key equal to the time in seconds from the simulation StartTime, and the value being a dictionary (map) of GenRecords.

The GenRecord keys are generator numbers, which will match the dictionary. The GenRecord values are arrays of three indexed output values, with indices and units matching the Metadata. This structure minimizes nesting in the JSON file, and facilitates quick loading in a Python post-processor program. Valuation may require the use of both metrics and the dictionary. For example, suppose an analyst needs 
the profit earned by a generator at a time 300 seconds after the simulation starting time. The revenue comes from the metrics as LMP_P $\times$ Pgen. In order to find the cost, one would start with cost function coefficients obtained from the dictionary for that generator, and substitute Pgen into that cost function. In addition, the post-processing script should add startup and shutdown costs based on Pgen transitions between zero and nonzero values; MATPOWER itself does not handle startup and shutdown costs. Furthermore, aggregating across generators and times would have to be done in post-processing, using built-in functions from Python's NumPy package. The repository includes an example of how to do this.

Turning to more complicated GridLAB-D metrics, Figure 4.8 provides the dictionary. At the top level, it includes the substation transformer size and the MATPOWER substation name for FNCS connection. There are four dictionaries (maps) of component types, namely houses, inverters, billing meters, and feeders. While real substations often have more than one feeder, in this model only one feeder dictionary will exist, comprising all GridLAB-D components in that model. The reason is that feeders are actually distinguished by their different circuit breakers or reclosers at the feeder head, and GridLAB-D does not currently associate components with switches that way. In other words, there is one feeder and one substation per GridLAB-D file in this version of the TESP. When this restriction is lifted in a future version, attributes like feeder_id, house_count, and inverter_count will become helpful. At present, all feeder_id attributes will have the same value, while house_count and inverter_count will simply be the length of their corresponding JSON dictionary objects. Figure 4.8 shows that a BillingMeter must have at least one House or Inverter with no upper limit; otherwise, it would not appear in the dictionary. The wh_gallons attribute can be used to flag a thermostat-controlled electric water heater, but these are not yet treated as responsive loads in Version 1. Other attributes like the inverter's rated power ("rated_W") and the house's square footage ("sqft") could be useful in weighting some of the metric outputs.

Figure 4.9 shows the structure of substation metrics output from GridLAB-D, consisting of real power and energy, reactive power and energy, and losses from all distribution components in that model. As with MATPOWER metrics files, the substation metrics JSON file contains the StartTime of the simulation, Metadata with an array index and units for each metric value, and a dictionary (map) of time records, keyed on the simulation time in seconds from the StartTime. Each time record contains a dictionary (map) of SubstationRecords, each of which contains an array of 18 values. This structure, with minimal nesting of JSON objects, was designed to facilitate fast loading and navigation of arrays in Python. The TESP code repository includes examples of working with metrics output in Python.

Figure 4.10 shows the structure of billing meter metrics, which is very similar to that of substation metrics, except that each array contains 30 values. The billing meter metrics aggregate real and reactive power for any houses and inverters connected to the meter, with several voltage magnitude and unbalance metrics. The interval bill is also included, based on metered consumption and the tariff that was input to GridLAB-D. In some cases, revenues may be recalculated in post-processing to explore different tariff designs. It should be possible to recalculate the billing determinants from metrics that have been defined. 


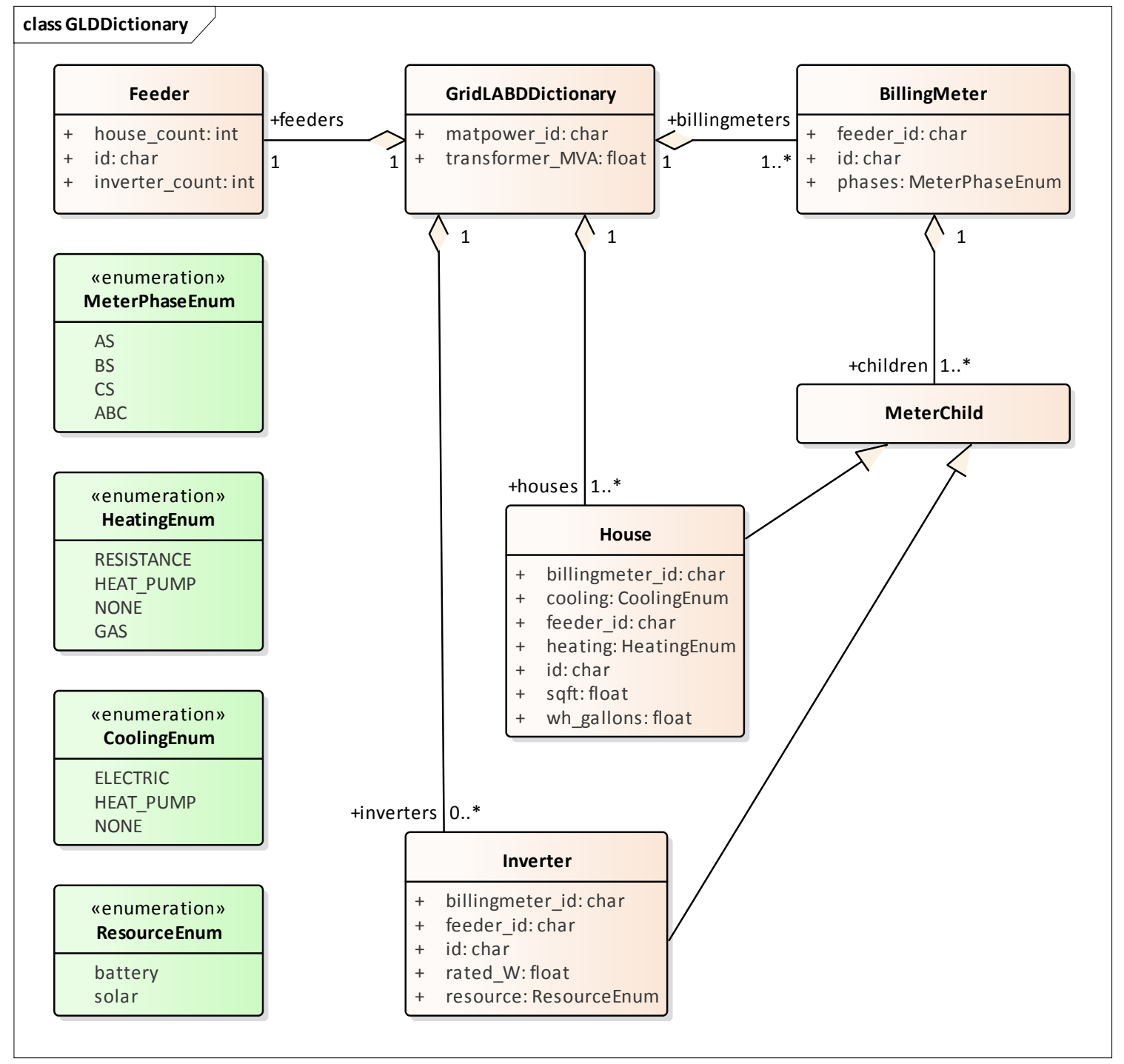

Figure 4.8. GridLAB-D Dictionary

The Range A and Range B metrics in Figure 4.10 refer to ANSI C84.1 (ANSI 2016). For service voltages less than $600 \mathrm{~V}$, Range A is $\pm 5 \%$ of nominal voltage for normal operation. Range B is $-8.33 \%$ to $+5.83 \%$ of nominal voltage for limited-extent operation. Voltage unbalance is defined as the maximum deviation from average voltage, divided by average voltage, among all phases present. For three-phase meters, the unbalance is based on line-to-line voltages, because that is how motor voltage unbalance is evaluated. For triplex meters, unbalance is based on line-to-neutral voltages, because there is only one line-to-line voltage. In Figure 4.10, "voltage_” refers to the line-to-neutral voltage, while "voltage12_" refers to the line-to-line voltage. The "below_10_percent" voltage duration and count metrics indicate when the billing meter has no voltage. That information would be used to calculate reliability indices in post-processing, with flexible weighting and aggregation options by customer, owner, circuit, etc. These include the System Average Interruption Frequency Index (SAIFI) and System Average Interruption Duration Index (SAIDI) (IEEE 2012, 2014). This voltage-based approach to reliability indices works whether the outage resulted from a distribution, transmission, or bulk generation event. The voltage-based metrics also support Momentary Average Interruption Frequency Index (MAIFI) for shorter duration outages. 


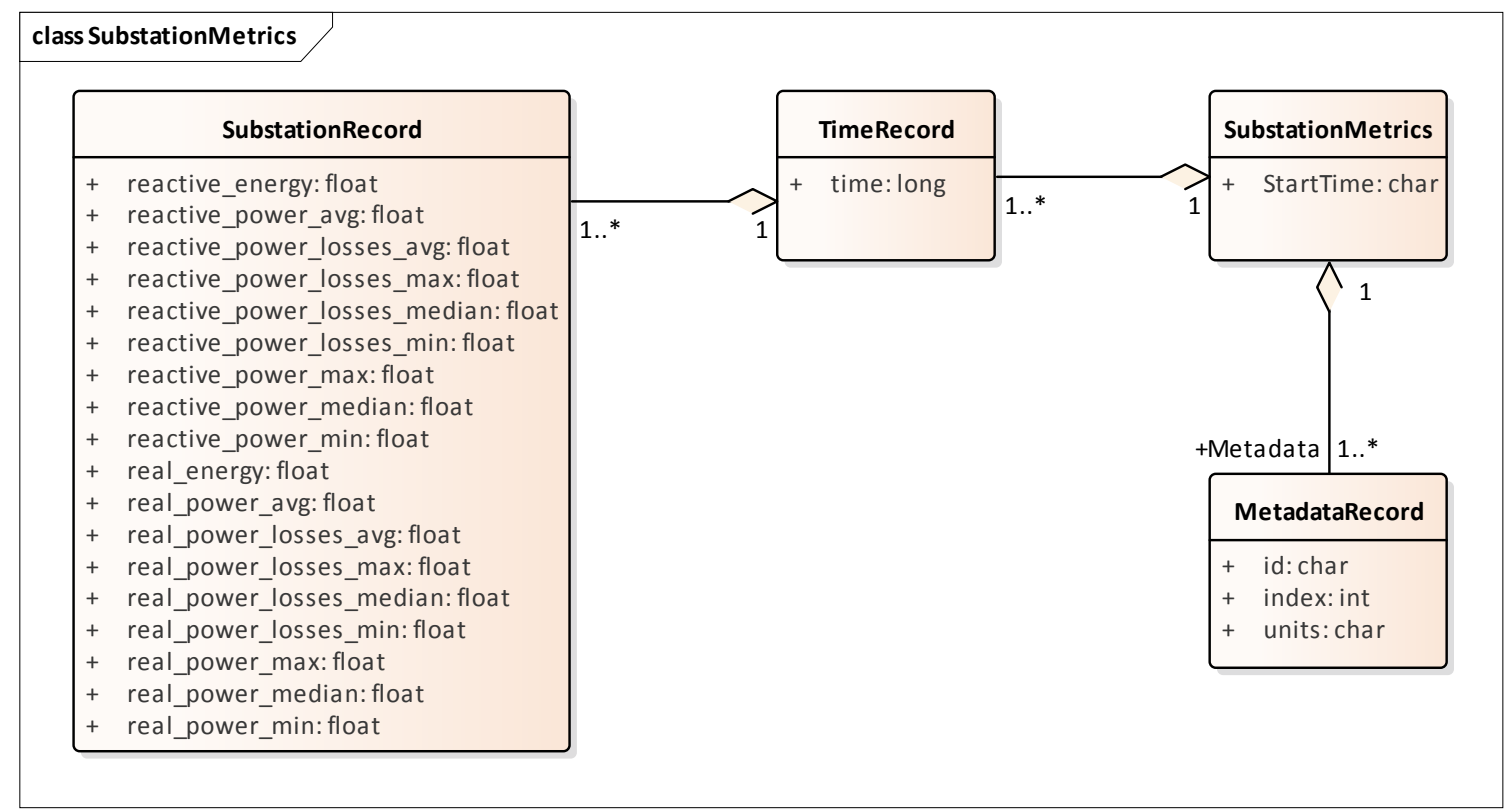

Figure 4.9. GridLAB-D Substation Metrics

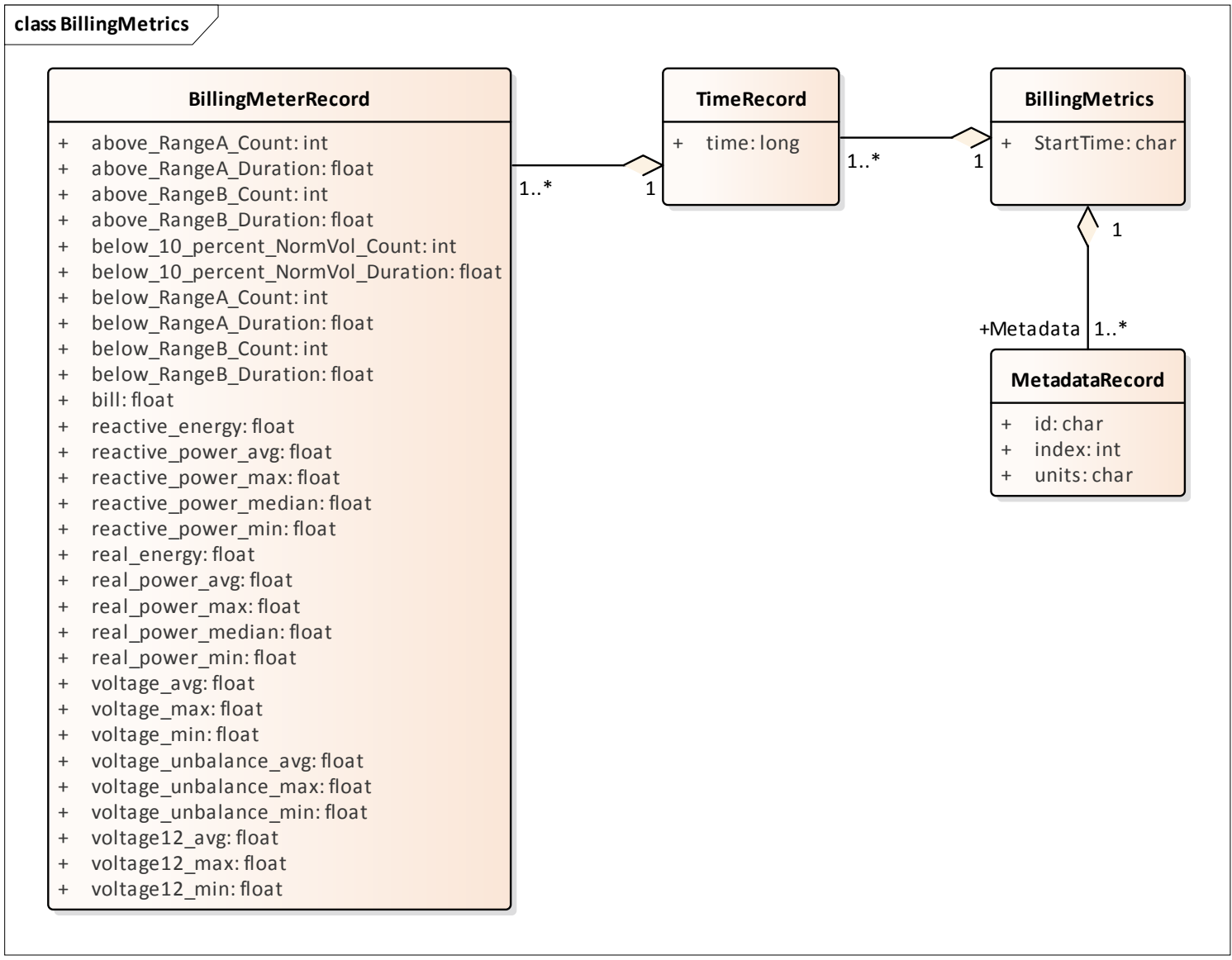

Figure 4.10. GridLAB-D Billing Meter Metrics 
The house metric JSON file structure is shown in Figure 4.11, following the same structure as the other GridLAB-D metrics files, with 18 values in each array. These relate to the breakdown of total house load into HVAC and water heater ("waterheater") components, which are both thermostat controlled. The house air temperature, and its deviation from the thermostat set point, are also included. Note that the house bill would be included in billing meter metrics, not the house metrics. Inverter metrics in Figure 4.12 include eight real and reactive power values in the array, so the connected resource outputs can be disaggregated from the billing meter outputs, which always net the connected houses and inverters. In Version 1, the inverters will be net metered, or have their own meter, but they do not have transactive agents yet.

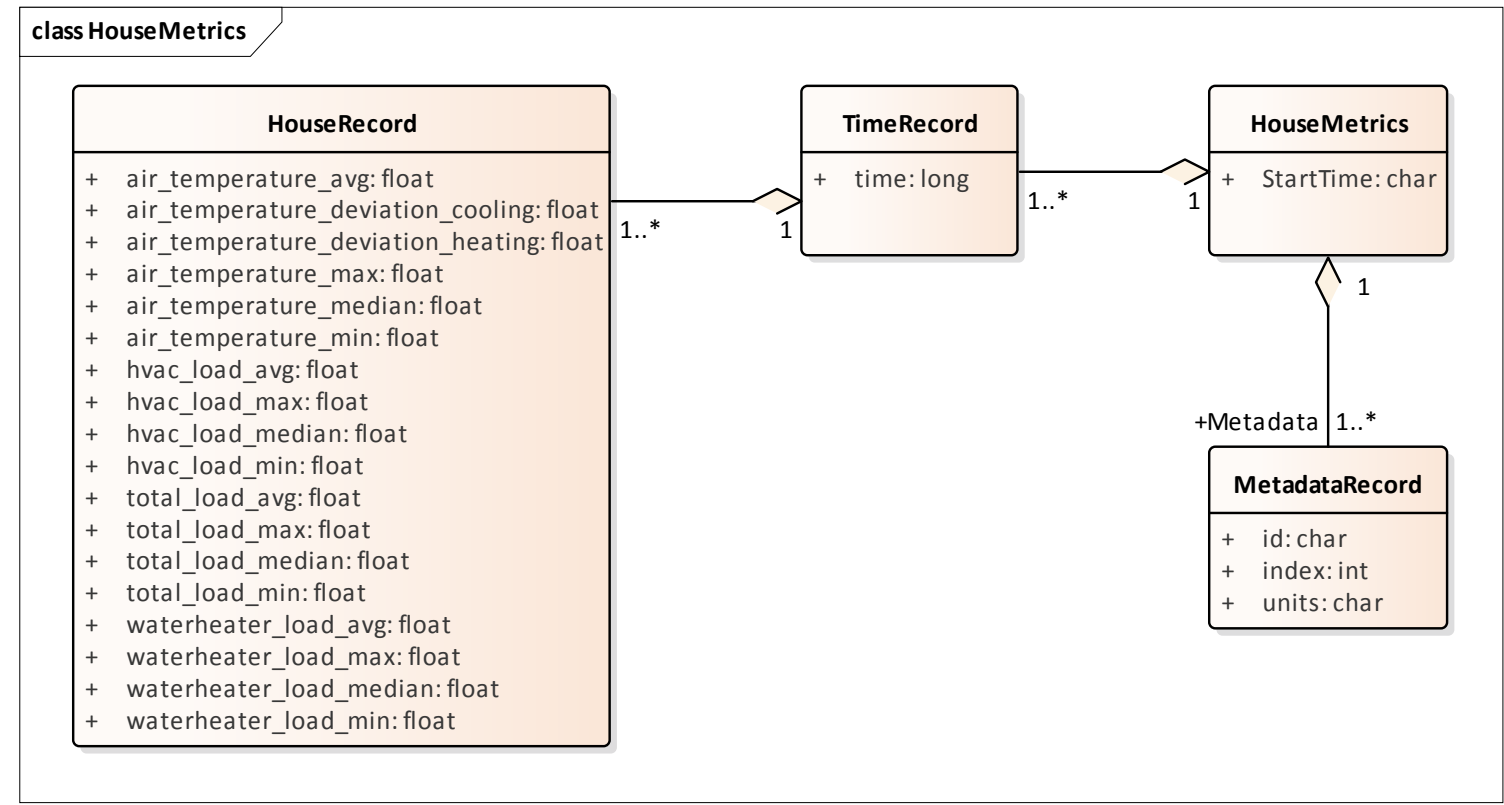

Figure 4.11. GridLAB-D House Metrics

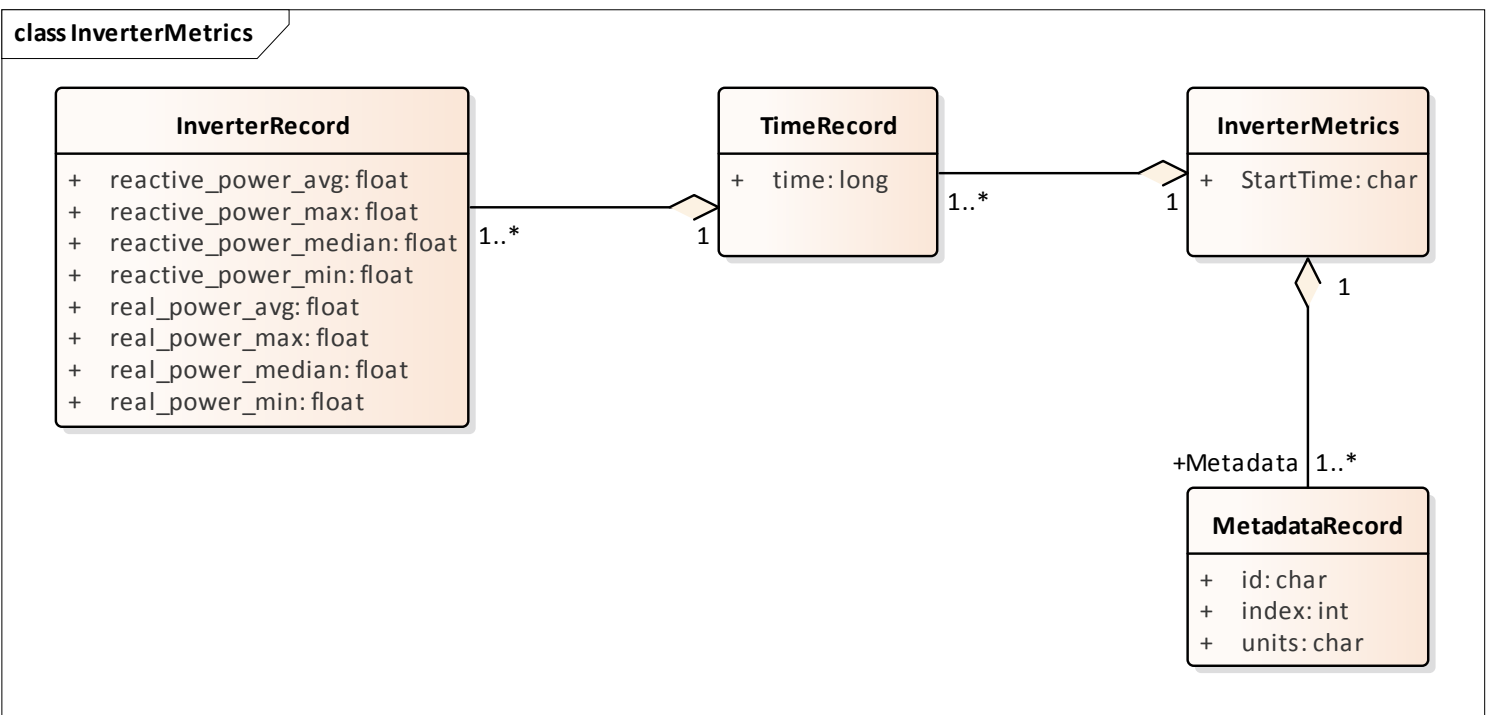

Figure 4.12. GridLAB-D Inverter Metrics 
Figure 4.13 shows the transactive agent dictionary and metrics file structures. Currently, these include one double-auction market per substation and one double-ramp controller per HVAC. Each dictionary (map) is keyed to the controller or market id. The Controller dictionary (top left) has a houseName for linkage to a specific house within the GridLAB-D model. In Version 1, there can be only one Market instance per GridLAB-D model, but this will expand in future versions. See the GridLAB-D market module documentation for information about the other dictionary attributes.

There will be two JSON metrics output files for TEAgents during a simulation, one for markets and one for controllers, which are structured as shown at the bottom of Figure 4.13. The use of StartTime and Metadata is the same as for MATPOWER and GridLAB-D metrics. For controllers, the bid price and quantity (kW, not kWh) is recorded for each market clearing interval's id. For auctions, the actual clearing price and type are recorded for each market clearing interval's id. That clearing price applies throughout the feeder, so it can be used for supplemental revenue calculations until more agents are developed.

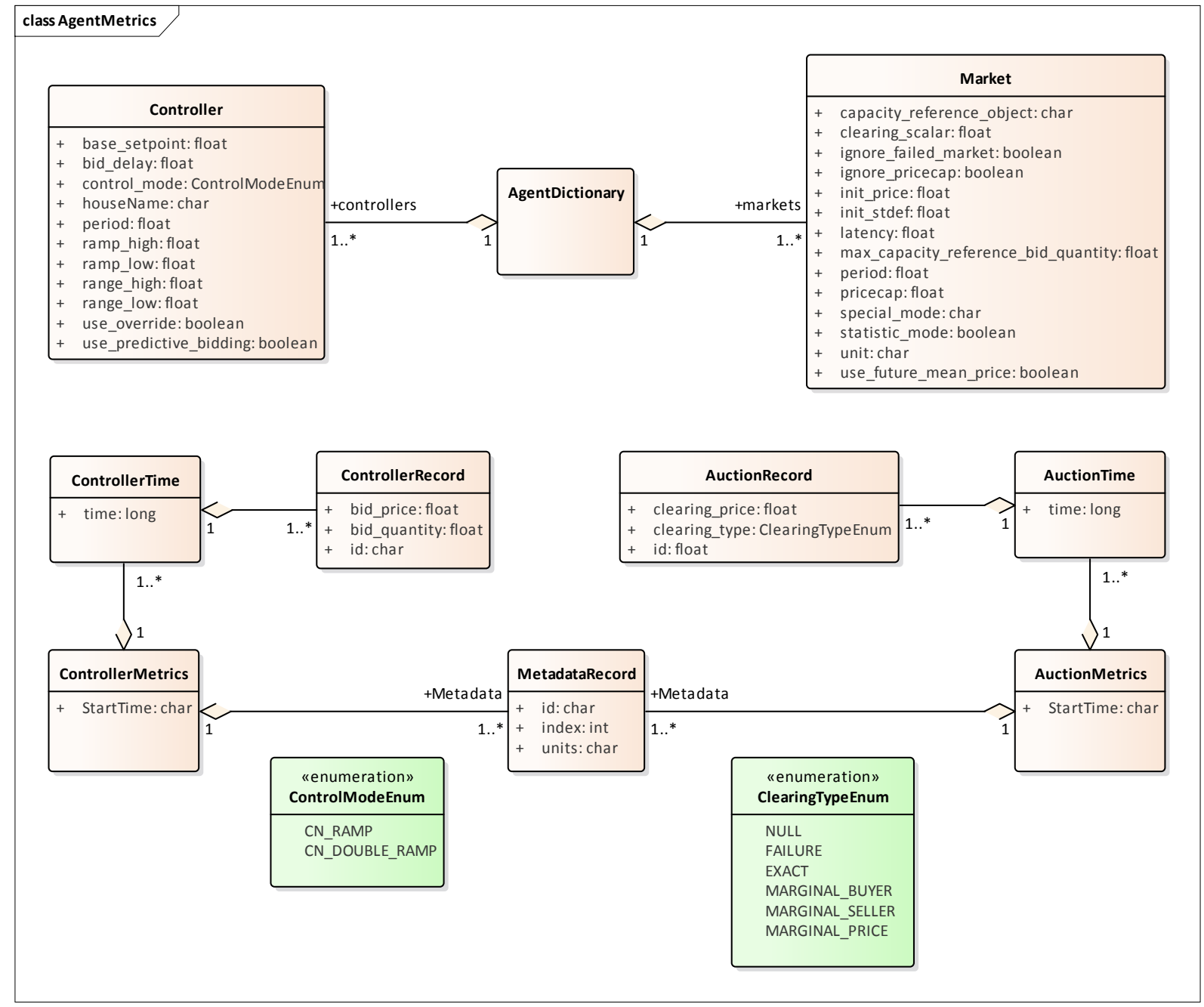

Figure 4.13. TEAgent Dictionary and Metrics

The EnergyPlus dictionary and metrics structure in Figure 4.14 follows the same pattern as MATPOWER, GridLAB-D, and TEAgent metrics. There are 42 metric values in the array, most of them pertaining to heating and cooling system temperatures and states. Each EnergyPlus model is custom-built 
for a specific commercial building, with detailed models of the HVAC equipment and zones, along with a customized energy management system (EMS) program to manage the HVAC. Many of the metrics are specified to track the EMS program performance during simulation. In addition, the "occupants" metric can be used for weighting the comfort measures; EnergyPlus estimates the number of occupants per zone based on hour of day and type of day, then TESP aggregates for the whole building. The electric_demand_power metric is the total three-phase power published to GridLAB-D, including HVAC and variable loads from lights, refrigeration, office equipment, etc. The kwhr_price will correspond to the market clearing price from Figure 4.13. Finally, the ashrae_uncomfortable_hours is based on a simple standardized model, aggregated for all zones (ASHRAE 2010).

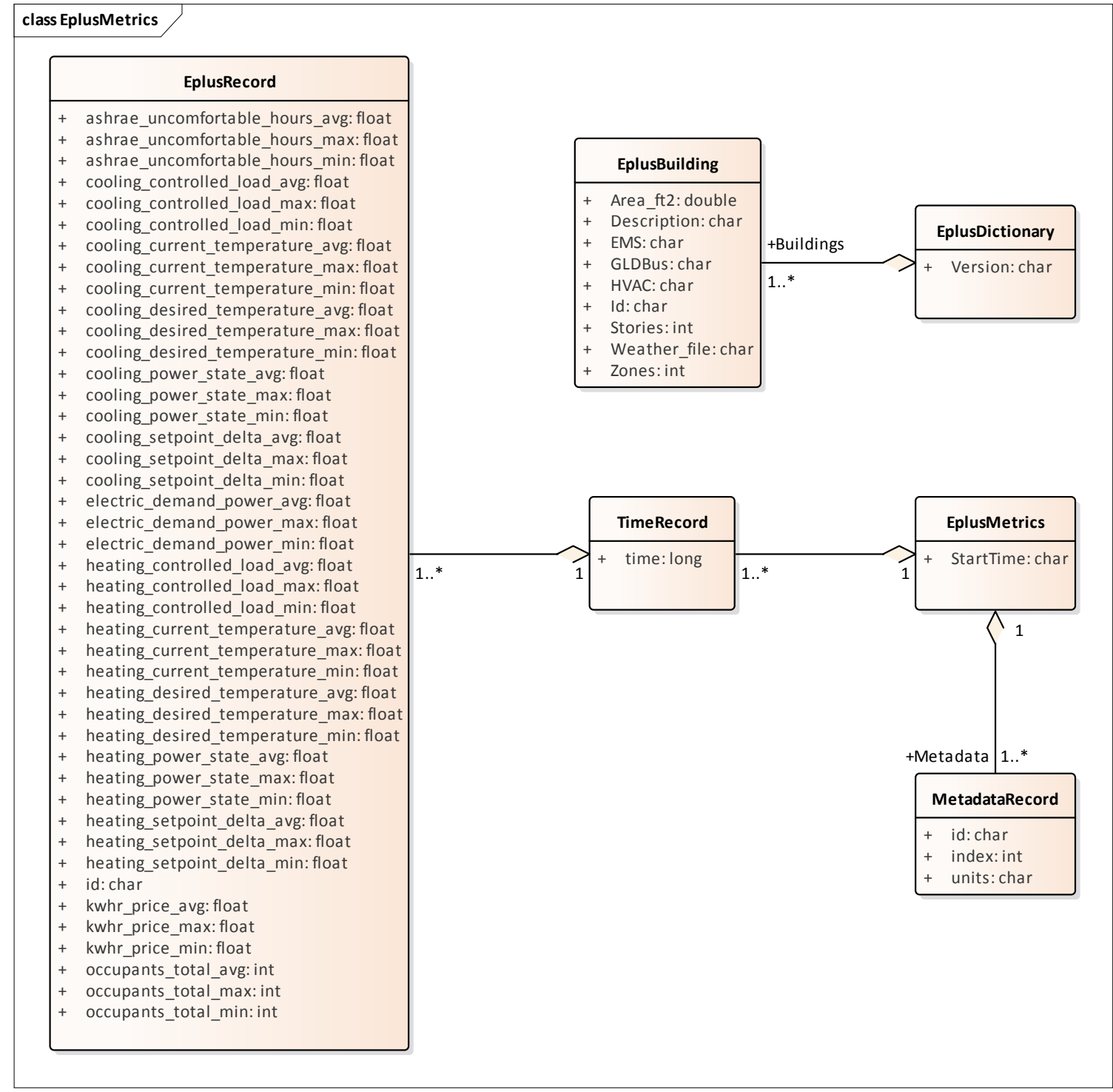

Figure 4.14. EnergyPlus Dictionary and Metrics 


\subsection{GridLAB-D Enhancements}

The simulation element includes maintenance and updates to GridLAB-D in support of TESP. This past year, the GridLAB-D enhancements done for TESP include the following:

1. The double-auction market and double-ramp controller were extracted into separate modules, with communication links to the internal GridLAB-D houses. This pattern can be reused to open up other GridLAB-D controller designs to a broader community of developers.

2. The FNCS-enabled version of GridLAB-D to was ported to Microsoft Windows. This had not been working with the MinGW compiler that was recently adopted for GridLAB-D on Windows, and it will be important for other projects.

3. The JSON metrics collector and writer classes were implemented in the tape module. This should provide efficiency and space benefits to other users who need to post-process GridLAB-D outputs.

4. A JSON-based message format was implemented for agents running under FNCS. Again, this should provide efficiency benefits for other projects that need more complicated FNCS message structures.

\subsection{Using and Customizing the TESP}

The TESP runs on Linux (Ubuntu tested), Mac OS X, and Microsoft Windows. Installers, source code, examples, and documentation will be available at https://github.com/pnnl/tesp/, and the TESP will also be running under Linux at PNNL's Electricity Infrastructure Operations Center (EIOC) in Richland, WA. However, most users may wish to run the TESP on their own computers, which offers the possibility of customization and also helps to preserve proprietary information that might be developed or incorporated with the TESP. There are two basic levels of customization, depending whether the user chooses to install or build the TESP:

- Install TESP - This may require administrator privileges on the target computer and supplemental downloads. It will be possible to develop new TEAgents and valuation scripts by modifying or developing Python code. Development in Java should also be possible.

- Build TESP - In addition to the skill set for installing the TESP, users should be familiar with configuring environments and using $\mathrm{C} / \mathrm{C}++$ compilers on the target computer. This approach will enable the user to develop new TEAgents in $\mathrm{C} / \mathrm{C}++$, and to replace or upgrade co-simulators (i.e., GridLAB-D, MATPOWER, EnergyPlus) within the TESP.

The TESP has been designed to build and run with free compilers, including MinGW but not MSVC on Windows. The Python code has been developed and tested with Python 3, including the NumPy, SciPy, Matplotlib, and Pandas packages. There are several suitable and free Python distributions that will install these packages. MATPOWER has been compiled into a shared object library with wrapper application, which requires the MATLAB run time to execute. This is a free download, but it is very large and the version must exactly match the MATLAB version that the TESP used in building the library and wrapper. This is true even if you have a full version of MATLAB installed, so better solutions are under investigation. At this time, the authors expect to support MATPOWER only on Linux, with the alternative PYPOWER (Lincoln 2017) supported on Windows, Mac OS X, and Linux. The code repository should always have the most up-to-date information.

In order to provide new or customized valuation scripts in Python, the user should first study the provided examples. These illustrate how to load the JSON dictionaries and metrics described in Section 4.5, how to aggregate and post-process the values, make plots, etc. Coupled with some experience or learning in Python, this constitutes the easiest route to customizing the TESP. 
The next level of complexity would involve customizing or developing new TEAgents in Python. The existing auction and controller agents provide examples of how to configure the message subscriptions, publish values, and link with FNCS at runtime. Section 4.4 describes the existing messages, but these constitute a minimal set for Version 1. It is possible to define your own messages between your own TEAgents, with significant freedom. It is also possible to publish and subscribe, or "peek and poke,” any named object/attribute in the GridLAB-D model, even those not called out in Section 4.4. For example, if writing a water heater controller, you should be able to read its outlet temperature and write its tank set point via FNCS messages, without modifying GridLAB-D code. You will probably also want to define metrics for your TEAgent, as in Section 4.5. Your TEAgent will run under supervision of an FNCS broker program. This means you can request time steps, but not dictate them. The overall pattern of an FNCS-compliant program will be as follows:

1. Initialize FNCS and subscribe to messages, i.e., notify the broker.

2. Determine the desired simulation stop_time, and any time step size (delta_t) preferences. For example, a transactive market mechanism on 5-minute clearing intervals would have a delta_t of 300 seconds.

3. Set time_granted to zero; this will be under control of the FNCS broker.

4. Initialize time_request; this is usually $0+$ delta_t, but it could be stop_time if you just wish to collect messages as they come in.

5. While time_granted $<$ stop_time,

a. Request the next time_request from FNCS; your program then blocks.

b. FNCS returns time_granted, which may be less than your time_request. For example, controllers might submit bids up to one second before the market interval closes, and you should keep track of these.

c. Collect and process the messages you subscribed to. There may not be any if your time request has simply reached its limit. On the other hand, you might receive bids or other information to store before taking action on them.

d. Perform any supplemental processing, including publication of values through FNCS. For example, suppose 300 seconds have elapsed since the last market clearing. Your agent should settle all the bids, publish the clearing price (and other values), and set up for the next market interval.

e. Determine the next time_request, usually by adding delta_t to the last one. However, if time_granted has been coming irregularly in step 5b, you might need to adjust delta_t so that you do land on the next market clearing interval. If your agent is modeling some type of dynamic process, you may also adapt delta_t to the observed rates of change.

f. Loop back to step 5a, unless time_granted $\geq$ stop_time.

6. Write your JSON metrics file; Python has built-in support for this.

7. Finalize FNCS for an orderly shutdown, i.e., notify the broker that you are done.

The main points are to realize that an overall "while loop" must be used instead of a "for loop," and that the time_granted values do not necessarily match the time_requested values.

Developers working with $\mathrm{C} / \mathrm{C}++$ instead of Python must be familiar with compiling and linking to other libraries and applications and must be familiar with any co-simulators they wish to replace. This development process generally takes longer, which represents added cost. The benefits could be faster execution times, more flexibility in customization, code reuse, etc. 


\subsection{Trial Analyses}

Two trial analyses were conducted to test and demonstrate the program's new simulation capabilities, valuation documentation, and economic metrics:

- Smart Grid Interoperability Panel (SGIP) Use Case 1 (Holmberg et al. 2016)

- SGIP Use Case 3 (Holmberg et al. 2016), combined with a demonstration of the new simulation growth modeling capability (SGIP 3).

\subsection{Trials Inspired by TE Use Cases and Growth Model}

The trial analyses respond to an SGIP use case (Holmberg et al. 2016) and an additional use case that is intended to demonstrate a rudimentary growth model.

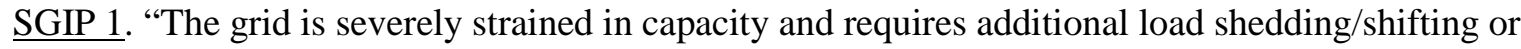
storage resources" (Holmberg et al. 2016). The details confirm that this use case addresses only generation capacity constraints of the type that might be needed after existing demand-response resources become exhausted.

This use case takes place on a day that available resources are inadequate in a warm location like California or Arizona. In the base-case scenario, the system anticipates the event that morning or even earlier. Each distribution utility must also conduct emergency curtailment, meaning that entire distribution circuits must be intentionally de-energized to reduce system demand. Each utility is allocated a fraction of the total shortfall to correct.

In the transactive scenario, nearly everything remains the same, except a double-auction transactive market coordinates residential space conditioning. As the last available resources become dispatched, the costly final resources elevate the transactive price signal, thus causing transactive assets to respond. As the peak demand nears, the need for emergency curtailment might be reduced or fully avoided by the actions of the transactive system.

The original use case says that conventional demand-response assets are deployed on this event day, but they prove inadequate for the need. The program's simulation environment is not yet able to emulate conventional demand responses separately from the economic resources that are employed by the transactive system. The conventional demand responses are not emulated in this report's trial analysis. However, the conduct and effects of emergency curtailment were emulated and estimated using a final, emergency generation resource. As this final emergency generator becomes dispatched, it is understood that emergency curtailment is necessary. The magnitude of load supplied by the emergency generator is understood to be equivalent to unserved load during the emergency curtailment.

The principal valuation metrics for this use case address the costs and inconvenience of the emergency curtailment. Interesting effects include changes in the numbers of customers curtailed, the durations of the emergency curtailment, and unserved load.

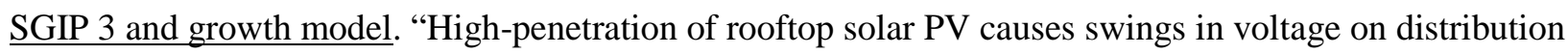
grid” (Holmberg et al. 2016). Solar generation capacity is stated to be up to $120 \%$ of load. Reversals of power flow can occur. Solar power intermittency creates corresponding voltage power quality issues. 
In the base case, this condition might today be disallowed at the planning stage because of the challenges that reversed power flow might induce in protection schemes. Presuming that such high penetration and reversed flows are allowed, the distribution feeder must use its existing resources-capacitors, reactors, regulating transformers - to keep voltage within its acceptable range. Solar power inverters mostly correct to unity power factor today. Voltage tends to increase, if uncorrected, at times that solar power is injected into the distribution system. It is likely that this feeder will encounter voltage violations and flicker because of the high penetration and intermittency of the photovoltaic (PV) generation.

In the transactive case, the double-auction transactive system is operating on the high-solar-penetration feeder. Voltage management is not directly targeted by transactive mechanisms today, but the behaviors of the mechanisms can affect voltage management.

PNNL's implementation of trial analysis was not perfectly responsive to SGIP-2. The focus will be the voltage management challenge, given that flow reversal is not itself a problem if it makes sense for system economics. Rather than testing the simulation environment under $120 \%$ penetration, a lower penetration-30\%-was tested. The testing of a PV penetration use case was further melded with tests of the simulation growth model, which demonstrates a rapid growth in the penetration of PV over a series of successive years.

The primary effects anticipated will be changes in the occurrences of voltage range violations, power quality events, and operations of voltage controls (e.g., tap changes) on the feeder.

\subsection{Responsive to Asset Classes}

Figure 5.1 shows the types of assets and stakeholders considered for the use cases in this version. The active market participants include a double-auction market at the substation level, the bulk transmission and generation system, a large commercial building with a responsive HVAC thermostat, and singlefamily residences that have responsive HVAC thermostats. Transactive message flows and key attributes are indicated in orange. 


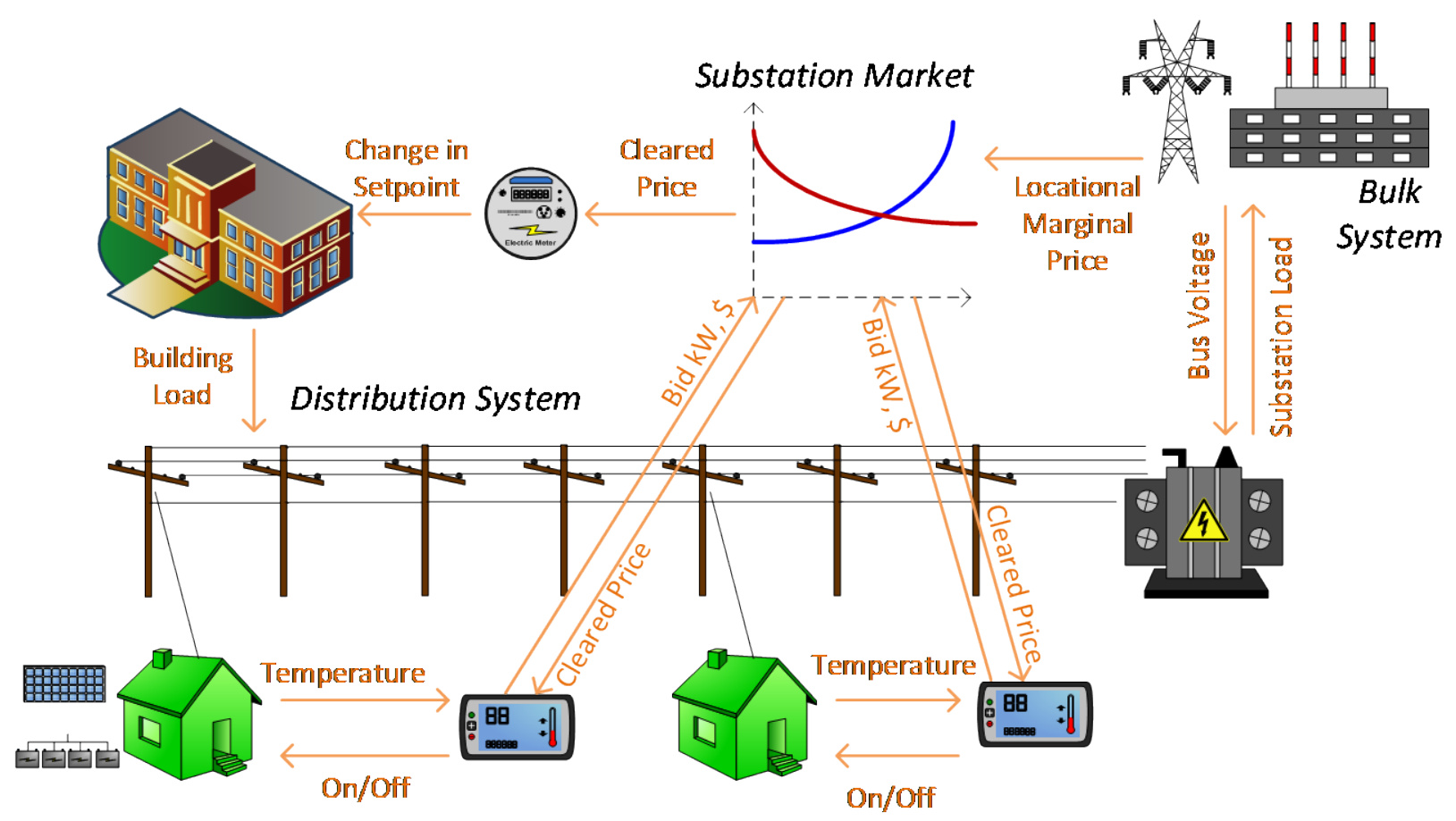

Figure 5.1. SGIP-1 System Configuration with Partial PV and Storage Adoption

In addition, the model includes PV and storage resources at some of the houses, and water heaters at many houses. These resources can be transactive, but are not in this version because the corresponding separate TEAgents have not been implemented yet. Likewise, the planned new TEAgent that implements load shedding from the substation has not yet been implemented.

\subsection{The Circuit Model}

Figure 5.2 shows a 9-bus bulk system model in MATPOWER. It is a small system with three generating units and three load buses that comes with MATPOWER, to which was added a high-cost peaking unit to assure convergence of the optimal power flow in all cases. In SGIP-1 simulations, Generating Unit 2 was taken off-line on the second day to simulate a contingency. The GridLAB-D model was connected to Bus 7, and scaled up to represent multiple feeders. In this way, prices, loads, and resources on transmission and distribution systems can affect each other. 


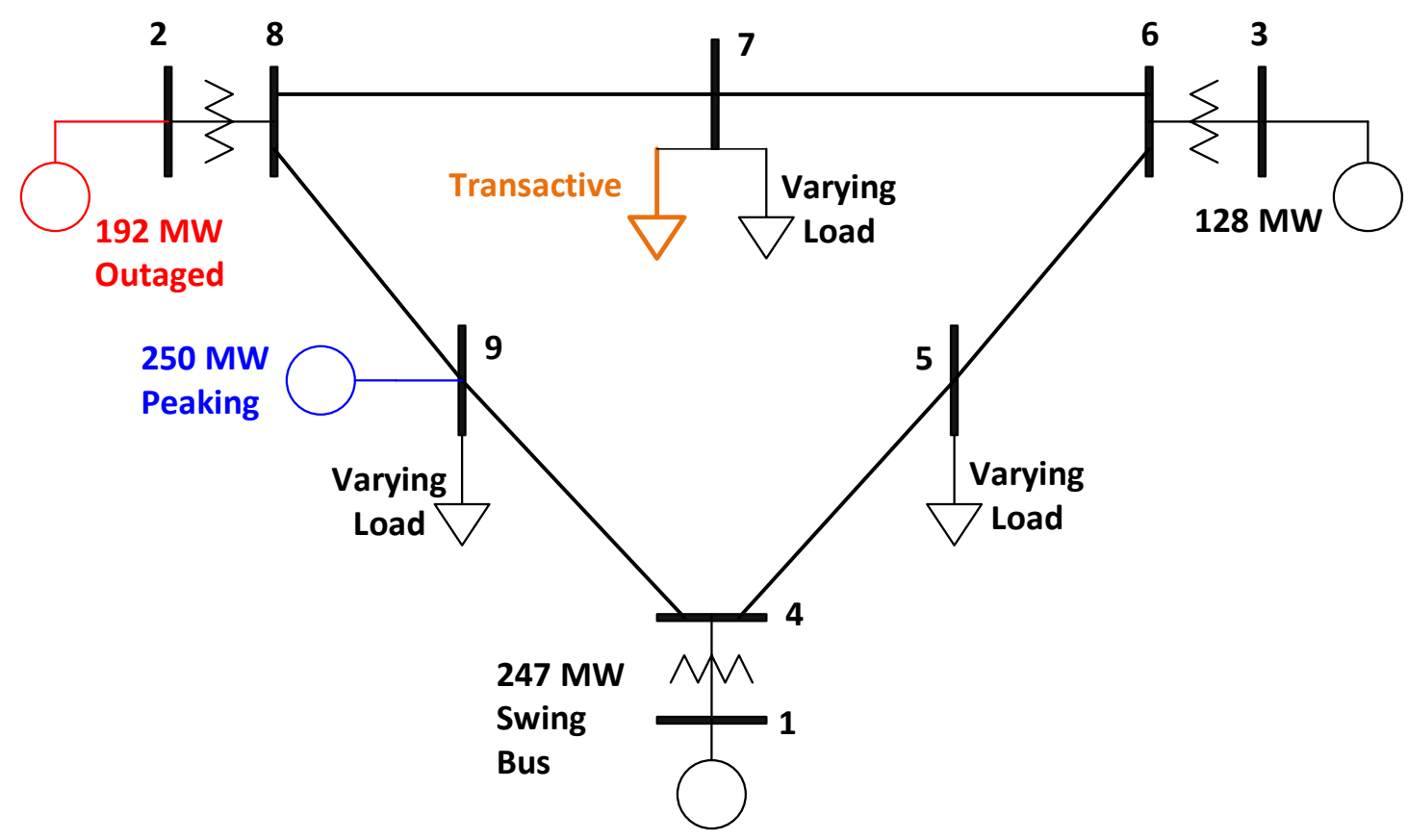

Figure 5.2. 9-Bus Bulk System Model with Maximum Generator Real Power Output Capacities

Figure 5.3 shows the topology of the R1-1 $12.47 \mathrm{kV}$ feeder based on the western region of PNNL's taxonomy of typical distribution feeders (Schneider et al. 2009). A MATLAB feeder generator script was used that produces these models from a typical feeder, including random placement of houses and load appliances of different sizes appropriate to the region. The model generator can also produce small commercial buildings, but these were not used here in favor of a detailed large building modeled in EnergyPlus. The resulting feeder model included 1594 houses, 755 of which had air conditioning, and approximately 4.8 MW peak load at the substation. A typical weather file for Arizona was used, and the simulation was run for two days, beginning at midnight on July 1, 2013, which was a weekday. A normal day was simulated in order for the auction market history to stabilize, and on the second day, a bulk generation outage was simulated. See Appendix C or the code repository for more details. 


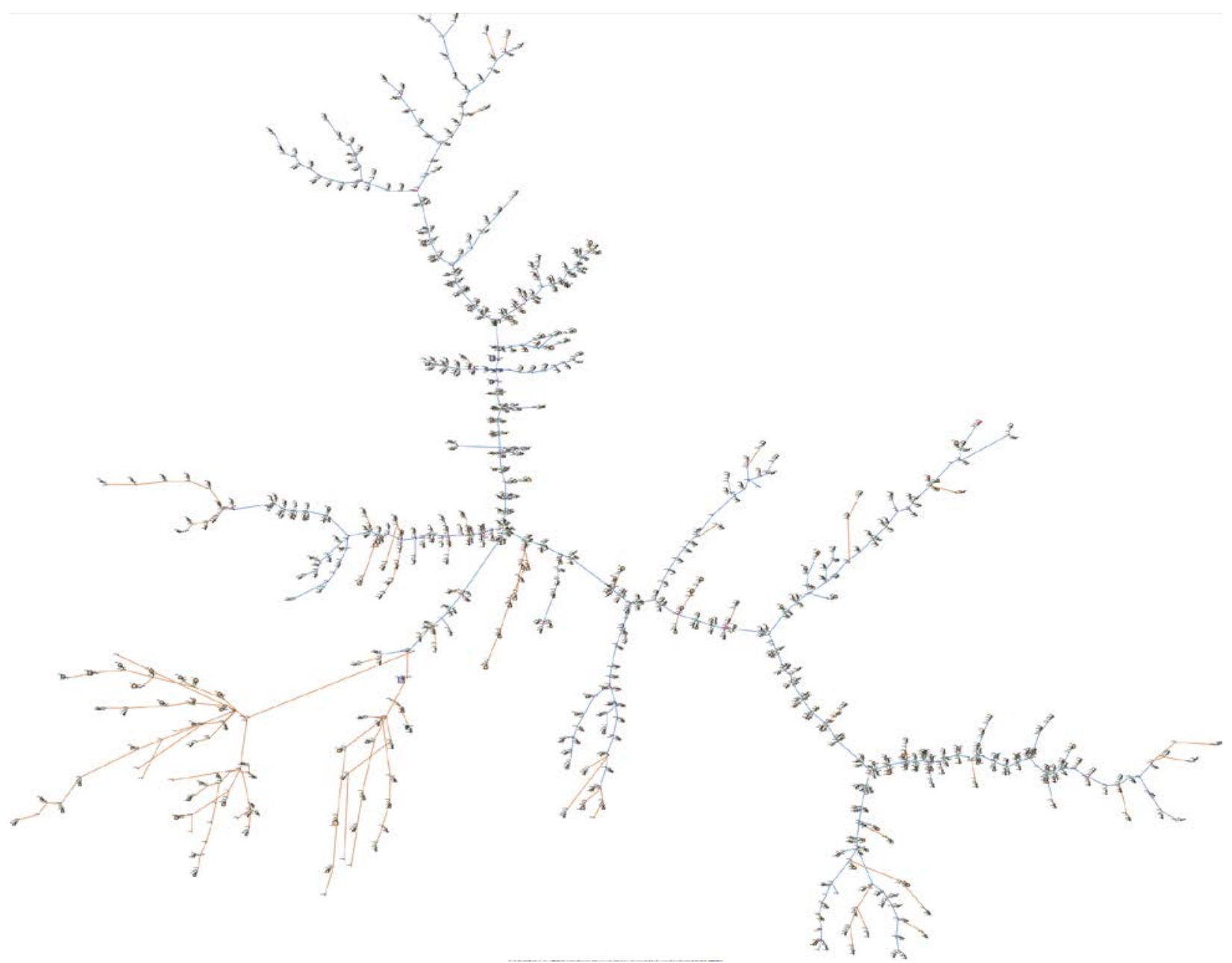

Figure 5.3. R1-1 Distribution Feeder Model(http://emac.berkeley.edu/gridlabd/taxonomy graphs/)

Figure 5.4 shows the building envelope for a primary school reference building model (DOE 2017) that was connected to the GridLAB-D feeder model at a 480-volt, three-phase transformer secondary. The total electric load varied from $48 \mathrm{~kW}$ to about $115 \mathrm{~kW}$, depending on the hour of day. The EnergyPlus agent program collected metrics from the building model, and adjusted the thermostat set points based on the real-time price, which is a form of passive response. 


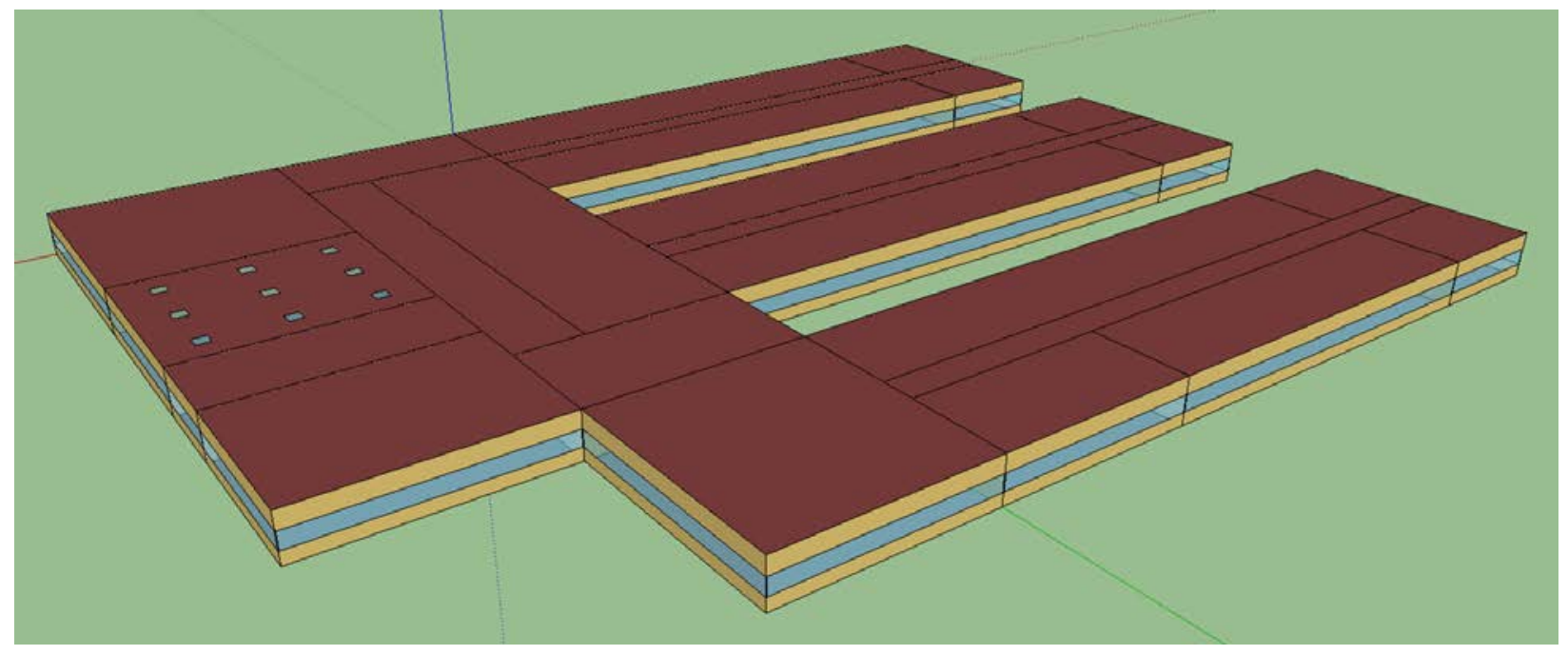

Figure 5.4. Primary School Model (DOE Commercial Reference Building)

\subsection{The Growth Model}

This version of the growth model has been implemented for yearly increases in PV adoption, storage adoption, new (greenfield) houses, and load growth in existing houses. For SGIP-1, only the PV and storage growth has actually been used. A planned near-term extension will cover automatic transformer upgrades, making use of load growth more robust and practical.

Table 5.1 summarizes the growth model used in this report for SGIP-1. In row 1, with no (significant) transactive mechanism, one HVAC controller and one auction market agent were still used to transmit MATPOWER's LMP down to the EnergyPlus model, which still responded to real-time prices. In this version, only the HVAC controllers were transactive. PV systems would operate autonomously at full output, and storage systems would operate autonomously in load-following mode.

Table 5.1. Growth Model for SGIP-1 Simulations

\begin{tabular}{cccccc}
\hline Case & Houses & HVAC Controllers & Water Heaters & PV Systems & Storage Systems \\
\hline No TE & 1594 & 1 & 1151 & 0 & 0 \\
Year 0 & 1594 & 755 & 1151 & 0 & 0 \\
Year 1 & 1594 & 755 & 1151 & 159 & 82 \\
Year 2 & 1594 & 755 & 1151 & 311 & 170 \\
Year 3 & 1594 & 755 & 1151 & 464 & 253 \\
\hline
\end{tabular}

\subsection{Summary Results of the Trial Analyses}

The results from the trial analyses simulation and valuation exercises are in Appendix C (Trial Analysis \#1 that addresses an event where generation supply becomes inadequate) and Appendix D (Trial Analysis \#2 that demonstrates a rudimentary ability to model the growth of PV penetration over time). Here are some of the highlights from those results: 


\subsubsection{Trial Analysis \#1-Inadequate Generation Supply}

The system is confirmed to consume more on the event day, a particularly hot summer day, than on the non-event day. The LMP, which was passed unchanged to retail customers for Trial Analysis 1, became very high the afternoon of the hot summer event day. Interestingly, the transactive system reduced customer load similarly both during normal operation (non-event day) and as generation supply was becoming inadequate-by between 1.0 and $1.5 \mathrm{kWh} /$ day. The controlled HVAC systems responded strongly on the event day, but residences also needed their HVAC systems more that hot day. Using the double-ledger accounting table, the transactions of electricity and electricity fees could be traced from bulk generation through to end-use electricity customers.

The system reduced its production of all greenhouse gases when operated under a transactive system both during normal and stressed operation days.

In this case, the transactive system was not shown to avert customer outages, and the duration of the outages was reduced by only a very small amount.

\subsubsection{Trial Analysis \#2-Modeling Growth of Solar PV Generation}

The transactive system reduced total load again for both normal and generation-constrained days, even with no solar PV installed. The successive inclusion further reduced the load to be supplied by the distribution utility. This effect could be observed all the way from end-use customers to bulk generators, from which the solar-provided energy would have otherwise been procured.

A possibly oscillatory clearing price and quantity were noted in the discussion of Appendix D and its figures. Future metrics from the theory elements of transactive systems have the potential to identify and characterize such behavior.

As in Trial Analysis \#1, the transactive system was not shown to avert customer outages, and the duration of the outages was reduced by only a very small amount.

The successive increase in PV solar and battery device penetration showed corresponding decrements in the amounts of environmental pollutants.

\subsection{Insights and Lessons Learned}

The main accomplishment, of the simulation element, is the successful integration of all of the essential TESP components in the FNCS framework and on multiple operating systems. This has established the foundation for adding many more features and use-case simulations over the next couple of release cycles, as described in Chapter 6. Many of these developments will be incremental, while others are more forward-looking.

Two significant lessons about this version of the TESP have been learned in this trial. The first lesson relates to MATPOWER. It has been difficult to deploy compiled versions of MATPOWER on all three operating systems, and it will be inconvenient for users to manage different versions of the required MATLAB runtime. This is true even for users who might already have a full version of MATLAB. Furthermore, the MATPOWER source code would need to be modified in order to detect nonconvergence and summarize transmission system losses. Alternatives are being considered, such as PYPOWER (Lincoln 2017) or AMES (Li and Tesfatsion 2009); although both have their own limitations, they are much easier to modify and deploy. 
The second lesson relates to EnergyPlus modeling, which is a completely different domain from power system modeling. Small corrections were made in the EnergyPlus model depicted in Figure 5.4, but it is clear that more building model experts will be needed on the team going forward.

Concerning the valuation process, adherence to a structured valuation methodology helps make valuation results defensible. Even the consistent usage of terminology that is enforced by a valuation methodology strengthened our ability to collaborate across interdisciplinary teams. Still, consistent use of the valuation methodology is challenging. The double-entry approach used in the results ledger table will appeal to many because of its inherent support of checks that value is neither lost nor appears. The ledger supports valuation from the perspectives of the system's actors.

The diagrams and tables recommended herein to make valuation studies and their assumptions more transparent were demonstrated in this report. The project solicits feedback from analysis and simulation experts on these recommendations and direction of these capabilities in general. Admittedly, there is a risk that analysts may find the rigor that is recommended by PNNL's valuation methodology, plus the recommended diagrams, unnecessary or too burdensome to follow. Outreach by the project in technical meetings and interactions with the NIST TE Challenge community are planned as a way to gain this important feedback.

While the valuation methodology provided guidance, the development of a set of available valuation models has only started. The trial analyses demonstrated continuity all the way from an initial use case to consequent derived effects. Many more metrics and the models from which the metrics are quantified need to be investigated and defined. The espoused approach lays a foundation for a community of valuation analysts sharing libraries of methods. Nurturing such a community is needed. 


\subsection{Future Work}

The accomplishments in the report featured capability building features; while gaps remain, the simulation environment steadily improves to accommodate the co-simulation of transmission and distribution circuits, wholesale markets, unit dispatch, and transactive market interactions. Valuation methodology is evolving to be able to differentiate alternative transactive mechanisms while taking steps to support collaboration among analysts and transparency of PNNL's findings. The authors are beginning to recognize metrics, too, for the stability and performance of transactive mechanisms as control systems. In the near term, these tools must be further refined.

Next, a transformation begins toward a more transactive power grid. Analysts' tools must help them design useful transactive energy systems. Researchers must be prepared to instill confidence in those who will apply and regulate these systems. Researchers must be prepared to incrementally test them, first in a simulation environment then in pilot studies, to make the systems perform well.

\subsection{Planning for the Next TESP Version}

At this stage, the TESP comprises a basic framework to conduct design and evaluation of transactive mechanisms, and it is open for use by others on Windows, Linux, and Mac OS X. The next version of the TESP should rapidly expand its capabilities, by building on the established framework.

1. New TEAgents - these are arguably the most important, because they add key features that are directly in the TESP's scope, and likely not available elsewhere integrated into a single platform. The more examples available, the easier it should be for others to write their own (better) TEAgents.

a. VOLTTRON is a standard for building automation and management systems, and it has been used to implement building-level transactive mechanisms for electricity, air and chilled water in co-simulation with EnergyPlus (Hao et al. 2016). A TEAgent based on VOLTTRON could manage the building-level transactive system, and also participate in the feeder-level or substation-level electricity markets on behalf of the building loads and resources. The work involves porting the Python-based VOLTTRON program to interface with EnergyPlus via FNCS instead of EnergyPlus's built-in Building Control Virtual Test Bed (BCVTB). Then, the VOLTTRON program will need to construct bid curves for the grid market.

b. PowerMatcher is a transactive mechanism implemented by the Netherlands Organisation for Applied Scientific Research (TNO) (Kok, J. K. et al. 2005). The existing code is in Java, with a custom API and message schema. TNO would have to undertake the work of interfacing PowerMatcher to the TESP, with technical support from PNNL.

c. TeMix is another transactive mechanism that has been implemented by a California-based company (Temix Inc 2017), and selected for some pilot projects. TeMix would have to undertake the work of interfacing its product to the TESP, with technical support from PNNL.

d. A consensus method is a fundamental transactive mechanism that relies on iterative negotiations between transacting entities. For example, the Pacific Northwest Smart Grid Demonstration (Battelle 2015) implemented a consensus transactive mechanism.

e. Passive controller (load shedding) - GridLAB-D includes a built-in passive controller, and switches that can isolate sections of a circuit. This function would be extracted into a separate TEAgent that implements load shedding in response to a message from MATPOWER. If the bulk system capacity margin falls below minimum - or worse, if the optimal power flow fails to converge- the bulk system operator would have to invoke load shedding. In TESP, the 
MATPOWER simulator would initiate load shedding a few seconds prior to the market clearing time, which initiates a new GridLAB-D power flow and reduced substation load published to MATPOWER. Load shedding is a traditional approach that will reduce the system reliability indices, whereas transactive mechanisms could maintain resource margins without affecting the reliability indices.

f. Passive controller (demand response) - the GridLAB-D passive controller already simulates various forms of price-responsive or directly controlled loads. These would be extracted into a separate TEAgent for control of water heaters and other loads, complementing the transactive dual-ramp controller for HVAC.

g. Generator controller - GridLAB-D has a built-in generator controller that is tailored for conventional (i.e., dispatchable) generators with operating, maintenance, and capital recovery costs included. This has not been completely developed, but it would be useful in the TESP as a separate TEAgent so that cogeneration may be included. For example, several teams are developing $1 \mathrm{~kW}$ generators for cogeneration with residential gas furnaces (the ARPA-E GENSETS program).

h. Storage controller - GridLAB-D's built-in battery only implements a load-following mode with state-of-charge and charge/discharge thresholds. PNNL expects to develop a more capable battery controller during 2017 as part of a Washington State Clean Energy Fund project in collaboration with Avista Utilities and Washington State University. This new agent would be implemented and tested in the TESP.

2. Other Enhancements - these are also important for usability and widespread adoption of TESP.

a. Capacitor switching and tap changer metrics - GridLAB-D includes built-in counters for capacitor switching and tap changer operations, which reflect wear-and-tear on utility infrastructure. These should be added to the metrics described in Section 4.5, and this would likely complete the intermediate metrics output from GridLAB-D.

b. TE Challenge message schemas - NIST has defined several classes and message schemas for the TE Challenge project (NIST 2017). Many of these tie directly to GridLAB-D, so they are already supported via FNCS. PNNL will continue to review all of them to make sure that the TESP remains compatible with TE Challenge to the extent possible.

c. Solution monitor - at present, the TESP is configured and launched via script-building utilities and console commands, which are adequate for developers. The two-day simulations described in this report finish within an hour or two, but that will increase as the time horizons and system sizes increase. PNNL plans to provide a graphical user interface (GUI) with spreadsheet interfaces for configuring the TESP, live strip charts to indicate solution progress, and moreconvenient methods to stop a simulation.

d. Valuation GUI - the post-processing scripts for valuation also run from the command line, which is adequate for developers. PNNL plans to provide a GUI that presents results in formatted tables and lists, plots variables that are selected from lists, etc. Both the solution monitor and postprocessing GUIs will be implemented in Python using the Tkinter package that comes with it. This makes the GUIs portable across operating systems, and allows for user customization, just as with the Python-based TEAgents.

e. IEEE 1516 (IEEE 2010a, b, c) is a comprehensive family of standards for co-simulation, sometimes referred to as high-level architecture (HLA). As part of Grid Modernization Lab Consortium (GMLC) project 1.4.15, "Development of Integrated Transmission, Distribution, and Communication (TDC) Models,” FNCS and other National Laboratory co-simulation frameworks are evolving toward greater compliance with IEEE 1516. PNNL plans to adopt a reduced-profile, 
lightweight version of FNCS or some other framework in the TESP, so that it will be fully compliant with IEEE 1516. This fosters interoperability among simulators and agents developed by others. However, compared to some other HLA frameworks that were evaluated, FNCS is much more efficient, handling thousands of federated processes. For the TESP, that level of performance will need to be maintained in the new standards-compliant framework.

f. Intermediate time aggregations - for a single feeder as described in Chapter 5.0, a two-day simulation produces about 1 GB in JSON metrics before compression. (CSV files would be even larger). To mitigate the growth of these files, PNNL plans to implement aggregation in time for yearly and multi-year simulations, in which metrics are aggregated by hour of the day, season, weekday vs. weekend or holiday, and by year of the simulation. No accuracy would be lost in cumulative metrics, and it would still be possible to identify metrics for individual stakeholders.

The enhancements $1 \mathrm{a}, 1 \mathrm{~b}$, and $1 \mathrm{c}$ are probably the most important. A VOLTTRON agent is strategic because it enables intrabuilding-to-grid transactions. It also fills a weakness in GridLAB-D’s own commercial building models, which are adequate for small-box establishments and strip malls, but not for larger buildings like the school in Chapter 5.0. The PowerMatcher and TeMix agents are strategic because they would show usability of the TESP by others and facilitate cross-vendor experiments.

The enhancements listed above are of known complexity, and could be implemented within the next year, subject to resource availability (including external parties TNO and TeMix). PNNL expects to do some prioritization at a TESP prerelease workshop on April 27, 2017, and implement the selected enhancements over a series of two six-month release cycles.

Some important longer-term enhancements are described in the next four subsections. Besides these important features, consideration will also be given to the need for a faster building simulator than EnergyPlus, and federating the ns-3 simulator to simulate communication networks.

\subsubsection{Growth Model Enhancements}

The growth model described in Chapter 5.0 follows a predefined script, with some random variability. This is adequate for short horizons, up to a few years. Over longer terms, an intelligent growth model will be needed that mimics the analytics and heuristics used by various stakeholders to make investment decisions. For example, the TESP user may wish to evaluate effects of a policy initiative that will have a ten-year lifetime. That policy initiative may influence investments that have a twenty-year lifetime. It is not possible to realistically script that kind of growth model ahead of time. Instead, growth model agents are needed that will make investment decisions appropriate to the system as it evolves.

\subsubsection{Agent Learning Behaviors}

Participants in any market will naturally try to optimize their outcomes, or "game the system," depending on the observer's perspective. In designing brand-new market mechanisms for transactive energy, it is critically important to account for this human behavior; otherwise undesired and unanticipated outcomes will occur. It is up to the policy makers to design market rules so that, with enforcement of the rules, undesired outcomes do not occur. Agents in the current software take algorithmic and sometimes probabilistic approaches to transactions, but they are not smart enough to "game the system" as a human would. PNNL has teamed with Iowa State University to investigate these agent learning behaviors beginning this year. 


\subsubsection{Stochastic Modeling}

The TESP currently uses random input variables, but the simulations are deterministic and in full detail (e.g., every house, every HVAC thermostat, every water heater, etc.) It would be more efficient, and perhaps more realistic, to have stochastic simulations on reduced-order models as an option. This opens the door to more use of sensitivity analysis and automatic optimization routines than is currently practical. PNNL has teamed with the University of Pittsburgh to investigate the subject beginning this year, building on previous work in circuit model order reduction and probabilistic modeling.

\subsubsection{Testing and Validation}

Testing and validation will be a continuous process throughout the life of the TESP. Some opportunities will arise through past and future pilot projects in transactive energy. Other test cases will have to be created. PNNL expects to team with Dartmouth College in formalizing this process, and also to work with Case Western University in modeling their transactive campus project with the National Aeronautics and Space Administration.

\subsection{Steps toward a Testing Platform}

A goal of the Transactive Systems Project is to create tests against which new transactive formulations may be tested. The program expects to explore the development of libraries of use cases and scenarios, each featuring a limited number of system objectives. The initial configuration of the simulation environment can be static, except for uniqueness of the transactive methods that analysts bring to the table. The valuation should be mostly in place and ready to evaluate various innovations, including transactive systems that are to be tested.

\subsection{Transactive System Metrics to be Developed}

Some metrics concerning the performance of the transactive systems were exercised by the trial analysis of Chapter 5.0. PNNL has identified the following additional metrics to be formulated and tested in the future:

- Number of iterations (\#). Consensus-based transactive mechanisms use iterative algorithms and predefined convergence criteria. A large number of iterations may be required for such systems to converge. Therefore, a meaningful measure of the numbers of iterations will be required.

- Communication delay (time). Many evaluations of transactive systems presume that communications will be adequate to support transactions. This assumption will be incorrect, especially as market periods are made very short. A metric must be developed to predict the latency that results from communication delays.

- Communication drops (count). It would be wise to anticipate that communication packets may be altogether dropped, and communication networks may become unavailable. A metric is needed to predict the reliability and resiliency of the networks and packet communications.

- Load forecast error ( $k W$ or \%). All transactive mechanisms rely on prediction. Some further include a future horizon and must therefore predict both price and demand for hours or days into the future. Whereas conventional wholesale markets rely on bulk load forecasts, decentralized systems, like transactive energy systems, may require load predictions for much smaller regions and perhaps even for individual devices. For these reasons, load forecasts are gaining importance. A load forecast error metric is needed to quantify the quality of such forecasts. 
- Market participation / market power. Markets having many, many participants can usually be assumed to be competitive and to converge on a solution that maximizes social welfare. This is not true when the number of participants becomes small, in which case individual participants might assert market power to change the solution. A metric is needed to monitor when a market is acting ideally and when it is potentially affected by limited numbers of strong market participants. 



\subsection{Conclusions}

This report documents new capabilities within the TSP at PNNL. Advances were made concerning our abilities to perform time-series simulations, to organize and document valuation studies, and to quantify specific metrics concerning the performance of transactive energy systems.

The TESP demonstrated a rudimentary growth model. At present, the TESP can perform a somewhat automated update of system growth at predetermined time intervals. In a trial analysis, the growth model reinitiated simulations with increasingly higher penetrations of PV solar generation. But there are two types of growth that must eventually be emulated. The demonstrated one is the easier of the two, where predetermined changes may be scheduled to alter the future challenges faced by the system. The more difficult growth model component intends to mimic the strategic actions taken by the system's actors over time. For example, a growth scenario might eventually recognize that load growth (an example of the simpler, first type of growth) has, over time, narrowed the capacity margin on a transmission line, and the simulation should initialize a transmission system upgrade, consistent with heuristics strategies in the region.

The FNCS platform continues to facilitate co-simulation across diverse simulation platforms. For example, trial analyses demonstrated the use of MATPOWER to represent a transmission system and the dispatch of bulk generation in conjunction with the GridLAB-D simulation of distribution feeders and customer load behaviors. The TEAgent module was successfully separated from GridLAB-D, which should facilitate simulation of more complex transactive systems and ones that use alternative transactive mechanisms in the future.

Important further steps were taken in the TESP design to facilitate valuation studies. First, sets of base metrics were defined for each co-simulation environment. These base metrics are a modest set of lowlevel metrics that should support most valuations. Post-processing is now supported, meaning that analysts can now peruse data dictionaries, select needed base metrics, and perform aggregations and more complex calculations for valuation studies.

Finally, documentation of the TESP environment has been improved. The program seeks ways to foster adoption of the TESP environment by other transactive system researchers outside PNNL.

The TSP continues to refine its structural understanding of the valuation process and methodology. The program strives to present continuity throughout the process, from the informal use cases that introduce a challenge to the valuation study, all the way through to the effects that the valuation study quantifies, to support decision making. The program's desire is that this effort will encourage convergence in the terminology used by analysts during valuation studies.

The TSP advocates a set of documentation artifacts and have mapped these artifacts to the valuation study components that each supports. Examples of these artifacts were demonstrated during trial analyses; admittedly, the exemplification of these artifacts was emphasized over the completeness of the trial analyses' valuations. Most of the recommended artifacts can be represented using standard UML diagrams. The assumptions and methods of valuation studies can be revealed and shared by such documentation.

The TSP has compiled a list of many eligible metrics and their respective calculation methods. These are documented at a high level using a library of short, one-page valuation metric model definitions. Over 70 such documents have been drafted by the TSP. A list, a template, and an example valuation metric model definition have been provided in this report. The library concept is intended to support a community of 
collaborators who would share their metrics, methods, and models. The library concept recognizes that some metrics have multiple acceptable methods by which they may be calculated or estimated.

The report featured several metrics that are responsive specifically to the performance of the transactive system. These metrics should measure qualities of the transactive systems themselves, as will be needed to compare alternative transactive mechanisms. They also intend to quantify the stability and efficiency of the transactive systems as control processes. Only some of these metrics were demonstrated during the trial analyses.

A future-work section of this report suggests specific future activities for the simulation, valuation, and theory elements of the TSP. Rather than summarizing those individual advancements, the focus will be on the future strategy of helping to move transactive system approaches to commercial deployments. First and foremost, the work should be influential. The TESP should be available to and used by many individuals and organizations who wish to explore transactive energy systems. The insights about valuation methodology are relevant for all valuation studies, but these insights will be essential for the comparison of alternative transactive mechanisms. The transactive community has so far only scratched the surface in its ability to evaluate, much less compare, alternative transactive mechanisms. A thoughtful attention to economic and control theory will help those who use the TESP and valuation tools design and test superior transactive systems. 


\subsection{References}

ANSI - American National Standards Institute. 2016. ANSI C84.1-2016; American National Standard for Electric Power Systems and Equipment-Voltage Ratings (60 Hz). Accessed April 12, 2017, at https://www.nema.org/Standards/ComplimentaryDocuments/ANSI\%20C84-12016\%20CONTENTS\%20AND\%20SCOPE.pdf.

Arlow J and I Neustadt. 2005. UML 2.0 and the Unified Process: Practical Object-Oriented Analysis and Design (2nd Edition). Addison-Wesley Professional.

ASHRAE. 2010. "ANSI/ASHRAE Standard 55-2010 - Thermal Environmental Conditions for Human Occupancy.” http://library.hartford.edu/eres/reserves/Haggan/ANSI_ASHRAE/ASHRAE-D-86150.

Battelle. 2015. Pacific Northwest Smart Grid Demonstration Project. Webpage online at http://www.pnwsmartgrid.org/.

Chassin DP, JC Fuller, and N Djilali. 2014. "Gridlab-D: An Agent-Based Simulation Framework for Smart Grids,” Journal of Applied Mathematics 2014(492320):1-12. doi:10.1155/2014/492320. Accessed April 12, 2017, at https://www.hindawi.com/journals/jam/2014/492320/.

Ciraci S, J Daily, J Fuller, A Fisher, L Marinovici, and K Agarwal. 2014. "FNCS: A Framework for Power System and Communication Networks Co-Simulation,” Proceedings of the Symposium on Theory of Modeling \& Simulation - DEVS Integrative, Tampa, Florida, Article No. 36. 1-8 pp. Society for Computer Simulation International, San Diego, California, 2665044. Accessed April 12, 2017, at http://delivery.acm.org/10.1145/2670000/2665044/a36ciraci.pdf?ip=130.20.182.28\&id=2665044\&acc=ACTIVE\%20SERVICE\&key=70F97CA9565FDD93\%2 E70F97CA9565FDD93\%2E4D4702B0C3E38B35\%2E4D4702B0C3E38B35\&CFID=923163706\&CFT OKEN=15756716\&_acm_=1492024078_7d5790cb477507b6ee8cc00b3c7a7331.

DOE. 2017. Commercial Reference Buildings. Accessed 2017 at https://energy.gov/eere/buildings/commercial-reference-buildings.

$\mathrm{e}^{3}$ value. 2017. Website. Online at http://e3value.few.vu.nl/\#.

Fuller JC, KP Schneider, and D Chassin. 2011. “Analysis of Residential Demand Response and DoubleAuction Markets.” In Proceedings of 2011 IEEE Power and Energy Society General Meeting, July 24-29, 2011, Detroit, Michigan. Institute of Electrical and Electronics Engineers, Piscataway, NJ. doi:10.1109/PES.2011.6039827. Accessed April 12, 2017, at http://ieeexplore.ieee.org/document/6039827/.

Hammerstrom DJ, CD Corbin, N Fernandez, JS Homer, A Makhmalbaf, RG Pratt, A Somani, EI Gilbert, S Chandler, and R Shandross. 2016a. Valuation of Transactive Systems Final Report. PNNL-25323, Pacific Northwest National Laboratory, Richland, Washington. Accessed at http://bgintegration.pnnl.gov/pdf/ValuationTransactiveFinalReportPNNL25323.pdf.

Hammerstrom DJ, A Makhmalbaf, and MC Marinovici. 2016b. Diagramming Transactive Building Business Cases: Using Principles of E3 Value to Document Valuation Studies. PNNL-26127, Pacific Northwest National Laboratory, Richland, WA. 
Hao H, CD Corbin, K Kalsi, and RG Pratt. 2016. “Transactive Control of Commercial Buildings for Demand Response,” IEEE Transactions on Power Systems, PP(99):1-1. doi:10.1109/TPWRS.2016.2559485. Accessed April 12, 2017, at http://ieeexplore.ieee.org/document/7460977/.

Ho JL, BF Hobbs, P Donohoo-Vallett, Q Xu, S Kasina, S Park, and Y Ouyang. 2015. Planning Transmission for Uncertainty: Applications and Lessons with the Western Interconnection. Western Electricity Coordinating Council (WECC). Accessed April 12, 2017, at https://www.wecc.biz/Reliability/Planning-for-Uncertainty-Final-Report.pdf.

Holmberg DG, D Hardin, R Melton, R Cunningham, and S Widergren. 2016. Transactive Energy Application Landscape Scenarios. Smart Grid Interoperability Panel. Accessed April 12, 2017, at http://www.sgip.org/wp-content/uploads/SGIP White Paper TE Application Landscape Scenarios 1215-2016_FINAL.pdf.

IEEE. 2010a. IEEE Standard for Modeling and Simulation (M\&S) High Level Architecture (HLA)Federate Interface Specification, IEEE Standard 1516.1-2010 (Revision of IEEE Std. 1516.1-2000):1378. doi:10.1109/IEEESTD.2010.5557728.

IEEE. 2010b. IEEE Standard for Modeling and Simulation (M\&S) High Level Architecture (HLA)Framework and Rules, IEEE Standard 1516-2010 (Revision of IEEE Std. 1516-2000):1-38. doi:10.1109/IEEESTD.2010.5553440.

IEEE. 2010c. IEEE Standard for Modeling and Simulation (M\&S) High Level Architecture (HLA)Object Model Template (OMT) Specification, IEEE Standard 1516.2-2010 (Revision of IEEE Std. 1516.2-2000):1-110. doi:10.1109/IEEESTD.2010.5557731.

IEEE. 2012. IEEE Guide for Electric Power Distribution Reliability Indices, IEEE Standard 1366-2012 (Revision of IEEE Std. 1366-2003):1-43. doi:10.1109/IEEESTD.2012.6209381.

IEEE. 2014. IEEE Guide for Collecting, Categorizing, and Utilizing Information Related to Electric Power Distribution Interruption Events, IEEE Standard 1782-2014:1-98. doi:10.1109/IEEESTD.2014.6878409.

Kok JK, CJ Warmer, and IG Kamphuis. 2005. "Powermatcher: Multiagent Control in the Electricity Infrastructure," Proceedings of the Fourth International Joint Conference on Autonomous Agents and Multiagent Systems, The Netherlands, 75-82 pp. ACM, 1082807. Accessed April 12, 2017, at http://delivery.acm.org/10.1145/1090000/1082807/p75-

kok.pdf?ip=130.20.182.28\&id=1082807\&acc=ACTIVE\%20SERVICE\&key=70F97CA9565FDD93\%2E 70F97CA9565FDD93\%2E4D4702B0C3E38B35\%2E4D4702B0C3E38B35\&CFID=923163706\&CFTO KEN=15756716\&_acm_=1492024422_30d8de8ba423a44f999917275e26e705.

Kok K and S Widergren. 2016. “A Society of Devices: Integrating Intelligent Distributed Resources with Transactive Energy,” IEEE Power and Energy Magazine 14(3):34-45. doi:10.1109/MPE.2016.2524962. Accessed April 12, 2017, at http://ieeexplore.ieee.org/document/7452756/.

Li H and L Tesfatsion. 2009. The AMES Wholesale Power Market Test Bed: A Computational Laboratory for Research, Teaching, and Training. In Proceedings of 2009 IEEE Power \& Energy Society General Meeting. Accessed April 12, 2017, at http://ieeexplore.ieee.org/document/5275969/.

Lincoln R. 2017. PYPOWER. Accessed April 12, 2017, at https://pypi.python.org/pypi/PYPOWER. 
NIST - National Institute of Standards and Technology. 2017. NIST Transactive Energy Challenge. Accessed April 12, 2017, at https://pages.nist.gov/TEChallenge/.

OMG - Object Management Group. 2017. Unified Modeling Language. Webpage available online at http://www.uml.org.

Schneider KP, Y Chen, D Engle, and D Chassin. 2009. “A Taxonomy of North American Radial Distribution Feeders.” In Proceedings of 2009 IEEE Power \& Energy Society General Meeting. Accessed April 12, 2017, at http://ieeexplore.ieee.org/document/5275900/.

Sultan V, B Alsamani, N Alharbi, Y Alsuhaibany, and M Alzahrani. 2016. “A Predictive Model to Forecast Customer Adoption of Rooftop Solar.” In Proceedings of 2016 4th International Symposium on Computational and Business Intelligence (ISCBI). Accessed April 12, 2017, at http://ieeexplore.ieee.org/stamp/stamp.jsp?arnumber=7743256.

Temix Inc. 2017. TeMix. Online. Accessed April 12, 2017, at www.temix.net.

Zhang H, Y Vorobeychik, J Letchford, and K Lakkaraju. 2015. "Data-Driven Agent-Based Modeling, with Application to Rooftop Solar Adoption,” Proceedings of the 2015 International Conference on Autonomous Agents and Multiagent Systems, Istanbul, Turkey, 513-521 pp. International Foundation for Autonomous Agents and Multiagent Systems, 2772945.

Zimmerman RD, CE Murillo-Sanchez, and RJ Thomas. 2011. "MATPOWER: Steady-State Operations, Planning, and Analysis Tools for Power Systems Research and Education,” IEEE Transactions on Power Systems 26(1):12-19. doi:10.1109/TPWRS.2010.2051168. Accessed April 12, 2017, at http://ieeexplore.ieee.org/document/5491276/. 

Appendix A

\section{Source of Uncertainty in Valuations}





\section{Appendix A: Source of Uncertainty in Valuations}

Table A.1. Sources of Uncertainty and their Effects on Valuation

\begin{tabular}{|c|c|c|}
\hline Uncertainty Source & System Embodiment & Effect on Valuation \\
\hline Input values $(\mathrm{P})$ & $\begin{array}{l}\text { Natural variability expressed with } \\
\text { statistical distributions of input values, } \\
\text { including those in the time dimension. }\end{array}$ & $\begin{array}{l}\text { Consequent variability and statistical } \\
\text { distributions in the valuation metrics. Uncertainty } \\
\text { must be propagated during valuation. }\end{array}$ \\
\hline Input values (E) & $\begin{array}{l}\text { Errors in assumed input values, } \\
\text { including those in the time dimension. }\end{array}$ & $\begin{array}{l}\text { Consequent bias errors in the valuation metrics, } \\
\text { which cannot be eliminated. The importance of } \\
\text { incorrect assumptions may be assessed through } \\
\text { sensitivity analysis. }\end{array}$ \\
\hline $\begin{array}{l}\text { Statistical } \\
\text { distribution of input } \\
\text { values (E) }\end{array}$ & $\begin{array}{l}\text { Incorrect assumptions about the inputs' } \\
\text { statistical range or distribution shape. }\end{array}$ & $\begin{array}{l}\text { Consequent poor estimation of the range and } \\
\text { shape of natural variability in valuation metrics. } \\
\text { Sensitivity analysis may be used to assess the } \\
\text { importance of an error. }\end{array}$ \\
\hline $\begin{array}{l}\text { Valuation theory and } \\
\text { models (E) }\end{array}$ & $\begin{array}{l}\text { Mistaken or incomplete models of how } \\
\text { valuation metrics are derived from } \\
\text { inputs. }\end{array}$ & $\begin{array}{l}\text { Incorrect correlations between inputs and } \\
\text { metrics. Cannot be resolved without improved } \\
\text { modeling or experimentation. }\end{array}$ \\
\hline $\begin{array}{l}\text { Random failure event } \\
\text { occurrences by place } \\
\text { and in time (P) }\end{array}$ & $\begin{array}{l}\text { Randomized occurrences of device } \\
\text { failures and inadequacy constraints. } \\
\text { Both event timing and event counts } \\
\text { over time are variable. Each event has } \\
\text { corresponding consequences. }\end{array}$ & $\begin{array}{l}\text { Statistical treatment is required for variable event } \\
\text { timing and variable numbers of events. Rich } \\
\text { computational models and theory have evolved to } \\
\text { statistically quantify many types of failure events } \\
\text { and to estimate their consequences. }\end{array}$ \\
\hline $\begin{array}{l}\text { Device failure rates } \\
\text { or likelihoods (E) }\end{array}$ & $\begin{array}{l}\text { Poorly understood statistics for event } \\
\text { likelihood, especially for infrequent } \\
\text { events having little historical data. } \\
\text { Incomplete models of event causes and } \\
\text { correlations. }\end{array}$ & $\begin{array}{l}\text { Epistemic uncertainty must be addressed through } \\
\text { sensitivity analysis. Because events are } \\
\text { infrequent, short-term use-case scenarios are } \\
\text { often used as substitutes to explore timing effects } \\
\text { and event consequences. }\end{array}$ \\
\hline $\begin{array}{l}\text { Failure event } \\
\text { consequences (E) }\end{array}$ & $\begin{array}{l}\text { The consequences of a failure event are } \\
\text { poorly known or are poorly modeled. }\end{array}$ & $\begin{array}{l}\text { The severity of an event becomes skewed. This is } \\
\text { insidious. Effects might be reduced through } \\
\text { improved modeling and with long-term historical } \\
\text { data. }\end{array}$ \\
\hline $\begin{array}{l}\text { Poor execution or } \\
\text { incorrectly executed } \\
\text { process (E) }\end{array}$ & $\begin{array}{l}\text { Execution errors cause the built system } \\
\text { to differ from the one planned and } \\
\text { modeled. }\end{array}$ & $\begin{array}{l}\text { Metrics and models become meaningless. One } \\
\text { might treat this case as a (hopefully) unlikely } \\
\text { event based on historical execution, and weight } \\
\text { the event accordingly. }\end{array}$ \\
\hline
\end{tabular}





\section{Appendix B}

\section{Valuation Metric Model Definition Template}





\section{Appendix B: Valuation Metric Model Definition Template}

The following template has been used to define and catalog 70 valuation metrics and the models by which the metrics are informed. The intention of these "one-pagers" is to define, at some high level, precise metrics and methods. The activity block invites analysts to think of valuation models as UML activities that may be strung together, outputs to inputs, to represent alternative selectable pathways for calculating valuation metrics. The assembly of these documents may be an important step toward documenting, sharing, collaborating upon, and automating valuation methodology. The second page of the template is a set of instructions and suggestions. A completed example is appended.

\section{Valuation Model

\begin{tabular}{|l|l|l|l|}
\multicolumn{1}{|l}{ V.v $\mathrm{mm} / \mathrm{dd} / \mathrm{yy}$} & \multicolumn{1}{c|}{ Author } & Change \\
\hline 1.1 & & & \\
\hline 1.0 & & & First draft \\
\hline
\end{tabular}

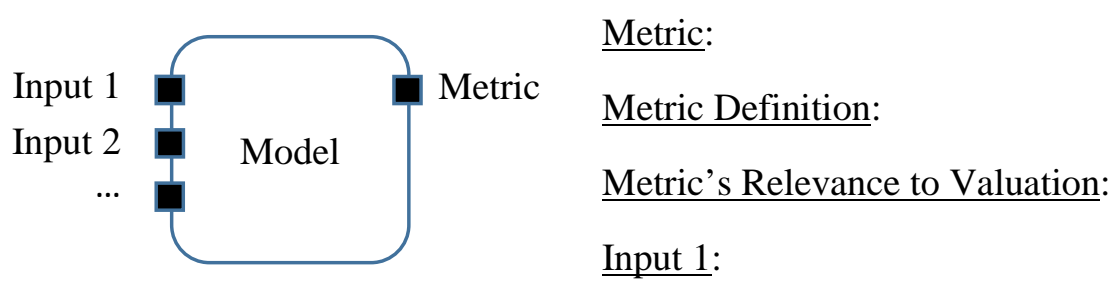

Input 1 Definition:

Input 2:

Input 2 Definition:

Basic Calculation Method:

(Optional) Available Implementations of this Model (e.g., code, spreadsheets, etc.):

(Optional) Related and Alternative Methods:

(Optional) Comments:

(Optional) References: 
NOTES:

Purpose: This is a template for the definition of valuation metrics and how they may be calculated. Valuation metrics are treated as outputs from valuation models. UML activity diagrams may be used to capture the model first as a simple input/output block, the details of which may be deferred in time, hidden, or viewed. A long-term goal is to collect these metric definitions and models and string them together as a somewhat automated collection of alternative valuation pathways.

Please try to keep your document to one page or less in length.

Please let the SharePoint manage versioning for us. Work within the SharePoint. Do not check documents out. Do not modify document names. Use of tracked changes is encouraged, please, if you are modifying existing documents.

- Versioning block. Please fill in a row for your initial draft and subsequent changes. Add your row above the prior one and increment the sub-version number.

- $\quad$ Block diagram. Please do not alter the representative block diagram. This simple block is adequate to guide the listing of a metric and its inputs.

- $\quad$ Metric. Provide the short name of a single class of metric. Avoid comparative words like "improvement in," "change in," "difference between," which are likely indications that an impact, not metric, is being described.

- Metric definition. What is the metric? What are acceptable measurement units? Will the metric lie within a given range? Reference the source of a standard definition if one exists. As space permits, include important qualities of the metric. Does the metric include or otherwise address effects of uncertainty?

- $\quad$ Relevance of metric. Briefly, why is the metric needed? How should it be used? What does it tell us about a valuation scenario? Is the metric used directly by decision makers?

- $\quad$ Inputs: Name and define each input, as has been done for the metric. Number the inputs consecutively. Add inputs as needed. If an input block is itself a valuation metric, cite accordingly.

- Basic calculation method. State briefly how the metric is derived from the listed inputs. Consider this following content, for example:

o Uncertainty. State known sources of epistemic, random, or temporal uncertainty and how are they addressed or represented by the model.

o Assumptions. State important assumptions underlying the model.

o Limitations. List any limitations of the model or its calculation method.

o Nature of calculation. Is the method analytical, or is simulation required?

- Optional sections. You may choose to include these sections if they add value.

o Implementations. List any software programs, spreadsheets, example calculations that have implemented this calculation.

o Related/alternative models. State if this document is the parent or child of a previous, alternative document. List documents that calculate the inputs in this document or that use this document's metric as an input.

o Comments. Use this if you feel compelled to state something that could not be said in the above sections.

o $\quad$ References. Provide full citations for referenced sources. 


\section{LOLE Valuation Model}

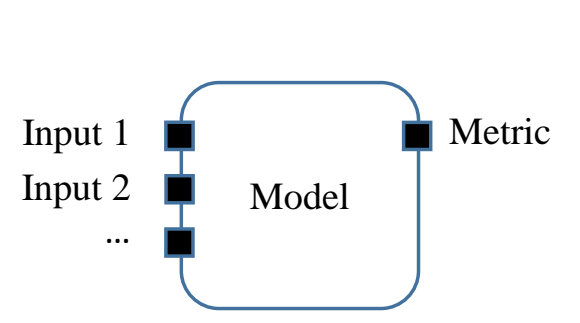

Metric: Loss of load expectation (LOLE)

Metric Definition: average number of days in a given year in which the daily peak load is expected to exceed the available generating capacity (Billinton and Yuan 1994)

Metric's Relevance to Valuation: Useful for generation capacity planning (Billinton and Yuan 1994)

Input 1: \#Generating Units

Input 1 Definition: number of power plant generating units

Input 2: Forced Outage Rates (FOR)

Input 2 Definition: Probability of failure of each generating unit. FOR = MTTR/(MTTR+MTTF), where MTTR is mean time to repair and MTTF is mean time to failure. Randomness in failure and repair rates makes FOR an uncertain entity.

Input 3: Generation Capacity

Input 3 Definition: derated capacity of each generating unit (MW)

Input 4: Quantity of load to be supplied

Input 4 Definition: load that the generation plant is required to supply (MW). For operational planning, expected load is available from the logs. For long-term planning, this variable is uncertain, requiring complex prediction models (PJM 2003).

Basic Calculation Method: A capacity outage probability table (COPT) is developed from outage rates and available capacity. The cumulative probabilities from COPT determine loss of load probability (LOLP) for a given quantity of load to be supplied. Multiplying LOLP by 365 yields LOLE. Acceptable LOLE is 0.1 days/year.

Available Implementations of this Model (e.g., code, spreadsheets, etc.): Textbook version to generate basic COPT is available as a MATLAB script (Chakraborty 2010). A probabilistic simulation method is outlined by PJM (PJM 2003).

\section{$\underline{\text { References }}$}

Billinton R and W Li. 1994. Reliability Assessment of Electric Power Systems using Monte Carlo Methods. Springer Publishing, New York, New York. ISBN-13: 978-0306447815.

PJM. 2003. PJM Generation Adequacy Analysis: Technical Methods. PJM Interconnection, LLC, Norristown, Pennsylvania. Accessed April 6, 2017, at https://www.pjm.com/ /media/etools/oasis/references/whitepaper-sections-12.ashx.

Chakraborty A. Generator Capacity Outage Probability Table. Accessed April 6, 2017, at https://www.mathworks.com/matlabcentral/fileexchange/27599-generator-capacity-outage-probabilitytable. 

Appendix C

Valuation Results from the Trial Analyses 



\section{Appendix C: Valuation Results from the Trial Analysis}

Table C.1. Example Valuation Ledger from the Trial Analysis \#1 (Inadequate Generation Supply)

\begin{tabular}{|c|c|c|c|c|c|c|c|c|c|c|}
\hline \multirow[b]{2}{*}{$\begin{array}{l}\text { Use } \\
\text { Case }\end{array}$} & & \multirow[b]{2}{*}{ Use Case Description } & \multirow[b]{2}{*}{ Actor } & \multirow[b]{2}{*}{ Extent } & \multirow[b]{2}{*}{ Metric } & \multirow[b]{2}{*}{ Units } & \multicolumn{2}{|c|}{ Non-Event Day ${ }^{(a)}$} & \multicolumn{2}{|c|}{ Event Day $^{(\mathbf{b})}$} \\
\hline & & & & & & & Baseline & $\begin{array}{c}\text { Test } \\
\text { Impact }^{(\mathrm{c})} \\
\end{array}$ & Baseline & $\begin{array}{c}\text { Test } \\
\text { Impact }^{(\mathrm{c})}\end{array}$ \\
\hline \multirow{10}{*}{ 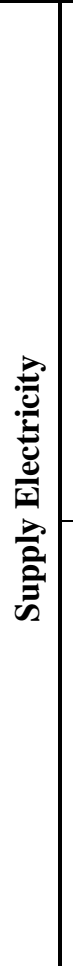 } & \multirow{6}{*}{ 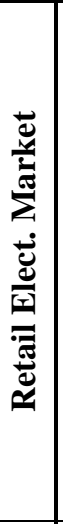 } & \multirow{6}{*}{$\begin{array}{l}\text { The distribution utility } \\
\text { supplies electricity to its } \\
\text { customers }\end{array}$} & \multirow{2}{*}{$\begin{array}{l}\text { Residential } \\
\text { customer }\end{array}$} & \multirow{2}{*}{$\begin{array}{l}\text { Sim. dur.; } \\
\text { Test feeder }{ }^{(\mathrm{d})}\end{array}$} & $\begin{array}{l}\text { Electricity } \\
\text { /day/cust. }\end{array}$ & kWh & 47.9 & -1.5 & 48.8 & -1.1 \\
\hline & & & & & $\begin{array}{l}\text { Electricity fee } \\
\text { /day/cust. }\end{array}$ & $\$$ & -5.95 & 0.18 & -6.07 & 0.14 \\
\hline & & & \multirow{4}{*}{$\begin{array}{l}\text { Electric } \\
\text { distribution } \\
\text { utility }\end{array}$} & \multirow{4}{*}{$\begin{array}{l}\text { Sim. dur.; } \\
\text { Test feeder }^{(d)}\end{array}$} & $\begin{array}{l}\text { Electricity } / \text { day } \\
\end{array}$ & MWh & -76.3 & 2.3 & -77.8 & 1.7 \\
\hline & & & & & /day/cust. & kWh & -47.9 & 1.5 & -48.8 & 1.1 \\
\hline & & & & & $\begin{array}{l}\text { Electricity } \\
\text { (transactive) fee } \\
\text { /day }\end{array}$ & $\$$ & 9,484 & -287 & 9,676 & -223 \\
\hline & & & & & /day/cust. & $\$$ & 5.95 & -0.18 & 6.07 & -0.14 \\
\hline & \multirow{4}{*}{ 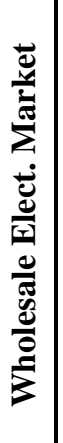 } & \multirow{4}{*}{$\begin{array}{l}\text { Distribution utility } \\
\text { procures electricity } \\
\text { from wholesale market }\end{array}$} & \multirow{2}{*}{$\begin{array}{l}\text { Electric } \\
\text { distribution } \\
\text { utility }\end{array}$} & \multirow{2}{*}{$\begin{array}{l}\text { Sim. dur.; } \\
\text { Test feeder }{ }^{(\mathrm{d})}\end{array}$} & $\begin{array}{ll}\text { Electricity } & \\
& \text { /day } \\
\end{array}$ & MWh & 76.3 & -2.3 & 77.8 & -1.7 \\
\hline & & & & & $\begin{array}{l}\text { Elect. (LMP) } \\
\text { fee } \quad / \text { day }\end{array}$ & $\$$ & $-9,485$ & 291 & $-9,673$ & 214 \\
\hline & & & \multirow{2}{*}{$\begin{array}{l}\text { Wholesale } \\
\text { market }\end{array}$} & \multirow{2}{*}{$\begin{array}{l}\text { Sim. dur.; } \\
\text { Test feeder }^{(\mathrm{d})}\end{array}$} & $\begin{array}{l}\text { Electricity } \\
\end{array}$ & MWh & -76.3 & 2.3 & -77.8 & 1.7 \\
\hline & & & & & $\begin{array}{l}\text { Elect. (LMP) } \\
\text { fee } \quad / \text { day }\end{array}$ & $\$$ & 9,485 & -291 & 9,673 & -214 \\
\hline
\end{tabular}




\begin{tabular}{|c|c|c|c|c|c|c|c|c|c|}
\hline \multirow[b]{2}{*}{$\begin{array}{l}\text { Use } \\
\text { Case }\end{array}$} & \multirow[b]{2}{*}{ Use Case Description } & \multirow[b]{2}{*}{ Actor } & \multirow[b]{2}{*}{ Extent } & \multirow[b]{2}{*}{ Metric } & \multirow[b]{2}{*}{ Units } & \multicolumn{2}{|c|}{ Non-Event Day $^{(a)}$} & \multicolumn{2}{|c|}{ Event Day $^{(\mathbf{b})}$} \\
\hline & & & & & & Baseline & $\begin{array}{c}\text { Test } \\
\text { Impact }^{(\mathrm{c})}\end{array}$ & Baseline & $\begin{array}{c}\text { Test } \\
\text { Impact }^{(\mathrm{c})}\end{array}$ \\
\hline \multirow{5}{*}{ 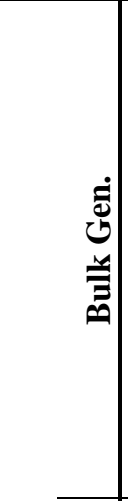 } & \multirow{5}{*}{$\begin{array}{l}\text { Wholesale market } \\
\text { procures electricity from } \\
\text { bulk electricity suppliers }\end{array}$} & \multirow{3}{*}{$\begin{array}{l}\text { Bulk } \\
\text { electricity } \\
\text { supplier }\end{array}$} & \multirow{3}{*}{ Sim. dur. } & $\begin{array}{l}\text { Electricity } \\
\text { /day }\end{array}$ & MWh & $-9,986$ & 50 & $-9,994$ & 54 \\
\hline & & & & $\begin{array}{l}\text { Production } \\
\text { cost /day }\end{array}$ & $1000 \$$ & -148.9 & 1.0 & -450.5 & 9.1 \\
\hline & & & & $\begin{array}{r}\text { Electricity fee } \\
\text { /day }\end{array}$ & $1000 \$$ & 210.6 & -2.7 & 4,531 & -158 \\
\hline & & \multirow{2}{*}{$\begin{array}{c}\text { Wholesale } \\
\text { market }\end{array}$} & \multirow{2}{*}{ Sim. dur. } & $\begin{array}{r}\text { Electricity } \\
\text { /day }\end{array}$ & MWh & 9,986 & -50 & 9,994 & -54 \\
\hline & & & & $\begin{array}{r}\text { Electricity fee } \\
\text { /day }\end{array}$ & $1000 \$$ & -210.6 & 2.7 & $-4,531$ & 158 \\
\hline \multirow{6}{*}{ 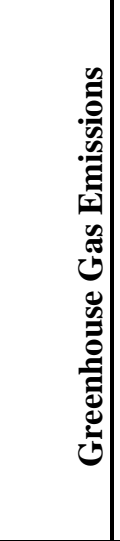 } & \multirow{6}{*}{$\begin{array}{l}\text { Bulk generators emit } \\
\text { greenhouse gas emissions } \\
\text { during electricity } \\
\text { generation }\end{array}$} & \multirow{3}{*}{$\begin{array}{c}\text { Bulk } \\
\text { generators }\end{array}$} & \multirow{3}{*}{ Sim. dur. } & $\mathrm{CO}_{2}$ & MT & $-4,067$ & 20 & $-4,071$ & 22 \\
\hline & & & & $\mathrm{SO}_{\mathrm{x}}$ & $\mathrm{kg}$ & -34.7 & 0.2 & -34.8 & 0.2 \\
\hline & & & & $\mathrm{NO}_{\mathrm{x}}$ & $\mathrm{kg}$ & -260.5 & 1.3 & -260.8 & 1.4 \\
\hline & & \multirow{3}{*}{ Society } & \multirow{3}{*}{ Sim. dur. } & $\mathrm{CO}_{2}$ & MT & 4,067 & -20 & 4,071 & -22 \\
\hline & & & & $\mathrm{SO}_{\mathrm{x}}$ & $\mathrm{kg}$ & 34.7 & -0.2 & 34.8 & -0.2 \\
\hline & & & & $\mathrm{NO}_{\mathrm{x}}$ & $\mathrm{kg}$ & 260.5 & -1.3 & 260.8 & -1.4 \\
\hline
\end{tabular}




\begin{tabular}{|c|c|c|c|c|c|c|c|c|c|}
\hline \multirow[b]{2}{*}{$\begin{array}{l}\text { Use } \\
\text { Case }\end{array}$} & \multirow[b]{2}{*}{ Use Case Description } & \multirow[b]{2}{*}{ Actor } & \multirow[b]{2}{*}{ Extent } & \multirow[b]{2}{*}{ Metric } & \multirow[b]{2}{*}{ Units } & \multicolumn{2}{|c|}{ Non-Event Day ${ }^{(a)}$} & \multicolumn{2}{|c|}{ Event Day $^{(\mathbf{b})}$} \\
\hline & & & & & & Baseline & $\begin{array}{c}\text { Test } \\
\text { Impact }^{(\mathrm{c})}\end{array}$ & Baseline & $\begin{array}{c}\text { Test } \\
\text { Impact }^{(\mathrm{c})}\end{array}$ \\
\hline \multirow{8}{*}{ 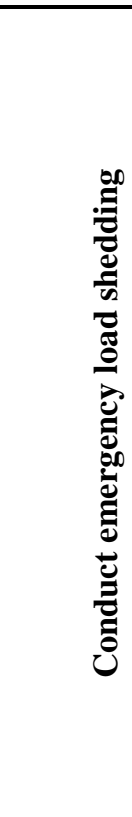 } & \multirow{8}{*}{$\begin{array}{l}\text { Electricity customers. } \\
\text { incur outages }\end{array}$} & \multirow{3}{*}{$\begin{array}{l}\text { Electric } \\
\text { distribution } \\
\text { utility }\end{array}$} & \multirow{3}{*}{$\begin{array}{l}\text { Sim. dur.; } \\
\text { Test fdr.(d) }\end{array}$} & $\begin{array}{r}\text { Peak power } \\
\text { /day }\end{array}$ & kW & $-4,851$ & $-380^{(\mathrm{e})}$ & $-4,826$ & $-897^{(\mathrm{e})}$ \\
\hline & & & & $\begin{array}{l}\begin{array}{l}\text { Power shed } \\
\text { dur. } \\
\quad / \text { day }\end{array} \\
\end{array}$ & min. & 0 & 0 & 869.4 & -0.6 \\
\hline & & & & $\begin{array}{l}\text { No. of cust. } \\
\text { impacted } \\
\end{array}$ & $\#$ & 0 & 0 & 1559 & $0^{(\mathrm{f})}$ \\
\hline & & Customer & $\begin{array}{l}\text { Sim. dur.; } \\
\text { Test fdr.(d) }\end{array}$ & $\begin{array}{l}\begin{array}{l}\text { Peak power } \\
\text { (i.e., demand) } \\
\text { /day }\end{array} \\
\end{array}$ & $\mathrm{kW}$ & 4,851 & $380^{(e)}$ & 4,826 & $897^{(\mathrm{e})}$ \\
\hline & & \multirow{2}{*}{$\begin{array}{l}\text { Residential } \\
\text { customer }\end{array}$} & \multirow{2}{*}{$\begin{array}{l}\text { Sim. dur.; } \\
\text { Res. custs.; } \\
\text { Test fdr. }{ }^{\text {(d) }}\end{array}$} & $\begin{array}{r}\text { Outage count } \\
\text { /day }\end{array}$ & $\#$ & 0 & 0 & 1559 & $0^{(\mathrm{f})}$ \\
\hline & & & & $\begin{array}{l}\text { Outage dur. } \\
\text { /day }\end{array}$ & $\min$. & 0 & 0 & 869.4 & -0.6 \\
\hline & & \multirow{2}{*}{$\begin{array}{l}\text { Commercial } \\
\text { customer }\end{array}$} & \multirow{2}{*}{$\begin{array}{l}\text { Sim. dur.; } \\
\text { Comm. } \\
\text { custs.; } \\
\text { Test fdr. }{ }^{\text {(d) }}\end{array}$} & $\begin{array}{l}\text { Outage count } \\
\text { /day }\end{array}$ & \# & 0 & 0 & 1 & $0^{(\mathrm{f})}$ \\
\hline & & & & $\begin{array}{l}\text { Outage dur. } \\
\text { /day }\end{array}$ & $\min$. & 0 & 0 & 869.4 & -0.6 \\
\hline
\end{tabular}

(a) The "non-event" day was the first simulation day, on which generation supply was adequate.

(b) The "event day" was the second simulation day, on which generation supply was inadequate.

(c) "Test impact" is the metric value for the transactive test scenario, minus the value from the non-transactive base scenario.

(d) "Test feeder" refers to the part of Bus 7 that hosts the transactive system that is being tested.

(e) Customer peak demand increased in the transactive scenario. This impact is affected by an oscillatory behavior in the transactive scenario simulations (Figure D.1). This metric quantified the maximum of the oscillations.

(f) These zeros in the Test Impact column mean that the numbers of outages or impacted customers did not change for the test scenario that included a transactive energy system. 



\section{Appendix D}

\section{Valuation Results from Trial Analysis 2 (Growth Model)}





\section{Appendix D: Valuation Results from Trial Analysis 2 (Growth Model)}

1. Case descriptions

Five different study cases have been analyzed (Table D.1). The "growth" among the cases is as follows:

- $\quad$ Case $\mathrm{a}=$ base case

- $\quad$ Case $b=$ Case $\mathrm{a}+755$ TE controllers for HVAC

- $\quad$ Case c = Case b + add 10\% PV and 5\% battery storage

- $\quad$ Case $d=$ Case c + add another $10 \%$ PV and 5\% battery storage

- $\quad$ Case e $=$ Case $\mathrm{d}+$ add another $10 \% \mathrm{PV}$ and $5 \%$ battery storage

The percentages are based on the number of installed PV or battery storage with respect to the total number of houses on the test feeder (1594).

Table D.1. Summary of Study Cases

\begin{tabular}{lcccccc}
\hline \multicolumn{1}{c}{ Case } & Case ID & Houses & Controllers & Water Heaters & PV Systems & $\begin{array}{c}\text { Storage } \\
\text { Systems }\end{array}$ \\
\hline Base Case & a & 1594 & 1 & 1151 & 0 & 0 \\
Year 0 & b & 1594 & 755 & 1151 & 0 & 0 \\
Year 1 & c & 1594 & 755 & 1151 & 159 & 82 \\
Year 2 & d & 1594 & 755 & 1151 & 311 & 170 \\
Year 3 & e & 1594 & 755 & 1151 & 464 & 253 \\
\hline
\end{tabular}

2. Impacts on the transmission system

The trial analysis covers two days (48 hours). The starting time, Hour 0 , corresponds to midnight, September 1, 2013. The first day is the "normal" non-event day, and the second day is the event day, having a generation outage from 6 AM to 9 PM. Comparison of the system between these two days can identify the strengths and weaknesses of the studied transactive system under both normal and constrained operating conditions.

The total load and wholesale market clearing price, i.e., LMP, at bus 7 of the transmission system is shown in Figure D.1. This transmission substation is of special interest because it serves the modeled test utility in this trial analysis. The average, maximum, and minimum LMP at bus 7 are shown in Table D.2. 
Bus 7 total load
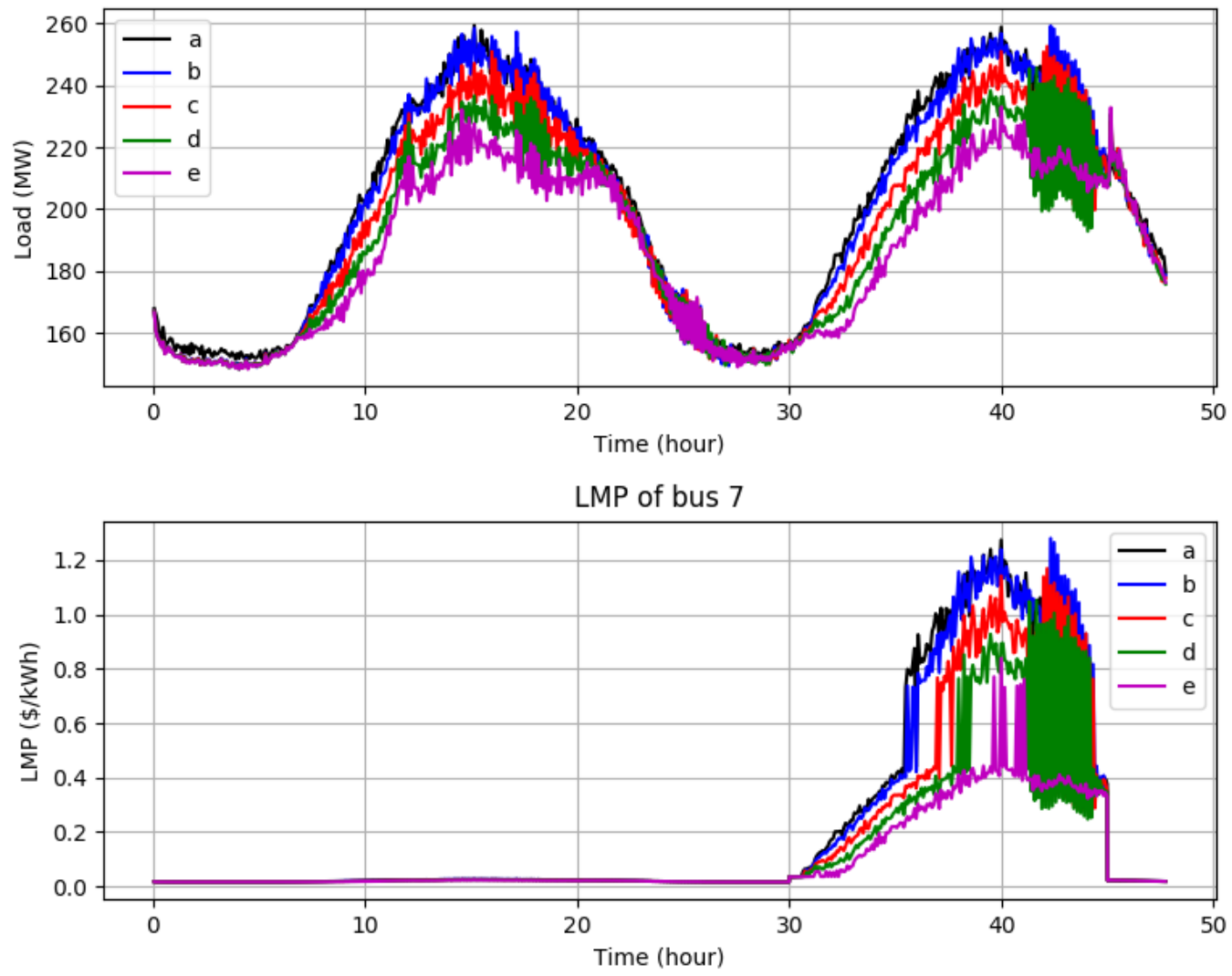

Figure D.1. The Total Load at Bus 7 and the LMP

Table D.2. Statistics of the LMP at Bus 7

\begin{tabular}{cccc}
\hline Case & $\begin{array}{c}\text { LMP Avg } \\
(\$ / \mathrm{kWh})\end{array}$ & $\begin{array}{c}\text { LMP Max } \\
(\$ / \mathrm{kWh})\end{array}$ & $\begin{array}{c}\text { LMP Min } \\
(\$ / \mathrm{kWh})\end{array}$ \\
\hline $\mathrm{a}$ & 0.220 & 1.275 & 0.016 \\
$\mathrm{~b}$ & 0.213 & 1.280 & 0.016 \\
$\mathrm{c}$ & 0.176 & 1.169 & 0.016 \\
$\mathrm{~d}$ & 0.145 & 1.051 & 0.016 \\
$\mathrm{e}$ & 0.101 & 0.839 & 0.016 \\
\hline
\end{tabular}

As shown in Figure D.1, the LMP is relatively low throughout the first day, responses of the HVAC controllers to the low prices are moderate. In contrast, for the second day starting at Hour 30, loss of one large generation unit in the transmission system leads to an increase in LMP. A peak LMP at Bus 7 (approximately $1.25 \$ / \mathrm{kWh}$ ) occurred at Hour 40. The responses of the HVAC TE controllers to the price also gradually increase, as shown in Figure D.2. Approximately 1 hour after reaching the peak, the accumulative effects of the increased LMP over the past serval hours result in oscillation of the total load, which in turn causes oscillation of the LMP. The underlying reason for this oscillation appears to be that the HVAC TE controllers lost their aggregated diversity and tended to homogeneously respond to price, which means their control the HVAC set points appear synchronized in the same direction almost at the same time. The ability of simulation to reveal such 
important behavior will lead to an investigation of the underlying causes (whether modeling and simulation shortcomings or design shortcomings) and insights to improve transactive system designs.
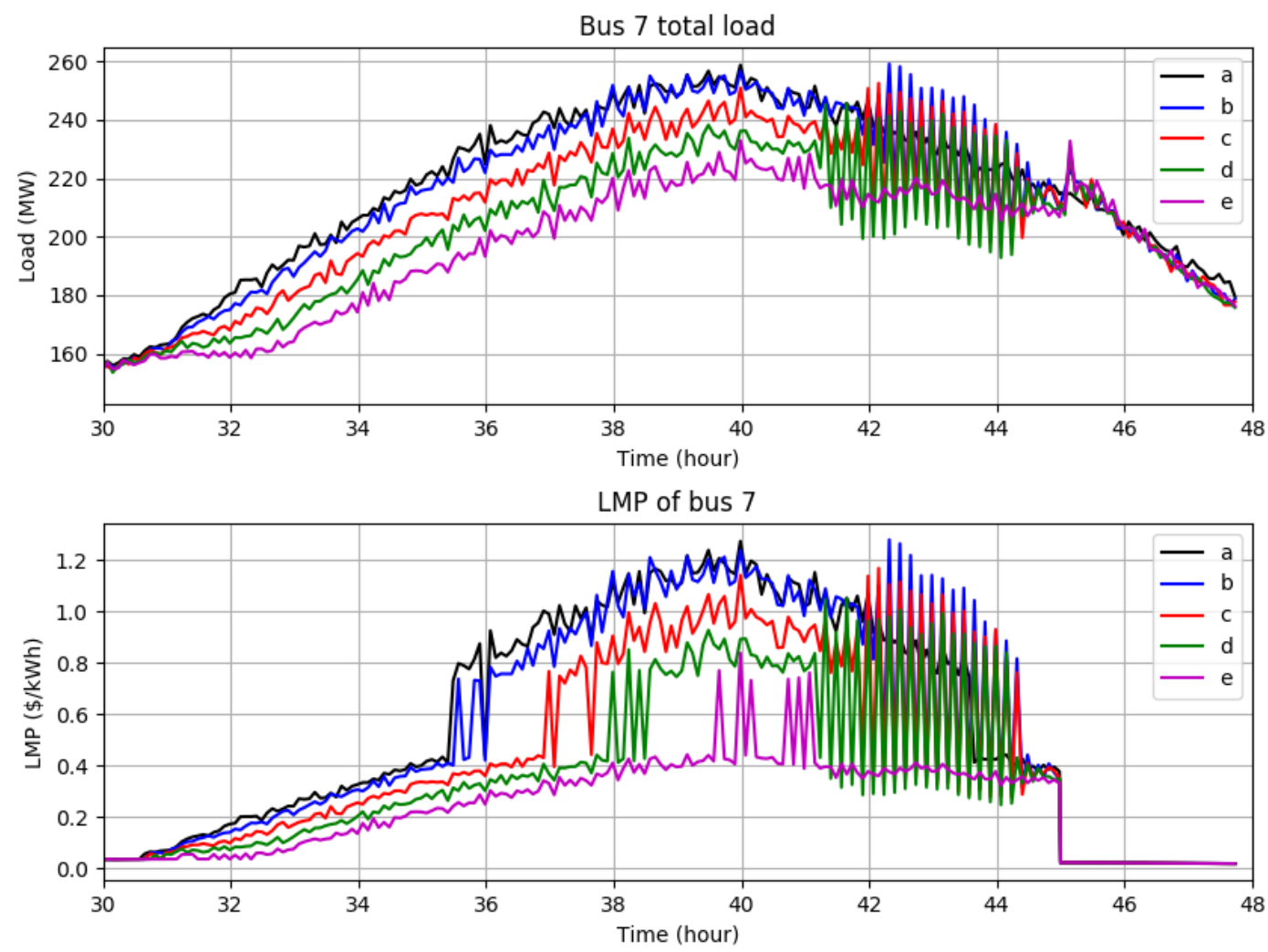

Figure D.2. The Total Load and LMP\$t Bus 7 (zoom-in for the period of Hours 30-48)

3. Impacts on the distribution system

1) Feeder load demand

Figure D.3 shows the test feeder load demand seen from the distribution substation in each scenario. Without controllers attached to the houses in Case a, house temperature is adjusted based on the scheduled temperature set points. The HVAC controller increases the house temperature set points when the market clearing price is high, and vice versa. More on-and-off variabilities of the house HVAC loads occur, which result in the oscillations seen in Cases b e. Load shedding happens at the second day of the simulations, which coincides with higher LMP prices. It was observed that more oscillations happen during the load shedding conditions. Further investigation is needed to understand the underlying cause of this behavior. 


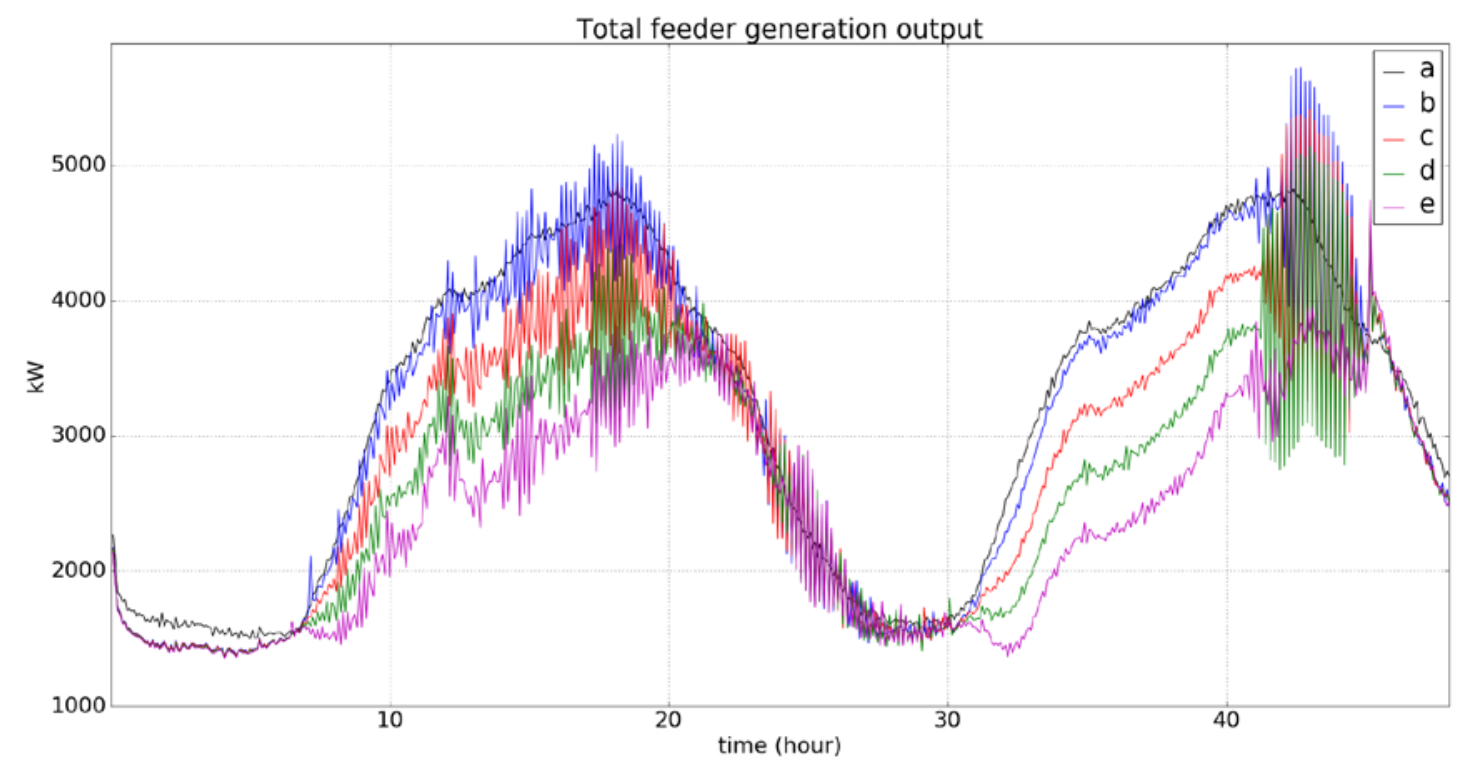

Figure D.3. Total Feeder Load by Case

2) Total electricity consumption

Total electricity consumption of the feeder, as well as the total house energy consumption in each case is summarized in Table D.3. In Case b, the total feeder electricity is reduced by $4065 \mathrm{kWh}$ compared to the Case a. The controllers adjust the house temperature with higher set points when market clearing prices are high, which reduces the total house energy consumption of $3968 \mathrm{kWh}$ in the Case b compared to Case a.

Table D.3. Total Electricity Consumption by Case ID

\begin{tabular}{ccc}
\hline Case & $\begin{array}{c}\text { Total Feeder Electricity } \\
(\mathrm{kWh})\end{array}$ & $\begin{array}{c}\text { Total Residential Energy } \\
\text { Consumption }(\mathrm{kWh})\end{array}$ \\
\hline a & 154129 & 141645 \\
$\mathrm{~b}$ & 150063 & 137677 \\
$\mathrm{c}$ & 138897 & 137640 \\
$\mathrm{~d}$ & 128496 & 137623 \\
$\mathrm{e}$ & 118157 & 137632 \\
\hline
\end{tabular}

3) Voltage violation

There are no voltage violations in Cases a-e. In the next phase of the project, simulations will be run for more days, and the voltage violations, as well as reliability indices, will be examined.

4. Impacts on the customers

1) Electricity bill

The electricity bills are calculated based on the billing meter powers and retail electricity price. As seen from Table D.4, the electricity bill is reduced in Case b compared to Case a, which is a result of the reduced household energy consumption under the temperature adjustments of controllers. In Cases a-e, 
less electricity is consumed due to the power supplied from PV systems and batteries to the meters. In this way, the electricity bills are further reduced with the increasing numbers of PV systems and batteries from Cases b to e.

Table D.4. Electricity Bills of Customers on One Feeder Served by Bus 7 by Case ID

\begin{tabular}{ccc}
\hline Case & $\begin{array}{c}\text { Total Billed } \\
\text { (USD) }\end{array}$ & $\begin{array}{c}\text { Electricity Bill per Customer } \\
\text { (USD /customer) }\end{array}$ \\
\hline a & 19158 & 12.02 \\
b & 18653 & 11.70 \\
c & 17265 & 10.83 \\
d & 15972 & 10.02 \\
e & 14687 & 9.21 \\
\hline
\end{tabular}

2) PV output and revenue

In Cases c to e, the fraction of residences having PV systems is successively increased by $10 \%$. Power outputs from the PV systems are increased, as indicated from Table D.5. The PV revenue is calculated based on the market clearing price of the auction agent in each time step, and the total PV revenue in each case is given in Table D.5.

Table D.5. PV Outputs and Revenue by Case

\begin{tabular}{ccc}
\hline Case & $\begin{array}{c}\text { Total PV Output } \\
(\mathrm{kWh})\end{array}$ & $\begin{array}{c}\text { Total PV Revenue } \\
(\text { USD })\end{array}$ \\
\hline a & - & - \\
b & - & - \\
c & 128438 & 3325 \\
d & 250468 & 5172 \\
e & 373898 & 5203 \\
\hline
\end{tabular}

3) Battery output and revenue

In Cases c to e, total number of residences on the test feeder having battery storage systems is increased successively by $5 \%$. As shown in Table D.6, total energy output from the batteries increase from $0 \mathrm{~kW}$ in Case a to $3782 \mathrm{~kW}$ in Case d. Since the batteries are working in load-following modes, the discharging threshold of the batteries is less likely to be reached in Case e compared to Case d. Therefore, less power output from the batteries is seen in Case e. 
Table D.6. Battery Outputs and Revenue by Case ID

\begin{tabular}{ccc}
\hline Case & $\begin{array}{c}\text { Total Battery Output } \\
(\mathrm{kWh})\end{array}$ & $\begin{array}{c}\text { Total Battery Revenue } \\
(\text { USD })\end{array}$ \\
\hline $\mathrm{a}$ & - & - \\
$\mathrm{b}$ & - & - \\
$\mathrm{c}$ & 2733 & 24 \\
$\mathrm{~d}$ & 3782 & 68 \\
$\mathrm{e}$ & 3137 & 66 \\
\hline
\end{tabular}

5. Impacts on the generators

Impacts on the generator cost, revenue, and profit are shown in Table D.7 and Figure D.4. With the increasing penetration of PV and battery storage, the operation cost of the bulk generation decreases due to their reduced output. At the same time, the revenue and profit also decrease.

Table D.7. The Total Operation Costs, Revenues, and Profits of the Bulk Generators by Case ID

\begin{tabular}{cccc}
\hline Case & $\begin{array}{c}\text { Operation Cost } \\
(\mathrm{M} \$)\end{array}$ & $\begin{array}{c}\text { Revenue } \\
(\mathrm{M} \$)\end{array}$ & Profit (M\$) \\
\hline a & 0.60 & 4.74 & 4.14 \\
b & 0.59 & 4.58 & 3.99 \\
c & 0.51 & 3.73 & 3.21 \\
d & 0.46 & 3.02 & 2.56 \\
e & 0.41 & 2.05 & 1.64 \\
\hline
\end{tabular}

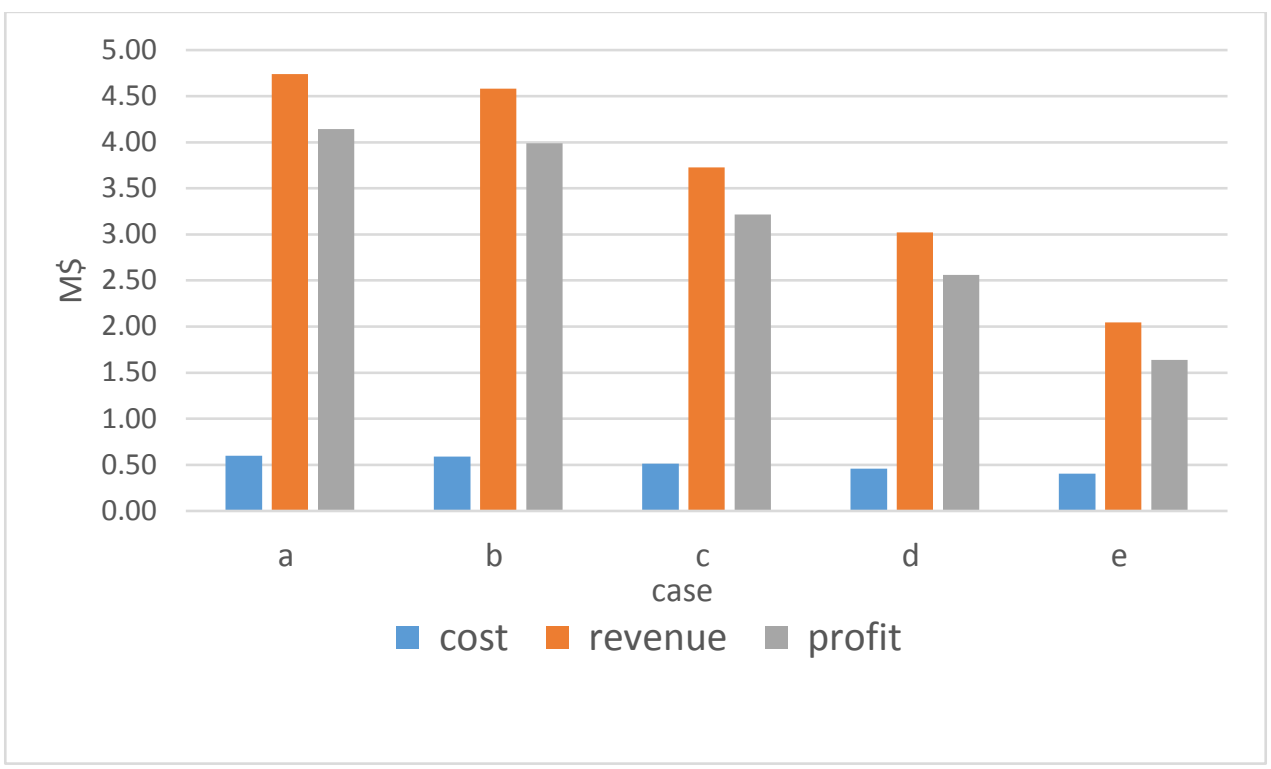

Figure D.4. The Total Operation Costs, Revenues, and Profits of the Bulk Generators by Case ID 
Supply inadequacy was modeled in the simulation by introducing a very expensive last-resort generation resource. Customer outages are assumed to be incurred if this generator is operating. The energy supplied by the generator is equal to the system's unserved load. This approach avoids having to truly reconfigure the system each time any part of the circuit incurs a service outage.

The output power of this generator is shown in Fig. D.5. For the first non-event day, its output is zero, and for the second day after the generation outage it becomes dispatched and its output increases as the unserved load increases, which leads to the dramatic increase of the LMP due to the much higher operating cost of this generator compared to the other generators.

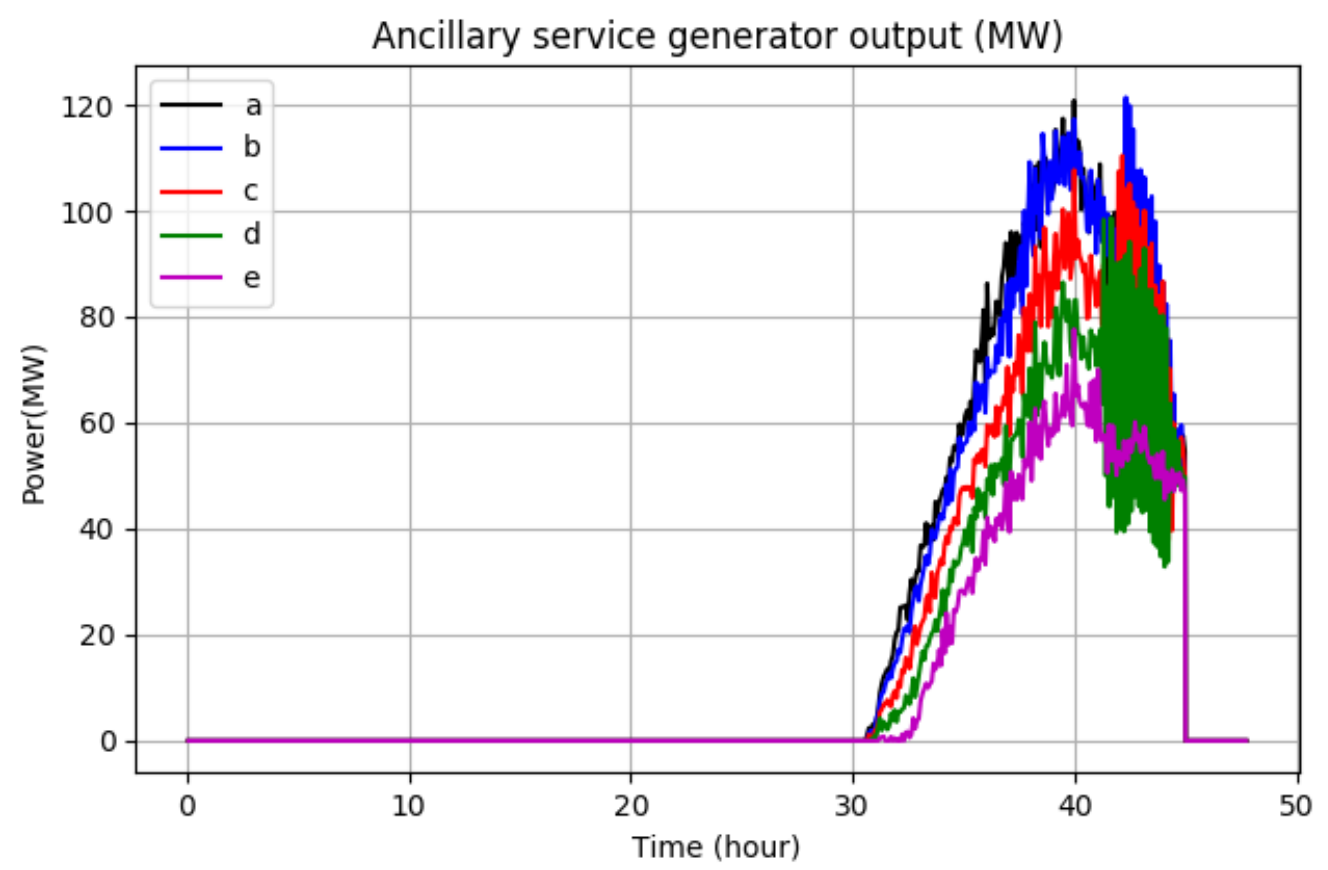

Figure D.5. The Total Operation Costs, Revenues, and Profits of the Bulk Generators by Case ID

\section{Buildings}

As shown in Table D.8, total house energy consumption declines by $3698 \mathrm{kWh}$ after attaching controllers to half of the houses in Case b compared to Case a. The total decrease of the energy is mainly due to the reduction of house HVAC energy consumption, which is $3981 \mathrm{kWh}$ as indicated in Table D.6. The HVAC energy consumption is not changed much in Cases c-e.

Table D.8. Total House HVAC Energy Consumption

\begin{tabular}{cc}
\hline Case & $\begin{array}{c}\text { Total House HVAC Energy Consumption } \\
(\mathrm{kWh})\end{array}$ \\
\hline a & 65002 \\
b & 61021 \\
c & 61025 \\
d & 61044 \\
e & 61098 \\
\hline
\end{tabular}


7. Social impacts

Table D.9. Total Greenhouse Gas Emissions from the Generation Sector

\begin{tabular}{cccc}
\hline Case & $\mathrm{CO}_{2}(1000 \mathrm{lb})$ & $\mathrm{SO}_{\mathrm{x}}(\mathrm{lb})$ & $\mathrm{NO}_{\mathrm{x}}(\mathrm{lb})$ \\
\hline $\mathrm{a}$ & 17941.9 & 153.2 & 1149.3 \\
$\mathrm{~b}$ & 17848.5 & 152.4 & 1143.4 \\
$\mathrm{c}$ & 17647.5 & 150.7 & 1130.5 \\
$\mathrm{~d}$ & 17464.0 & 149.2 & 1118.7 \\
$\mathrm{e}$ & 17274.7 & 147.5 & 1106.6 \\
\hline
\end{tabular}


Table D.10. Example Valuation Ledger from the Trial Analysis that Tested the TESP Growth Model

\begin{tabular}{|c|c|c|c|c|c|c|c|c|c|c|c|c|c|c|c|}
\hline & \multirow{3}{*}{ 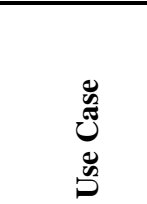 } & \multirow[b]{3}{*}{ 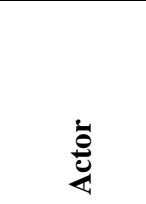 } & \multirow[b]{3}{*}{ 莛 } & \multirow[b]{3}{*}{ 茪 } & \multirow[b]{3}{*}{$\overrightarrow{\mathrm{g}}$} & \multicolumn{5}{|c|}{ Non-Event Day ${ }^{(a)}$} & \multicolumn{5}{|c|}{ Event Day $^{(\mathbf{b})}$} \\
\hline & & & & & & \multirow{2}{*}{$\begin{array}{c}\text { Baseline } \\
0 \%\end{array}$} & \multicolumn{4}{|c|}{ (Test @ PV Penetration ${ }^{(\mathrm{f})}$ - Baseline) } & \multirow{2}{*}{$\begin{array}{c}\text { Baseline } \\
\mathbf{0} \%\end{array}$} & \multicolumn{4}{|c|}{ (Test @ PV Penetration ${ }^{(\mathfrak{f})}$ - Baseline) } \\
\hline & & & & & & & $0 \%$ & $10 \%$ & $20 \%$ & $30 \%$ & & $0 \%$ & $10 \%$ & $20 \%$ & $30 \%$ \\
\hline \multirow{8}{*}{\multicolumn{2}{|c|}{$\begin{array}{l}\text { The dist. } \\
\text { utility } \\
\text { supplies } \\
\text { electr. to } \\
\text { its custs. }\end{array}$}} & \multirow{4}{*}{ Res. cust. } & \multirow{4}{*}{$\begin{array}{l}\text { Sim. dur.; } \\
\text { Test fdr. }\end{array}$} & $\begin{array}{r}\text { Electricity } \\
\text { /day }\end{array}$ & $\sum_{\Sigma}^{5}$ & 76.3 & -2.3 & -7.9 & -13.1 & -18.2 & 77.8 & -1.7 & -7.3 & -12.6 & -17.8 \\
\hline & & & & /day/cust. & $\sum_{\underline{y}}^{5}$ & 47.9 & -1.5 & -5.0 & -8.2 & -11.4 & 48.8 & -1.1 & -4.6 & -7.9 & -11.2 \\
\hline & & & & $\begin{array}{c}\text { Elect. fee } \\
\text { /day }\end{array}$ & $\infty$ & $-9,485$ & 291 & 982 & 1,625 & 2,256 & $-9,673$ & 214 & 911 & 1,561 & 2,215 \\
\hline & & & & /day/cust. & $\theta$ & -5.95 & 0.18 & 0.62 & 1.02 & 1.42 & -6.07 & 0.14 & 0.57 & 0.98 & 1.39 \\
\hline & & \multirow{4}{*}{$\begin{array}{l}\text { Elect. } \\
\text { dist. } \\
\text { utility }\end{array}$} & \multirow{4}{*}{$\begin{array}{l}\text { Sim. dur.; } \\
\text { Test fdr. }\end{array}$} & $\begin{array}{c}\text { Electricity } \\
\text { /day }\end{array}$ & $\sum_{\Sigma}^{5}$ & -76.3 & 2.3 & 7.9 & 13.1 & 18.2 & -77.8 & 1.7 & 7.3 & 12.6 & 17.8 \\
\hline & & & & /day/cust. & $\sum_{\underline{y}}^{\tilde{z}}$ & -47.9 & 1.5 & 5.0 & 8.2 & 11.4 & -48.8 & 1.1 & 4.6 & 7.9 & 11.2 \\
\hline & & & & $\begin{array}{l}\text { Elect. fee } \\
\text { /day }\end{array}$ & $\theta$ & 9,485 & -291 & -982 & $-1,625$ & $-2,256$ & 9,673 & -214 & -911 & $-1,561$ & $-2,215$ \\
\hline & & & & /day/cust. & $\theta$ & 5.95 & -0.18 & -0.62 & -1.02 & -1.42 & 6.07 & -0.14 & -0.57 & -0.98 & -1.39 \\
\hline
\end{tabular}




\begin{tabular}{|c|c|c|c|c|c|c|c|c|c|c|c|c|c|c|c|}
\hline & \multirow{3}{*}{ : } & \multirow{3}{*}{$\frac{\tilde{g}}{4}$} & \multirow{3}{*}{ 茙 } & \multirow{3}{*}{ 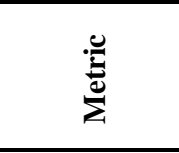 } & \multirow{3}{*}{ 竞 } & \multicolumn{5}{|c|}{ Non-Event Day (a) } & \multicolumn{5}{|c|}{ Event Day $^{(\mathbf{b})}$} \\
\hline & & & & & & \multirow{2}{*}{$\begin{array}{c}\text { Baseline } \\
0 \%\end{array}$} & \multicolumn{4}{|c|}{ (Test @ PV Penetration - Baseline) } & \multirow{2}{*}{$\frac{\text { Baseline }}{0 \%}$} & \multicolumn{4}{|c|}{ (Test @ PV Penetration - Baseline) } \\
\hline & & & & & & & $0 \%$ & $10 \%$ & $20 \%$ & $30 \%$ & & $0 \%$ & $10 \%$ & $20 \%$ & $30 \%$ \\
\hline \multirow{4}{*}{ 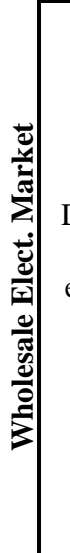 } & \multirow{4}{*}{$\begin{array}{l}\text { Dist. utility } \\
\text { procures } \\
\text { elect. from } \\
\text { wholesale } \\
\text { market }\end{array}$} & \multirow{2}{*}{$\begin{array}{l}\text { Elect. } \\
\text { dist. } \\
\text { utility }\end{array}$} & \multirow{2}{*}{$\begin{array}{c}\text { Sim. dur.; } \\
\text { Test elect. } \\
\text { utilityy }\end{array}$} & Elect. /day & $\sum_{\Sigma}^{\xi}$ & 4,826 & -50 & -163 & -260 & -366 & 4,852 & -54 & -165 & -272 & -377 \\
\hline & & & & $\begin{array}{l}\text { Elect. fee } \\
\begin{array}{l}\text { (LMP) /day } \\
\text { /d }\end{array}\end{array}$ & 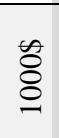 & -103 & 2 & 7 & 11 & 16 & $-2,369$ & 83 & 555 & 938 & 1,455 \\
\hline & & \multirow{2}{*}{$\begin{array}{l}\text { Wholes } \\
\text { ale } \\
\text { market }\end{array}$} & \multirow{2}{*}{$\begin{array}{c}\text { Sim. dur.; } \\
\text { Test elect. } \\
\text { utilityy }{ }^{(\mathrm{d})}\end{array}$} & $\begin{array}{c}\text { Electricity } \\
\text { /day }\end{array}$ & $\sum_{\Sigma}^{5}$ & $-4,826$ & 50 & 163 & 260 & 366 & $-4,852$ & 54 & 165 & 272 & 377 \\
\hline & & & & $\begin{array}{l}\text { Elect. fee } \\
\text { (LMP) } \\
\text { /day }\end{array}$ & 宅 & 103 & -2 & -7 & -11 & -16 & 2,369 & -83 & -555 & -938 & $-1,455$ \\
\hline \multirow{5}{*}{ 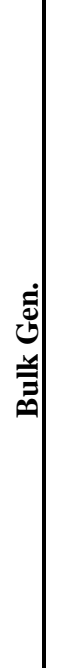 } & \multirow{5}{*}{$\begin{array}{l}\text { Wholesale } \\
\text { market } \\
\text { procures } \\
\text { electricity } \\
\text { from bulk } \\
\text { electricity } \\
\text { suppliers }\end{array}$} & \multirow{3}{*}{$\begin{array}{l}\text { Bulk } \\
\text { elect. } \\
\text { supplier }\end{array}$} & \multirow{3}{*}{$\begin{array}{l}\text { Sim. dur, } \\
\text { Test elect. } \\
\text { system }^{(\mathrm{e})}\end{array}$} & $\begin{array}{c}\text { Electricity } \\
\text { /day }\end{array}$ & $\sum_{\Sigma}^{\xi}$ & $-9,986$ & 50 & 163 & 260 & 366 & $-9,994$ & 54 & 165 & 272 & 377 \\
\hline & & & & $\begin{array}{l}\text { Production } \\
\text { cost /day }\end{array}$ & 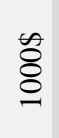 & -148.9 & 1.0 & 3.6 & 5.7 & 8.0 & -450.5 & 9.1 & 82.6 & 135.9 & 185.5 \\
\hline & & & & $\begin{array}{l}\text { Elect. fee } \\
\text { /day }\end{array}$ & 害 & 211 & -3 & -10 & -17 & -23 & 4,531 & -158 & $-1,003$ & $-1,705$ & $-2,673$ \\
\hline & & \multirow{2}{*}{$\begin{array}{l}\text { Wholes } \\
\text { ale } \\
\text { market }\end{array}$} & \multirow{2}{*}{$\begin{array}{l}\text { Sim. dur, } \\
\text { Test elect. } \\
\text { system }^{(\mathrm{e})}\end{array}$} & $\begin{array}{c}\text { Electricity } \\
\text { /day }\end{array}$ & $\sum_{\Sigma}^{\xi}$ & 9,986 & -50 & -163 & -260 & -366 & 9,994 & -54 & 357,898 & 304,566 & 255,027 \\
\hline & & & & $\begin{array}{l}\text { Elect. fee } \\
\text { /day }\end{array}$ & के & -211 & 3 & 10 & 17 & 23 & $-4,531$ & 158 & 1,003 & 1,705 & 2,673 \\
\hline
\end{tabular}




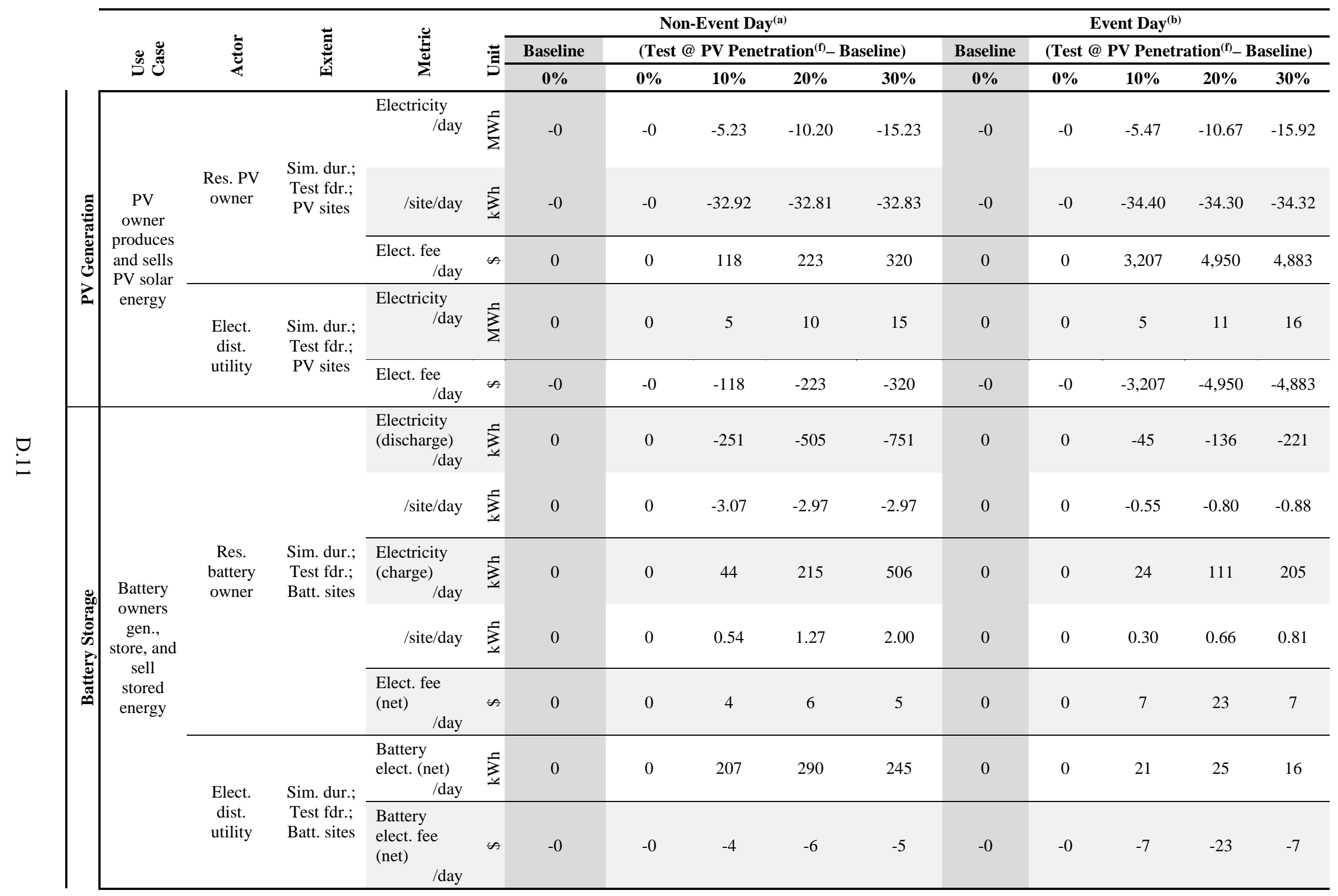




\begin{tabular}{|c|c|c|c|c|c|c|c|c|c|c|c|c|c|c|c|}
\hline & \multirow{3}{*}{ 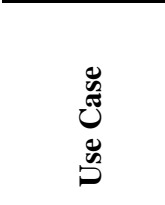 } & \multirow[b]{3}{*}{ 爮 } & \multirow[b]{3}{*}{ 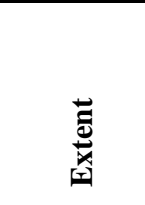 } & \multirow[b]{3}{*}{ 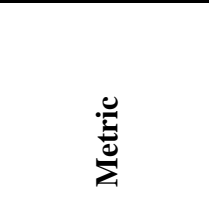 } & \multirow[b]{3}{*}{$\stackrel{\Xi}{\Xi}$} & \multicolumn{5}{|c|}{ Non-Event Day ${ }^{(\mathbf{a})}$} & \multicolumn{5}{|c|}{ Event Day $^{(\mathbf{b})}$} \\
\hline & & & & & & \multirow{2}{*}{$\begin{array}{c}\text { Baseline } \\
0 \%\end{array}$} & \multicolumn{4}{|c|}{ (Test @ PV Penetration $^{(\mathrm{f})}$ - Baseline) } & \multirow{2}{*}{$\begin{array}{c}\text { Baseline } \\
0 \%\end{array}$} & \multicolumn{4}{|c|}{ (Test @ PV Penetration $^{(f)}$ - Baseline) } \\
\hline & & & & & & & $\mathbf{0 \%}$ & $10 \%$ & $20 \%$ & $30 \%$ & & $\mathbf{0 \%}$ & $10 \%$ & $20 \%$ & $30 \%$ \\
\hline \multirow{6}{*}{ 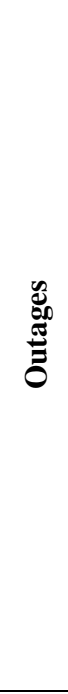 } & \multirow{6}{*}{$\begin{array}{c}\text { Elect. custs. } \\
\text { incur } \\
\text { expenses } \\
\text { during } \\
\text { outages }\end{array}$} & \multirow{2}{*}{$\begin{array}{l}\text { Res. } \\
\text { cust. }\end{array}$} & \multirow{2}{*}{$\begin{array}{l}\text { Sim. dur.; } \\
\text { Test fdr. }\end{array}$} & $\begin{array}{l}\text { Outage count } \\
\text { /day }\end{array}$ & \# & 0 & 0 & 0 & 0 & 0 & 1,559 & 0 & 0 & 0 & 0 \\
\hline & & & & $\begin{array}{l}\text { Outage dur. } \\
\text { /day }\end{array}$ &.$\Xi$ & 0 & 0 & 0 & 0 & 0 & 869.4 & -0.6 & -0.6 & -2.4 & -41.4 \\
\hline & & $\begin{array}{l}\text { Agg. } \\
\text { edge } \\
\text { actor }\end{array}$ & $\begin{array}{l}\text { Sim. dur.; } \\
\text { Test fdr. }\end{array}$ & $\begin{array}{l}\text { Est. outage } \\
\operatorname{cost}^{(\mathrm{c})}\end{array}$ & $\infty$ & - & - & - & - & - & - & - & - & - & - \\
\hline & & \multirow{2}{*}{$\begin{array}{l}\text { Comm. } \\
\text { Cust. }\end{array}$} & & $\begin{array}{l}\text { Outage count } \\
\text { /day }\end{array}$ & \# & 0 & 0 & 0 & 0 & 0 & 1 & 0 & 0 & 0 & 0 \\
\hline & & & & $\begin{array}{l}\text { Outage } \\
\text { duration/day } \\
\qquad / \text { day }\end{array}$ & 刍 & 0.0 & 0.0 & 0.0 & 0.0 & 0.0 & 869.4 & -0.6 & -0.6 & -2.4 & -41.4 \\
\hline & & $\begin{array}{l}\text { Agg. } \\
\text { edge } \\
\text { actor }\end{array}$ & & $\begin{array}{l}\text { Est. bus. } \\
\text { losses(c) }\end{array}$ & $\infty$ & - & - & - & - & - & - & - & - & - & - \\
\hline \multirow{6}{*}{ 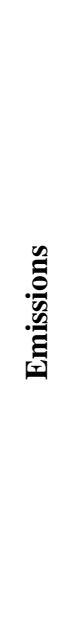 } & \multirow{6}{*}{$\begin{array}{l}\text { Bulk } \\
\text { gens. } \\
\text { produce } \\
\text { green- } \\
\text { house } \\
\text { gas } \\
\text { emission } \\
\text { s during } \\
\text { elect. } \\
\text { gen. }\end{array}$} & \multirow{3}{*}{$\begin{array}{l}\text { Bulk } \\
\text { gens. }\end{array}$} & \multirow{3}{*}{$\begin{array}{l}\text { Sim. } \\
\text { dur. }\end{array}$} & $\mathrm{CO}_{2}$ & $\stackrel{\xi}{\Sigma}$ & $-4,067$ & 20 & 66 & 106 & 149 & $-4,071$ & 22 & 67 & 111 & 154 \\
\hline & & & & $\mathrm{SO}_{\mathrm{x}}$ & $\stackrel{0}{x}$ & -34.74 & 0.17 & 0.57 & 0.90 & 1.27 & -34.77 & 0.19 & 0.57 & 0.95 & 1.31 \\
\hline & & & & $\mathrm{NO}_{\mathrm{x}}$ & $\underset{10}{\infty}$ & -260.6 & 1.3 & 4.2 & 6.8 & 9.5 & -260.8 & 1.4 & 4.3 & 7.1 & 9.8 \\
\hline & & \multirow{3}{*}{$\begin{array}{c}\text { Societ } \\
\mathrm{y}\end{array}$} & \multirow{3}{*}{ Sim. dur. } & $\begin{array}{l}\text { Environ. } \\
\mathrm{CO}_{2} \quad \text { /day } \\
\end{array}$ & $\stackrel{E}{\Sigma}$ & 4,067 & -20 & -66 & -106 & -149 & 4,071 & -22 & -67 & -111 & -154 \\
\hline & & & & $\begin{array}{l}\text { Environ. } \\
\mathrm{SO}_{\mathrm{x}} \quad \text { /day }\end{array}$ & $\underset{x}{01}$ & 34.74 & -0.17 & -0.57 & -0.90 & -1.27 & 34.77 & -0.19 & -0.57 & -0.95 & -1.31 \\
\hline & & & & $\begin{array}{l}\text { Environ. } \\
\mathrm{NO}_{\mathrm{x}} \quad \text { /day }\end{array}$ & هִ & 260.6 & -1.3 & -4.2 & -6.8 & -9.5 & 260.8 & -1.4 & -4.3 & -7.1 & -9.8 \\
\hline
\end{tabular}

(a) "Non-event day" refers to the first of two simulated days. Generation supply was adequate this day. 
(b) "Event day" refers to the second of two simulated days. Generation supply becomes inadequate this day.

(c) The TSP does not yet possess valuation models for these metrics. They are left blank rather than introducing unsubstantiated entries.

(d) "Test utility" refers to all of Bus 7 in the simulation circuit model. About half the circuit's load resides at this bus.

(e) "Test system" refers to all the buses in the simulation circuit model.

(f) PV penetration percentage, in this case, was based on the fraction of test feeder residences that had PV solar installed. 


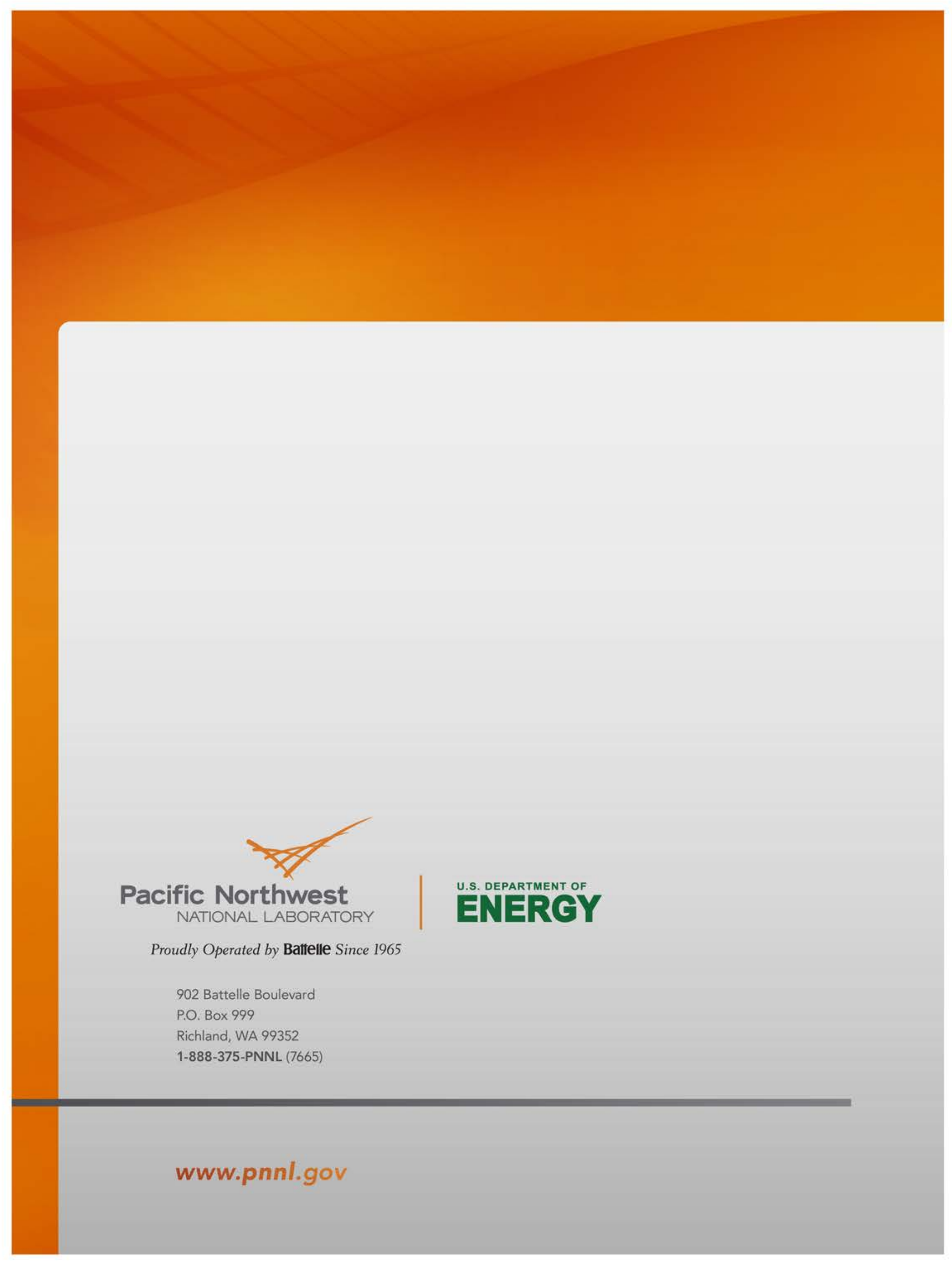

